NATHALIE AMORIM FERNANDES

REVISÃO TAXONÔMICA DE Synodus Scopoli, 1777 (Synodontidae, Aulopiformes, Teleostei) DO ATLÂNTICO SUL OCIDENTAL

São Paulo 


\title{
REVISÃO TAXONÔMICA DE Synodus Scopoli, 1777 (Synodontidae, Aulopiformes, Teleostei) DO ATLÂNTICO SUL OCIDENTAL
}

\author{
Versão Original
}

Dissertação apresentada ao Instituto Oceanográfico da Universidade de São Paulo, como parte dos requisitos para a obtenção do título de Mestre em Ciências, área de Oceanografia Biológica.

Orientador: Prof. Dr. Marcelo Roberto Souto de Melo. 
Nome: Nathalie Amorim Fernandes.

Título: Revisão Taxonômica de Synodus Scopoli, 1777 (Synodontidae, Aulopiformes, Teleostei) do Atlântico Sul Ocidental

Dissertação apresentada ao Instituto Oceanográfico da Universidade de São Paulo, como parte dos requisitos para a obtenção do título de Mestre em Ciências, área de Oceanografia Biológica.

Avaliada em:

Banca Examinadora

Prof. Dr. Instituição

Julgamento Assinatura

Prof. Dr. Instituição

Julgamento Assinatura

Prof. Dr. Instituição

Julgamento Assinatura 
Ao meu avô Dionisio, que sempre teve muito orgulho de mim e foi a principal razão para a conclusão deste trabalho. Onde estiver, te amarei para o resto da vida. 


\section{Agradecimentos}

Agradeço ao CNPq pela bolsa concedida nesses dois anos, sem o qual este mestrado não teria sido possível.

À FAPESP, pela verba para as visitas aos museus e coleções científicas que precisei conhecer.

Ao Instituto Oceanográfico da USP, por toda a estrutura e suporte, assim como aos funcionários da Comissão de Pós-graduação, sempre prontos a me ajudar em todas as dúvidas burocráticas que tive.

Ao meu orientador Marcelo Melo, pela oportunidade que me deu em fazer um mestrado, pela orientação nesses dois anos, e por me permitir realizar o sonho de embarcar em duas expedições científicas.

Ao Osvaldo Oyakawa do MZUSP, Cristiano Moreira do MNRJ, Matheus Rotundo e Gustavo Stabile do AZUSC e Jean-Christophe Joyeux e Kathiani Bastos da UFES, por me receberem sempre tão prestativos em suas coleções científicas.

Ao Alessio Datovo do MZUSP, Alberto Akama e Wolmar Wosiacki do MPEG, Ricardo Rosa e Robson Ramos da UFPB e Carlos Lucena e Roberto Reis da PUCRS, pelo empréstimo do material que precisei.

À equipe da Faculdade de Medicina Veterinária e Zootecnia da USP, Ana, Stefano e Reginaldo, pelo uso dos equipamentos que permitiram as radiografias presentes neste trabalho.

Ao Benjamin Frable, sempre prestativo em responder meus e-mails de dúvidas sobre seu trabalho com muita atenção e humildade.

Aos membros da banca, por suas contribuições.

Ao George Mattox, meu orientador da graduação, pelos ensinamentos e por fazer parte da minha trajetória acadêmica.

Ao Rodrigo e à Amanda, pela amizade, pelos conselhos pessoais e profissionais, e por me compreenderem e ajudarem sempre que precisei.

À Flávia, Bárbara, Rayane e Paola por sempre escutarem meus desabafos e me fazerem rir, tornando a minha trajetória acadêmica mais leve.

Ao Vagner e ao Paulo, motorista e coordenador do fretado que utilizei durante um ano e meio e por me permitirem viajar mesmo quando achei que ficaria sem bolsa.

À minha família, avós, tios e primos, por me apoiarem nas minhas decisões e por me incentivarem sempre.

À Nina, Sofia e Cecília, meus animais de estimação, por me distraírem e me darem carinho e amor quando mais precisei.

Ao meu pai Rogerio, minha mãe Denise, minha irmã Nicolle e meu namorado Hugo, por todo o amor, apoio, paciência, incentivo, compreensão e refúgio nesse período que não foi fácil tanto profissionalmente quanto pessoalmente.

À todos que direta ou indiretamente fizeram parte da minha formação, muito obrigada. 
Você nunca aprecia o mundo corretamente, até o mar manar em suas veias, até você estar vestido pelos céus e coroado com as estrelas.

(Thomas Traherne) 


\section{Resumo}

FERNANDES, Nathalie Amorim. Revisão Taxonômica de Synodus Scopoli, 1777 (Synodontidae, Aulopiformes, Teleostei) do Atlântico Sul ocidental. 2020. 101 f. Dissertação (Mestrado em Oceanografia Biológica) - Instituto Oceanográfico, Universidade de São Paulo, São Paulo, 2020.

O gênero Synodus inclui 48 espécies válidas de peixes marinhos popularmente conhecidos como peixe-lagarto. A distribuição dos peixes-lagarto é restrita às regiões tropicais e subtropicais dos oceanos Atlântico, Índico e Pacífico, onde são frequentemente encontrados em locais com fundos consolidados ou arenosos, inclusive áreas estuarinas. Anteriormente, cinco espécies de Synodus haviam sido registradas no Atlântico Sul ocidental (ASO): S. bondi Fowler, 1939; S. foetens (Linnaeus, 1766); S. intermedius (Agassiz, 1829); S. poeyi Jordan, 1887; e $S$. synodus (Linnaeus, 1758). O objetivo deste estudo foi realizar uma revisão do gênero no ASO a fim de caracterizá-las morfologicamente, identificar os padrões de distribuição e propor uma chave de identificação atualizada. Os caracteres morfométricos (34), merísticos (13) e descritivos (sete) foram obtidos a partir de 263 exemplares pertencentes aos principais museus e coleções científicas brasileiras. Alguns exemplares foram diafanizados ou radiografados para descrição osteológica e contagem de vértebras. Seis espécies de Synodus foram confirmadas no ASO: S. bondi, S. foetens, S. intermedius e S. synodus; S. macrostigmus Frable, Luther \& Baldwin, 2013 é registrada pela primeira vez; e uma nova espécie é apresentada. Synodus poeyi não foi confirmada na área de estudo. Synodus bondi e $S$. foetens são bastante semelhantes e frequentemente confundidas; as duas espécies diferenciam-se principalmente pelo número de raios da nadadeira anal (10-12 vs. 12-14), formato da membrana da narina anterior (afunilada $v s$. triangular) e formato do focinho (muito pontudo vs. pouco pontudo). Synodus synodus pode ser diferenciada das demais pela presença de uma mancha preta na parte superior do focinho e membrana da narina anterior em formato de colher; está distribuída desde o Golfo do México até o Uruguai, sendo a única espécie registrada nas ilhas oceânicas de Atol das Rocas, e nos arquipélagos de Fernando de Noronha e Vitória-Trindade. Um neótipo para Synodus synodus está sendo proposto afim de fornecer estabilidade ao nome e fixar a localidade tipo. Synodus intermedius possui 3-6 barras verticais na nadadeira caudal e presença de mancha escapular pequena. Synodus macrostigmus era confundida com $S$. intermedius, da qual pode ser diferenciada pelo tamanho da membrana da narina anterior (longa vs. curta), mancha escapular grande ( $v s$. pequena) e número de escamas na linha lateral (45-48 vs. 49-42); a espécie era conhecida do Atlântico Norte ocidental e teve a sua distribuição ampliada até o Rio de Janeiro, no sudeste brasileiro. Uma nova espécie de Synodus pode ser diagnosticada de seus congêneres por possuir o diâmetro da órbita maior que o comprimento do focinho. Ela é conhecida do 
Norte, Nordeste e parte do Sudeste do Brasil. Uma nova chave de identificação atualizada para as espécies de Synodus que ocorrem no ASO é apresentada.

Palavras-chave: Brasil. Peixe-lagarto. Chave de identificação. Distribuição. Taxonomia. 


\begin{abstract}
FERNANDES, Nathalie Amorim. Taxonomic Review of Synodus Scopoli, 1777 (Synodontidae, Aulopiformes, Teleostei) of South West Atlantic. 2020. 101 f. Dissertação (Mestrado em Oceanografia Biológica) - Instituto Oceanográfico, Universidade de São Paulo, São Paulo, 2020.

The genus Synodus includes 48 valid species of marine fish popularly known as lizardfish. The distribution of lizardfishes is restricted to tropical and subtropical regions in the Atlantic, Indian and Pacific oceans, where they are often found in marine areas with consolidated or sandy bottoms, including brackish waters. Previously, five species of Synodus were recorded in the western South Atlantic (WSA): S. bondi Fowler, 1939; S. foetens (Linnaeus, 1766); S. intermedius (Agassiz, 1829); S. poeyi Jordan, 1887; and S. synodus (Linnaeus, 1758). The objective of this study was to accomplish a taxonomic review of the genus in the WSA, in order to better characterize them morphologically, identify the patterns of distribution and propose an updated identification key. The morphometric (34), meristic (13) and descriptive (seven) characters were obtained based on 263 specimens from the main Brazilian museums and scientific collections. Selected specimens were cleared and stained or radiographed for osteological description and vertebras count. Six species of Synodus were recognized in WSA: S. bondi, S. foetens, S. intermedius and S. synodus; S. macrostigmus Frable, Luther \& Baldwin, 2013 is been reported for the first time; and a new species is introduced. Synodus poeyi was not confirmed in the study area. Synodus bondi and S. foetens are quite similar and frequently confused; those two species differ by the number anal-fin rays (10-12 vs. 12-14), the shape of the anterior-nostril membrane (narrow $v s$. triangular) and the shape of the snout (very pointed vs. not very pointed). Synodus synodus can be diagnosed by the presence of a black spot on the upper of the snout and anterior-nostril membrane in the shape of a spoon; and is distributed from the Gulf of Mexico to Uruguay, and is the only species recorded in the oceanic islands of Atol das Rocas, and Fernando de Noronha and Vitória-Trindade archipelagos. A neotype for Synodus synodus is being proposed in order to provide taxonomic stability and stablish the type locality. Synodus intermedius has 3-6 vertical bars on the caudal-fin and small scapular spot. Synodus macrostigmus was confused with S. intermedius, from which can be distinguished by the size of the anterior-nostril membrane (long $v s$. short), large scapular spot ( $v s$. small) and number of scales on the lateral line (45-48 vs. $49-42)$; it was previously known from the western North Atlantic and had its range extended to Rio de Janeiro, in southeastern Brazil. A new species of Synodus can be diagnosed from its congeners in the Atlantic Ocean by having orbit diameter larger than the snout length. It is known from the North, Northeastern and part
\end{abstract}


of the Southeastern Brazil. An update taxonomic key for the species of Synodus occurring in the WSA is proposed

Keywords: Brazil. Lizard fish. Identification key. Distribution. Taxonomy. 


\section{Lista de Figuras}

Figura 1. Esquema demonstrando os pontos homólogos do corpo de Synodus utilizados para a obtenção de caracteres morfométricos.

Figura 2. Esquema demonstrando os pontos homólogos da cabeça de Synodus utilizados para a obtenção de caracteres morfométricos.

Figura 3. Esquema mostrando a disposição dos raios da nadadeira pélvica em A. Synodus. B.

Saurida. Retirado de Russell (2002).

Figura 4. Holótipo de Synodus bondi. ANSP 68634, 275.0 mm CT. Retirado de Frable et al. (2013).

Figura 5. Synodus bondi. A. MPEG 35608, $239.5 \mathrm{~mm}$ CP; B. MPEG 35672, $247.5 \mathrm{~mm}$ CP; C. MPEG 35747, $249.5 \mathrm{~mm}$ CP. 27

Figura 6. Radiografia de Synodus bondi, MPEG 35608, 239.5 mm CP. 28

Figura 7. Área de distribuição dos lotes de $S$. bondi provenientes de coleções brasileiras..... 30

Figura 8. Neótipo de Synodus foetens. USNM 405413, 205 mm CP. Retirado de Frable et al. (2013).

Figura 9. Synodus foetens. A. MZUSP 18299, 177 mm CP; B. MCP 16248, $203.5 \mathrm{~mm} \mathrm{CP}$; C. MNRJ 46453, 131.7 mm CP; D. MNRJ 37114, 196 mm CP; E. MCP 5025, 204 mm CP. .... 34

Figura 10. Radiografias de Synodus foetens. A. MZUSP 18299, $177.8 \mathrm{~mm}$ CP; B. MZUSP 55465, $160.8 \mathrm{~mm} \mathrm{CP}$.

Figura 11. Área de distribuição dos lotes de $S$. foetens provenientes de coleções brasileiras. 38

Figura 12. Neótipo de Synodus intermedius. USNM 398292, 285 mm CP. A. Em vida. B. Em álcool. Retirado de Frable et al. (2013).

Figura 13. Synodus intermedius. A. MZUSP 52870, $68.5 \mathrm{~mm} \mathrm{CP}$; B. UFPB 4269, $94.2 \mathrm{~mm}$

CP; C. MZUSP 60547, 153.8 mm CP.

Figura 14. Radiografia de Synodus intermedius, MZUSP 52828, 127.6 mm CP.

Figura 15. Área de distribuição dos lotes de S. intermedius provenientes de coleções brasileiras.

Figura 16. Neótipo de Synodus macrostigmus. USNM 182810, 189 mm CP. A. Em vida. B.

Em álcool. Retirado de Frable et al. (2013).

Figura 17. Synodus macrostigmus. A. MNRJ 18209, 131.4 mm CP; B. MNRJ 49610, 197.1 $\mathrm{mm} \mathrm{CP}$

Figura 18. Área de distribuição dos lotes de S. macrostigmus provenientes de coleções brasileiras.

Figura 19. Synodus synodus. A. MS Néotipo MZUSP 45590, 206.0 mm CP; B. MZUSP 110433, $84.2 \mathrm{~mm}$ CP; C. MZUSP 75284, $59.9 \mathrm{~mm}$ CP.

Figura 20. Radiografias de Synodus synodus. A. MZUSP 69282, 190.4 mm CP; B. Synodus synodus, MZUSP 43483, $168.7 \mathrm{~mm}$ CP.

Figura 21. Área de distribuição dos lotes de S. synodus provenientes de coleções brasileiras. 
Figura 22. Synodus sp. n. A. MS Holótipo MNRJ 44976 (2), 81.8 mm CP; B. MZUSP 95441, 71.0 mm CP; C. MNRJ 44976 (3), 75.4 mm CP.

Figura 23. Radiografia de Synodus sp. N, MZUSP 95441, 71.8 mm CP

Figura 24. Área de distribuição dos lotes de Synodus sp. N provenientes de coleções brasileiras.

Figura 25. Exemplares de Synodus diafanizados. A. Synodus bondi, MPEG 35586, $252.5 \mathrm{~mm}$ CP; B. Synodus foetens, MZUSP 16472, $106.2 \mathrm{~mm}$ CP; C. Synodus intermedius, MZUSP 46254, 33.8 mm CP; D. Synodus synodus. MZUSP 110433, 69.2 mm CP.

Figura 26. Cabeça de Synodus bondi em vista dorsal evidenciando os ossos do crânio formando placas ósseas. A. MPEG 35202(1), 255.0 mm CP; B. MPEG 35586, 252.5 mm CP.

Figura 27. Suspensório direito de Synodus bondi em vista lateral (MPEG 35586, $252.5 \mathrm{~mm}$ $\mathrm{CP})$.

Figura 28. Suspensório, opérculo e arco mandibular direito de Synodus foetens, evidenciando ossos maxilares (MZUSP uncat., $222.0 \mathrm{~mm} \mathrm{CP}$ ).. .72

Figura 29. Arco branquial de Synodus bondi (MPEG 35586, 252.5 mm CP). ..................... 73

Figura 30. Arco branquial de Synodus synodus (MZUSP 110433, 69.2 mm CP). ................73

Figura 31. Arco branquial de Synodus foetens (MZUSP 16472, $106.2 \mathrm{~mm} \mathrm{CP}$ )................... 74

Figura 32. Cintura peitoral de Synodus foetens (MZUSP 16472, $106.2 \mathrm{~mm} \mathrm{CP}$ )................. 75

Figura 33. Comparação entre o suspensório das espécies de Synodus. A. MPEG 35586, $S$. bondi, $252.5 \mathrm{~mm}$ CP; B. MZUSP 110433, S. synodus, $69.2 \mathrm{~mm}$ CP; C. MZUSP 16472, $S$. foetens, $106.2 \mathrm{~mm}$ CP; D. MZUSP 46254, S. intermedius, $33.8 \mathrm{~mm} \mathrm{CP.}$

Figura 34. Cintura peitoral direita das espécies de Synodus em vista lateral. A. MPEG 35586, S. bondi, $252.5 \mathrm{~mm}$ CP; B. MZUSP 110433, S. synodus, $69.2 \mathrm{~mm}$ CP; C. MZUSP uncat., $S$. foetens, $222.0 \mathrm{~mm} \mathrm{CP}$; D. MZUSP 16472, S. foetens, $106.2 \mathrm{~mm} \mathrm{CP.}$ 76

Figura 35. Comparação entre a membrana da narina anterior de $S$. bondi (A-D) e $S$. foetens (E-H), vista lateral. A. MPEG 35202; B. MPEG 35586; C. MPEG 35608; D. MPEG 35672; E. MNRJ 37114(1); F. MNRJ 37114(2); G. MNRJ 3486(2); H. MCP 16248.

Figura 36. Comparação entre o focinho de $S$. bondi (A e B) e $S$. foetens $(\mathrm{C}$ e D) em vista dorsal. A. MPEG 35134; B. MPEG 35202(1); C. MZUSP 18405(1); D. MZUSP 90800(1). . 82

Figura 37. Comparação entre a mancha escapular de Synodus intermedius (A e B) e Synodus macrostigmus (C e D) em vista lateral. A. MZUSP 60547(1); B. MZUSP 65663; C. MNRJ 49610; D. MNRJ 18209(2).

Figura 38. Comparação entre a membrana da narina anterior de Synodus intermedius (A e B) e Synodus macrostigmus (C e D) em vista lateral. A. MZUSP 60547; B. MZUSP 65663; C. MNRJ 18209; D. MNRJ 49610..... 84

Figura 39. Fotografias evidenciando a membrana da narina anterior de Synodus synodus. A. MZUSP 66784; B. MZUSP 43483; C. CIUFES 1558(1); D. UFPB 3886.

Figura 40. Fotografias evidenciando a mancha escura na parte superior da maxila superior de Synodus synodus. A. MZUSP 43483; B. CIUFES 1558(1).

Figura 41. Fotografias evidenciando os lábios de A. S. foetens (MZUSP 18299) e B. S. 
Figura 42. Comparação entre Synodus sp. n e Synodus poeyi. A. Synodus sp. n, MS holótipo, MNRJ 44976 (2), 81.8 mm CP. B. Síntipo de Synodus poeyi, MNHN 1887-0383 (1), 85.0 mm

CT, Havana, Cuba. 88

\section{Lista de Tabelas}

Tabela 1. Caracteres morfométricos mensurados nas análises taxonômicas..........................20

Tabela 2. Caracteres merísticos mensurados nas análises taxonômicas.................................21

Tabela 3. Características descritivas observadas nas análises taxonômicas...........................21

Tabela 4. Dados morfométricos obtidos em Synodus bondi. ................................................ 28

Tabela 5. Dados morfométricos obtidos em Synodus foetens. .............................................. 36

Tabela 6. Dados morfométricos obtidos em Synodus intermedius ......................................... 43

Tabela 7. Dados morfométricos obtidos em Synodus macrostigmus. .................................... 48

Tabela 8. Dados morfométricos obtidos em Synodus synodus.............................................56

Tabela 9. Dados morfométricos obtidos em Synodus sp. N. ................................................61

Tabela 10. Médias obtidas em cada medição morfométrica, separadas por espécie...............64

Tabela 11. Principais diferenças entre as espécies de Synodus. .............................................66

Tabela 12. Características normalmente utilizadas para diferenciar Synodus bondi e $S$. foetens. 


\section{Sumário}

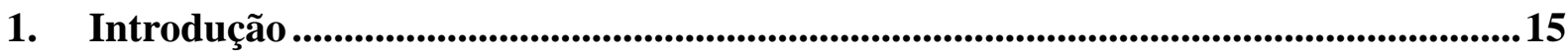

1.1. Histórico Taxonômico das Espécies no Oceano Atlântico.......................................... 17

1.2. Posicionamento Filogenético de Synodontidae ............................................................. 18

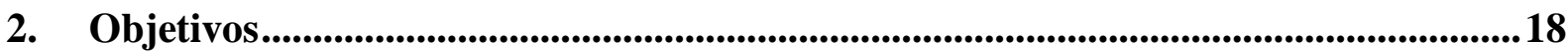

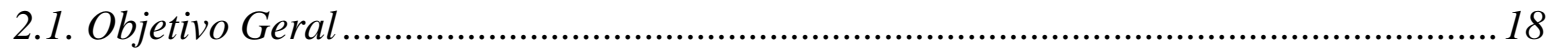

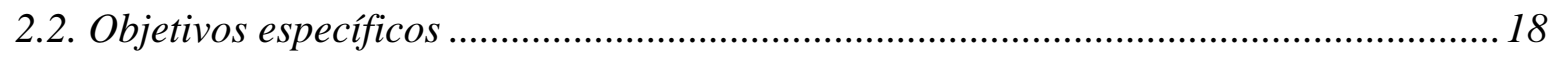

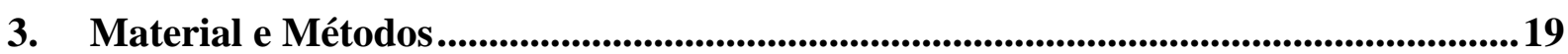

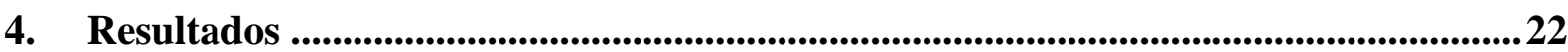

4.1. Descrição geral e Diagnose de Synodus Scopoli, 1777 ............................................ 22

4.2. Diagnoses e descrições das espécies de Synodus......................................................... 25

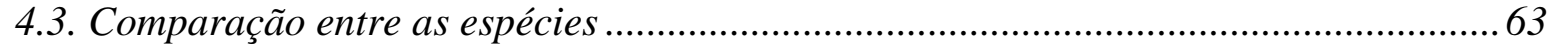

Nova chave de identificação das espécies de Synodus do Atlântico Sul ocidental. .......... 67

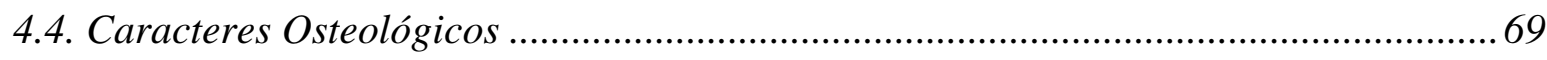

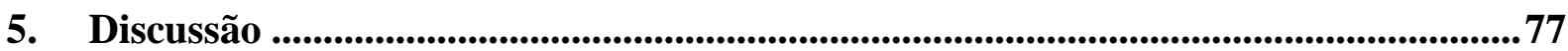

5.1. Comparação entre Synodus foetens e Synodus bondi ............................................... 78

5.2. Comparação entre Synodus sp. N, Synodus intermedius e Synodus macrostigmus...... 82

5.3. Comparação entre Synodus foetens e Synodus synodus ............................................. 85

5.4. Comparação entre Synodus intermedius e Synodus synodus ....................................... 86

5.5. Comparação entre Synodus sp. N. e Synodus poeyi e a presença da espécie em águas

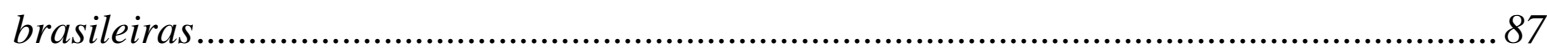

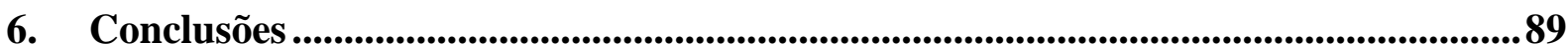

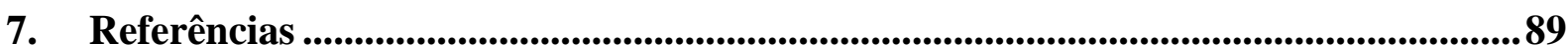

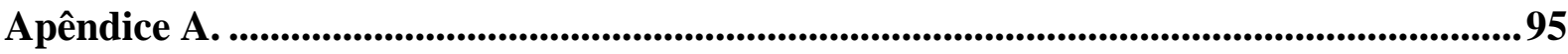




\section{Introdução}

Synodus Scopoli, 1777 é um gênero de peixes marinhos popularmente conhecidos como peixe-lagarto ou tira-vira. $\mathrm{O}$ gênero inclui 48 espécies válidas que ocorrem nas regiões tropicais dos oceanos Atlântico, Índico e Pacífico (HORTON et al., 2020). No Atlântico ocidental são registradas 11 espécies pertencentes à três gêneros: Synodus, com sete espécies; Saurida Valenciennes, 1850, com quatro espécies e Trachinocephalus Gill, 1861, com uma espécie (FRABLE et al., 2013; POLANCO et al., 2016). Estudos filogenéticos sugerem que T. myops também é membro de um clado que envolve outras espécies de Synodus, tornando o gênero parafilético (DAVIS, 2010; BETANCUR-R et al., 2013; FRABLE et al., 2013). Entretanto, Polanco et al. (2016) explicitam que para estabelecer a sinonímia de Trachinocephalus com Synodus, seria necessária a realização de estudos filogenéticos mais aprofundados, incluindo um maior número de espécies.

As espécies de Synodus são facilmente reconhecidas pelo corpo alongado e pela boca grande e terminal provida de numerosos dentes que normalmente ficam expostos, acarretando uma aparência semelhante aos lagartos (Lepidosauria, Squamata), o que dá origem ao nome comum. Possuem oito raios na nadadeira pélvica, sendo os raios internos muito mais longos que os externos; superfícies ósseas no topo da cabeça; pálpebra adiposa; maxila reduzida e conectada à pré-maxila; dentes no palato dispostos em uma única fileira e olhos localizados no ponto médio acima da maxila; os dois primeiros raios das nadadeiras dorsal e anal são sempre simples, os outros geralmente ramificados, o último sempre ramificado a partir da base (ANDERSON et al., 1966; FIGUEIREDO \& MENEZES, 1978; RUSSELL, 2002).

O gênero Synodus está alocado na ordem Aulopiformes, que inclui 373 espécies válidas alocadas em 16 famílias e 49 gêneros (NELSON et al., 2016; FRICKE et al., 2020). Somente nos últimos dez anos foram descritas 34 novas espécies da ordem (FRICKE et al., 2020), sendo nove pertencentes à família Synodontidae (FRABLE et al., 2013; RUSSELL et al., 2015; HO et al., 2016; ALLEN et al., 2017). Os representantes de Aulopiformes são exclusivamente marinhos, cujo monofiletismo é corroborado tanto por caracteres morfológicos quanto moleculares (DAVIS \& FIELITZ, 2010). Dentre os caracteres morfológicos estão sinapomorfias como bexiga natatória ausente; processo medial da nadadeira pélvica fusionado; origem dos epineurais no nível da primeira ou segunda vértebra; um ou mais epineurais deslocados sobre o septo horizontal; além de várias especializações nos arcos branquiais: processo uncinado do segundo epibranquial alongado; terceiro faringobranquial sem o côndilo 
cartilaginoso para articulação com o segundo epibranquial; quarto epibranquial com uma expansão proximal coberta por uma grande cartilagem e um processo uncinado no centro; e a presença do epibranquial cinco (ROSEN, 1973; JOHNSON, 1992; PATTERSON \& JOHNSON, 1995; BALDWIN \& JOHNSON, 1996; SATO \& NAKABO, 2002a; SATO \& NAKABO, 2002b; DAVIS, 2010).

Dentro de Aulopiformes, Synodontidae constitui a família mais numerosa em número de espécies válidas, possuindo 83 espécies; seguida de Paralepididae, com 66 spp.; Ipnopidae, 33 spp; Chlorophthalmidae, 21 spp.; Scopelarchidae, 18 spp.; Notosudidae, 17 spp.; Aulopidae, com 15 spp.; Paraulopidae, 14 spp.; Evermannellidae, 8 spp.; Pseudotrichonotidae, 4 spp.; Anotopteridae, 3 spp.; Alepisauridae, Bathysauridae e Giganturidae, com 2 spp cada; e famílias com apenas uma espécie, Bathysauroididae e Omosudidae (FRICKE et al., 2020).

A maior parte das espécies de Aulopiformes ocorre em oceano profundo, tanto em ambientes pelágicos quanto demersais; porém, os representantes da família Trachinidae e dos gêneros Synodus e Trachinocephalus podem ocorrer em águas costeiras mais rasas, podendo ser encontrados em fundos de recife, areia, lama ou consolidado, e até mesmo dentro dos estuários em áreas com salinidade reduzida (RUSSELL, 2002).

A família Synodontidae é dividida em quatro gêneros: Harpadon Lesueur, 1825 e Saurida (subfamília Harpadontinae), Synodus e Trachinocephalus (subfamília Synodontinae) (ROSEN, 1973; SULAK, 1977; JOHNSON, 1982; BALDWIN \& JOHNSON, 1996).

Os membros da família Synodontidae são caracterizados pela boca grande com fileiras de numerosos dentes pequenos também localizados no vômer e no palato; raios branquiais presentes como placas de dentes; corpo alongado e circular; nadadeira adiposa localizada sobre a base da anal; pequenas escamas ao longo da linha lateral; nadadeiras pélvicas localizadas ventralmente; membrana adiposa nas margens anterior e posterior do olho; quinto ceratobranquial em forma de V com membro mediano robusto; cartilagem quadrada separada em dois côndilos, 29-67 vértebras, 8-26 raios branquiostégios e a existência de 5-11 manchas ao longo do peritônio e da linha mesoventral da nadadeira anal (BALDWIN \& JOHNSON, 1996; DAVIS, 2010; RUSSELL, 2002).

Em sua tese de doutorado, Polanco (2006) revisou as espécies de peixes-lagarto que ocorrem na costa do Atlântico e do Pacífico da América do Sul. Polanco (2006) identificou três novas espécies ainda não descritas de Saurida, sendo uma pertencente ao complexo $S$. brasiliensis Norman, 1935; duas do complexo Saurida suspicio Breder, 192; além de 
Trachinocephalus gauguini Polanco, Acero \& Betancur 2016 descrita das Ilhas Marquesas. Cinco espécies de Synodus do Atlântico foram identificadas: S. foetens (Linnaeus, 1766), S. intermedius (Agassiz, 1829), S. poeyi Jordan, 1887, S. saurus (Linnaeus, 1758) e S. synodus (Linnaeus, 1758). Frable et al. (2013) publicaram o último estudo com o grupo no oceano Atlântico, que resultou na descrição de uma nova espécie do Atlântico Norte, Synodus macrostigmus Frable, Luther \& Baldwin, 2013 e na resolução de alguns problemas taxonômicos, como a fixação de um neótipo para S. foetens da Carolina do Sul (3247'34.80" $\left.\mathrm{N}, 7^{\circ} 39^{\prime} 46.80^{\prime \prime} \mathrm{O}\right)$ e $S$. intermedius do nordeste brasileiro ( $\left.0^{\circ} 13^{\prime} 48.00^{\prime \prime} \mathrm{N}, 44^{\circ} 49^{\prime} 47.99^{\prime \prime} \mathrm{O}\right)$, ambos depositados no United States Nacional Museum - Smithsonian Institution (USNM). Em nenhuma dessas revisões os autores examinaram quantidade significativa de material proveniente de coleções brasileiras, e consequentemente, as espécies que ocorrem no Atlântico Sul ocidental foram extrapoladas como as mesmas que ocorrem no Atlântico Norte ocidental.

\subsection{Histórico Taxonômico das Espécies no Oceano Atlântico}

O gênero Synodus foi erguido por Scopolli (1777) para incluir Synodus synodus e $S$. foetens, originalmente descritas como Esox synodus e Salmo foetens, respectivamente (Linnaeus, 1758; 1766). Bloch \& Schneider (1801) basearam o nome Synodus principalmente em Gronow (1754) a partir de uma figura e descrição, atualmente válida como Synodus Scopolli, 1777. Atualmente, o gênero inclui 48 espécies válidas, sendo que no Oceano Atlântico há ocorrência de sete espécies válidas: S. saurus, descrita da Europa; S. synodus, descrita da América do Norte; S. foetens, descrita da Carolina do Sul (EUA); S. intermedius, descrita do nordeste brasileiro; S. poeyi, descrita de Havana, Cuba; S. bondi Fowler 1939, descrita de Kingston, Jamaica; e S. macrostigmus, descrita da Flórida (EUA) (MENEZES et al., 2003; POLANCO, 2006; FRABLE et al., 2013; FRABLE, 2015; FRICKE et al. 2020; HORTON et al.; 2020). Ainda existem 26 espécies consideradas sinônimos, sendo 13 de $S$. saurus, 10 de $S$. synodus, duas de S. intermedius (uma apenas com erro ortográfico) e uma de S. foetens, Synodus poeyi, S. bondi e S. macrostigmus não possuem sinônimos (HORTON et al.; 2020).

Quando limitado ao Atlântico Sul ocidental, até o momento há registro de apenas cinco espécies válidas: S. bondi, S. foetens, S. intermedius; S. poeyi e S. synodus (MENEZES et al., 2003; POLANCO, 2006; CARVALHO-FILHO et al., 2010). Synodus macrostigmus, conhecida no Atlântico Norte ocidental (FRABLE et al., 2013; FRABLE, 2015), e S. saurus, conhecida no Atlântico Norte ocidental, Atlântico oriental e Mar Mediterrâneo (RUSSELL, 2016; ELBARAASI et al., 2019), não foram previamente registradas na área de estudo. 


\subsection{Posicionamento Filogenético de Synodontidae}

Greenwood et al. (1966) classificaram Synodontidae na Divisão III, Superordem Protacanthopterygii, Ordem Salmoniformes, Subordem Myctophoidei. Sulak (1977) incluiu a família Synodontidae na Superordem Scopelomorpha, dentro da Ordem Myctophiformes; essa classificação foi seguida por autores subsequentes (e.g., FIGUEIREDO \& MENEZES, 1978; JOHNSON, 1982). Johnson (1982) incluiu a família Synodontidae na subordem Synodontoidei, ainda dentro de Myctophiiformes. Finalmente, Baldwin \& Johnson (1996) corroboraram o monofiletismo de Aulopiformes proposto por Rosen (1973), e incluíram a família Synodontidae nesta ordem, dentro da Subordem Synodontoidei. Mais recentemente, Synodontidae foi incluída na Superordem Cyclosquamata, Ordem Aulopiformes, Subordem Aulopoidei, juntamente com as famílias Aulopidae e Pseudotrichonotidae (DAVIS, 2010; NELSON et al., 2016; BETANCUR-R et al., 2017).

Apesar da maioria dos autores corroborarem Synodontidae como monofilético (BALDWIN \& JOHNSON, 1996; DAVIS, 2010), Betancur-R et al. (2017) propõe que a família também inclui membros da família Pseudotrichonotidae e Paraulopidae, tornando Synodontidae parafilética. Porém, os autores alertam que a não-monofilia pode ser resultado de uma má resolução e que a validação tem fins de estabilidade, até que estudos adicionais que elucidem seu status sejam disponibilizadas.

\section{Objetivos}

\subsection{Objetivo Geral}

Realizar a revisão taxonômica das espécies de Synodus que ocorrem no Atlântico Sul ocidental através de métodos morfológicos.

\subsection{Objetivos específicos}

- Comparar as espécies do Atlântico Norte ocidental com as que ocorrem no Atlântico Sul ocidental;

- Revisar as espécies que ocorrem nas ilhas oceânicas do arquipélago de Fernando de Noronha e Vitória-Trindade, e no Atol das Rocas;

- Fornecer diagnoses atualizadas para as espécies;

- Atualizar os mapas de distribuição, identificando os limites setentrionais de distribuição das espécies com maior precisão. 
- Fornecer uma chave de identificação atualizada.

- Fornecer estabilidade taxonômica à Synodus synodus e fixar a localidade tipo, através da designação de um neótipo.

\section{Material e Métodos}

Foram examinados 263 exemplares que foram utilizados na obtenção de 34 caracteres morfométricos (Tabela 1) (Figuras 1 e 2), 13 caracteres merísticos (Tabela 2) e sete características descritivas (Tabela 3). Todas as medidas foram obtidas com auxílio de um paquímetro digital de precisão de $0,1 \mathrm{~mm}$ sob estereomicroscópio e realizadas preferencialmente no lado esquerdo do corpo dos exemplares. O material foi proveniente das seguintes coleções brasileiras: Coleção Ictiológica da Universidade Federal do Espírito Santo (CIUFES), Museu de Ciência e Tecnologia da Pontifícia Universidade Católica do Rio Grande do Sul (MCT-PUCRS), Museu Nacional do Rio de Janeiro (MNRJ), Museu de Zoologia da Universidade de São Paulo (MZUSP), Universidade Federal da Paraíba (UFPB), Museu Paraense Emílio Goeldi (MPEG) e Acervo Zoológico da Universidade Santa Cecília (AZUSC).

Para a contagem de vértebras, nove exemplares foram radiografados (quatro de $S$. foetens; dois de S. synodus, e um de S. intermedius, S. bondi e Synodus sp. N) na Faculdade de Medicina Veterinária e Zootecnia da USP (FMVZ-USP). Para estudos osteológicos, foi realizado o processo de diafanização e coragem diferencial de ossos e cartilagens segundo o protocolo descrito por Taylor \& Van Dyke (1985). Foram utilizados seis exemplares, sendo três de $S$. foetens e um de S. synodus, S. intermedius e $S$. bondi). Synodus macrostigmus e Synodus sp. N não foram diafanizados pelo baixo número de exemplares disponíveis em coleções. 
Tabela 1. Caracteres morfométricos mensurados nas análises taxonômicas.

\section{CARACTERES MORFORMÉTRICOS}

Medidas do Corpo (Figura 1)

1-2 Comprimento total (CT)

1-3 Comprimento padrão (CP)

1-4 Comprimento cabeça (CC)

1-5 Comprimento até extremidade da nadadeira anal deprimida

1-6 Comprimento pré-adiposa

1-7 Comprimento pré-anal

1-8 Comprimento pré-dorsal

1-9 Comprimento pré-pélvica

1-10 Comprimento pré-peitoral

8-11 Comprimento base da nadadeira dorsal

12-13 Comprimento raio mais longo da nadadeira dorsal

7-14 Comprimento base da nadadeira anal

15-16 Comprimento raio mais longo da nadadeira anal

6-17 Comprimento base da nadadeira adiposa

10 (d) - 10 (e) Largura do corpo na origem da nadadeira peitoral

8-18 Altura do corpo na origem da nadadeira dorsal

6-19 Altura do corpo na origem da nadadeira adiposa

18-20 Altura do corpo na origem da nadadeira pélvica

7-21 Altura do corpo na origem da nadadeira anal

22-23 Altura do corpo no pedúnculo caudal

Linha tracejada Largura do corpo na origem da nadadeira dorsal

10-24 Comprimento da nadadeira peitoral

9-25 Comprimento da nadadeira pélvica

3-2 Comprimento da nadadeira caudal

1-26 Distância entre ponta do focinho e a ponta da maxila

1-27 Comprimento do focinho

14-28 Comprimento pedúnculo caudal

\section{Medidas da Cabeça (Figura 2)}

1-4 Distância da narina anterior até a margem anterior da órbita

2-4 Distância da narina posterior até margem anterior da órbita

1-3 Comprimento da membrana da narina anterior

5-6 Largura da tampa adiposa em volta da órbita

7-8 Diâmetro da órbita

Comprimento longitudinal da mancha escapular (se houver) 
Tabela 2. Caracteres merísticos mensurados nas análises taxonômicas.

\section{CARACTERES MERÍSTICOS}

Número de raios da nadadeira peitoral

Número de raios da nadadeira pélvica

Número de raios da nadadeira dorsal

Número de raios da nadadeira anal

Número de raios da nadadeira caudal

Número de escamas da linha lateral

Número de escamas da linha lateral à base da nadadeira dorsal

Número de escamas da linha lateral à base da nadadeira anal

Número de escamas anteriores à nadadeira dorsal

Número de escamas entre o ânus e a nadadeira anal

Número de escamas do pedúnculo caudal

Fileiras de dentes no dentário

Fileiras de dentes na pré-maxila

Tabela 3. Características descritivas observadas nas análises taxonômicas.

\section{CARACTERÍSTICAS DESCRITIVAS}

Raios anteriores da nadadeira dorsal quando deprimida (longos ou curtos)

Ponta da nadadeira peitoral ultrapassa ou não origem da nadadeira pélvica

Presença ou ausência de mancha escapular preta

Presença ou ausência de mancha preta acima do focinho

Lobo caudal mais longo

Formato e tamanho da membrana da narina anterior

Formato focinho 


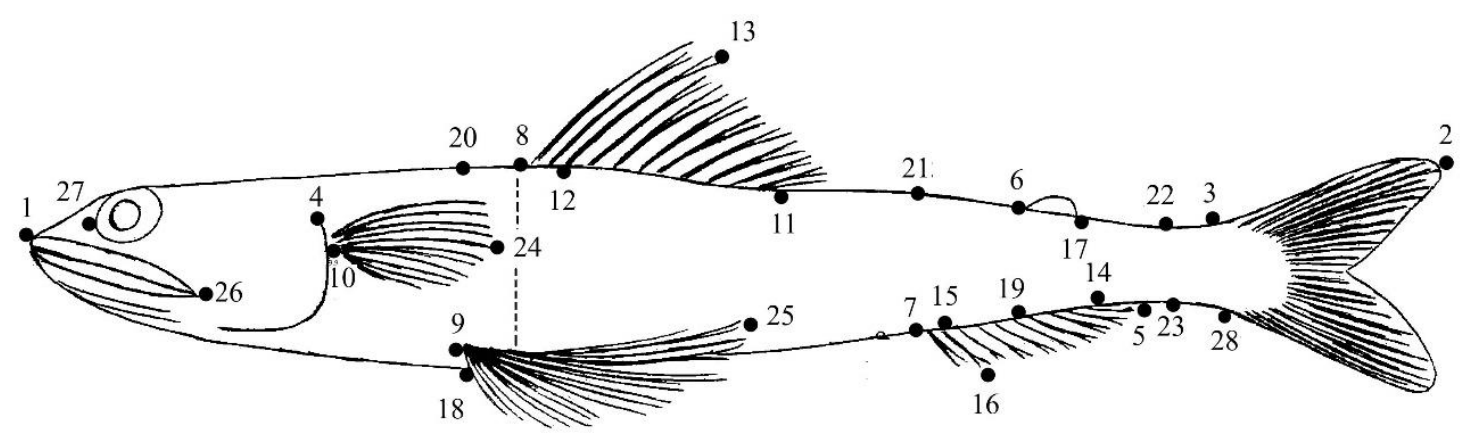

Figura 1. Esquema demonstrando os pontos homólogos do corpo de Synodus utilizados para a obtenção de caracteres morfométricos. A Tabela 1 mostra cada medida utilizada.

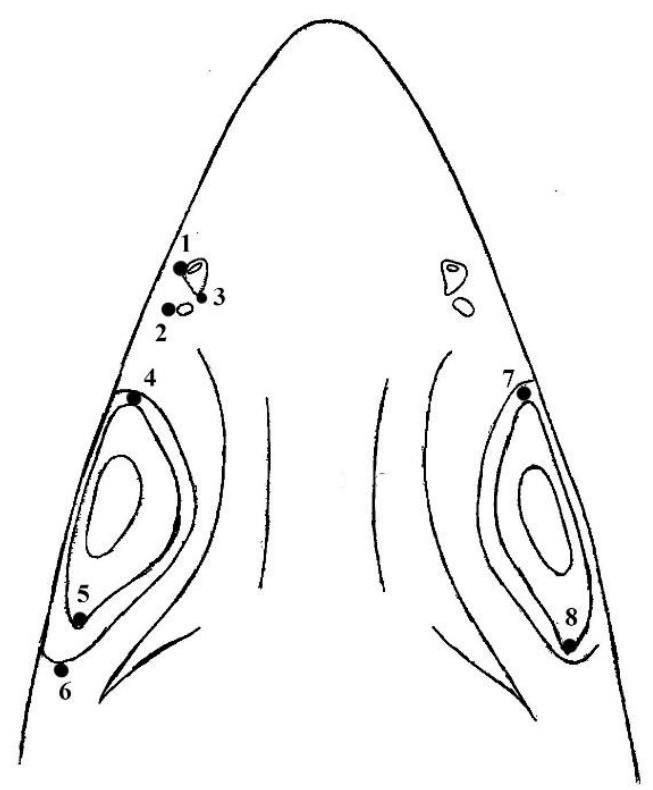

Figura 2. Esquema demonstrando os pontos homólogos da cabeça de Synodus utilizados para a obtenção de caracteres morfométricos. A Tabela 1 mostra cada medida utilizada.

\section{Resultados}

4.1. Descrição geral e Diagnose de Synodus Scopoli, 1777

\section{Synodus Scopoli, 1777}

Peixe-lagarto, lagarto-do-rolo, lagarto-do-mar, tira-vira, catinguento. 
Synodus Scopoli, 1777:449 [descrição realizada sem espécie tipo, Introductio ad historiam naturalem, sem localização, ext. Gronow, 1763, erguido para incluir Synodus synodus e S. foetens, originalmente descritas como Esox synodus e Salmo foetens, respectivamente (Linnaeus, 1758; 1766)]

Synodus Bloch \& Schneider, 1801:396 (xlix) [Systema Ichthyologiae, espécie tipo Esox synodus, substituído por Synodus Scopoli, 1777].

Tirus Rafinesque, 1810:56 [Caratteri di alcuni nuovi generi e nuove specie di animali e piante della Sicilia; atualmente sinônimo de Synodus Scopoli, 1777 por Nielsen, 1973:161].

Saurus Cuvier, 1816:169 [Le Règne Animal v. 2; Salmo saurus Linnaeus 1758, tipo por absoluta tautonímia, atualmente sinônimo de Synodus Scopoli, 1777, Anderson et al., 1966:47].

Alpismaris Risso, 1827: 458 [Histoire naturelle des principales productions de l'Europe méridionale, Synodus saurus por Jordan \& Evermann, 1896:533; também sinônimo de Aphanius Nardo, 1827 in Cyprinodontidae (Wildekamp et al., 1986:165, designação atual incerta como Synodus].

Salmosaurus Minding, 1832:120 [Lehrbuch der Naturgeschichte der Fische, novo nome desnecessário para Saurus Cuvier, 1816, atualmente sinônimo de Synodus Scopoli, 1777].

Laurida Swainson, 1838:242, 246 [The natural history and classification of fishes, amphibians, \& reptiles, or monocardian animals, tipo por designação subsequente, Synodus Scopoli, 1777 por Swain, 1882:279].

Xystodus Ogilby, 1910:5 [Proceedings of the Royal Society of Queensland v. 23; tipo por designação original, sinônimo de Synodus Scopoli, 1777 por Sulak, 1977:53 em revisão de Myctophiformes bentônicos].

Allouarnia Whitley, 1937:219 [tipo por designação original, subgênero de Synodus no catálogo de peixes dos recifes de Middleton e Elizabeth, oceano pacífico, atualmente Synodus sageneus Waite, 1905].

Austrotirus Whitley, 1937:219 [tipo por designação original, subgênero de Synodus no catálogo de peixes dos recifes de Middleton e Elizabeth, oceano pacífico, atualmente Synodus similis McCulloch, 1921]. 
Esosynodus Whitley, 1937:219 [tipo por designação original, subgênero de Synodus no catálogo de peixes dos recifes de Middleton e Elizabeth, oceano pacífico, atualmente sinônimo de Synodus Scopoli, 1777, Anderson et al., 1966:47]

Exotirichthys Whitley, 1937:219 [tipo por designação original, subgênero de Synodus no catálogo de peixes dos recifes de Middleton e Elizabeth, oceano pacífico, atualmente sinônimo de Synodus Scopoli, 1777, Anderson et al., 1966:47]

Negotirus Whitley, 1937:219 [tipo por designação original, subgênero de Synodus no catálogo de peixes dos recifes de Middleton e Elizabeth, oceano pacífico, atualmente Synodus evermanni Jordan \& Bollman, 1890].

Newtonscottia Whitley, 1937:219 [tipo por designação original, subgênero de Synodus no catálogo de peixes dos recifes de Middleton e Elizabeth, oceano pacífico, atualmente Synodus houlti McCulloch, 1921].

Os membros da família Synodontidae possuem fileiras de numerosos dentes pequenos também localizados no vômer e no palato; nadadeira adiposa localizada sobre a base da anal; nadadeiras pélvicas localizadas ventralmente; membrana adiposa nas margens anterior e posterior do olho; maxila reduzida e conectada à pré-maxila (BALDWIN \& JOHNSON, 1996; DAVIS, 2010; RUSSELL, 2002). Dentre os Synodontidae, Synodus pode ser diagnosticado por possuir 8 raios na nadadeira pélvica ( $v s .9$ raios em Saurida); raios internos da nadadeira pélvica muito mais longos que os externos (vs. aproximadamente iguais em tamanho em Saurida); (Figura 3); 8-14 raios na nadadeira anal (vs. 15-17 em Trachinocephalus); ausência de escamas nos raios procurrentes da nadadeira caudal (vs. presença em Trachinocephalus); ausência de supramaxila ( $v s$. presença de 2 pequenas em Saurida); presença de uma fileira de dentes no palatino (vs. 2 fileiras em Saurida); 15-18 raios branquiostégios (vs. 12 em Trachinocephalus e 13 em Saurida); dois primeiros raios das nadadeiras dorsal e anal simples, os outros geralmente ramificados, e o último sempre ramificado a partir da base (ANDERSON et al., 1966; FIGUEIREDO \& MENEZES, 1978; RUSSELL, 2002). 

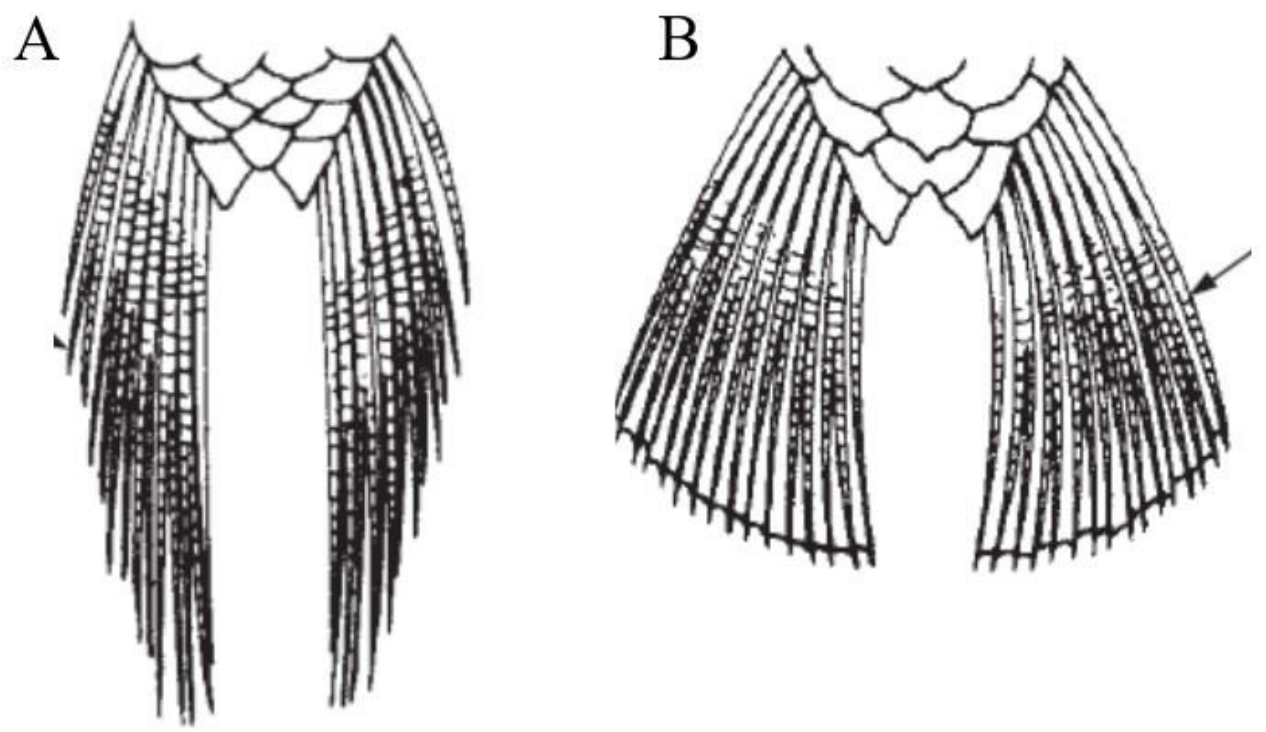

Figura 3. Esquema mostrando a disposição dos raios da nadadeira pélvica em A. Synodus. B. Saurida. Retirado de Russell (2002).

\subsection{Diagnoses e descrições das espécies de Synodus}

\section{Synodus bondi Fowler 1939}

Peixe-lagarto, tira-vira, catinguento [português]. Sharpnose Lizardfish [inglês] Frable et al. (2013);

(Figs. 4, 5, 6, 7, 25 A, 26, 27, 29, 33 A, 34 A, 35 A-D, 36 A-B; Tabelas 4, 10, 11)

Synodus bondi Fowler, 1939: 7, Figs. 5-6 [Notulae Naturae (Philadelphia) No. 35 [descrição original, localidade tipo: Kingston, Jamaica] holótipo - ANSP 68634, 275 mm CT, parátipo - ANSP 68635, 194,0 mm CT; Böhlke 1984:160 [catálogo de espécimes tipo depositados na coleção ictiológica da Academy of Natural Sciences of Philadelphia - ANSP]; Frable et al. 2013: 138, Figs 1, 2D, 5C -D, 6, Tab 1, 4, 5 [revisão da espécie, chave taxonômica, mapa de distribuição].

Holótipo. ANSP 68634, 275.0 mm CT, Kingston, Jamaica (Figura 4).

Parátipo. ANSP 68635, 194.0 mm CT.

Material analisado: Apêndice A. 


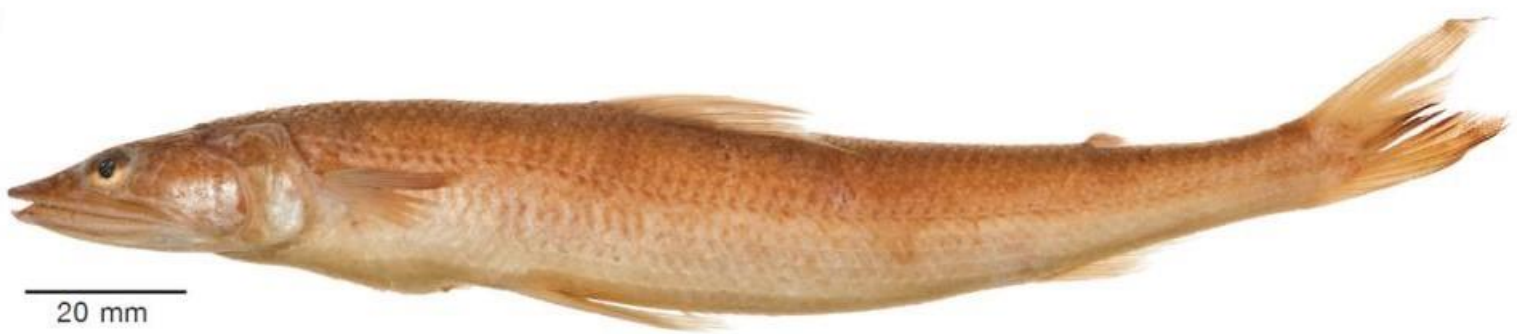

Figura 4. Holótipo de Synodus bondi. ANSP 68634, 275.0 mm CT. Retirado de Frable et al. (2013).

\section{Diagnose}

Synodus bondi pode ser diferenciado de seus congêneres pela combinação das seguintes características: 59-64 escamas na linha lateral (vs. 43-52 em S. poeyi, S. intermedius, S. macrostigmus e Synodus sp. N); 20-30 escamas pré-dorsais (vs. 15-18 em S. poeyi, S. macrostigmus, S. intermedius, S. synodus e Synodus sp. N); 4,5-5,5 escamas da linha lateral à base da nadadeira dorsal (vs. 3,5 em S. intermedius e S. macrostigmus); 10-12 raios na nadadeira anal (vs. 8-10 em S. synodus e 12-14 em S. foetens); raios anteriores da nadadeira dorsal longos, ultrapassando os posteriores quando deprimida (vs. raios curtos, não ultrapassando os posteriores quando deprimida em S. intermedius, S. macrostigmus e Synodus synodus); extremidade distal da nadadeira peitoral não ultrapassando a origem da nadadeira pélvica (vs. ultrapassando em S. intermedius, S. macrostigmus, S. poeyi, S. synodus e Synodus sp. N); comprimento do focinho maior que o diâmetro do olho (vs. menor ou igual em Synodus sp. N); membrana da narina anterior de espessura muito fina e formato triangular afunilado (vs. em formato de colher em S. synodus, triangular arredondada em S. foetens e S. intermedius); focinho muito pontudo quando visto dorsalmente, sendo possível observar o lábio supramaxilar ( $v s$. não muito pontudo, não sendo possível observar o lábio supramaxilar dorsalmente em $S$. foetens). 


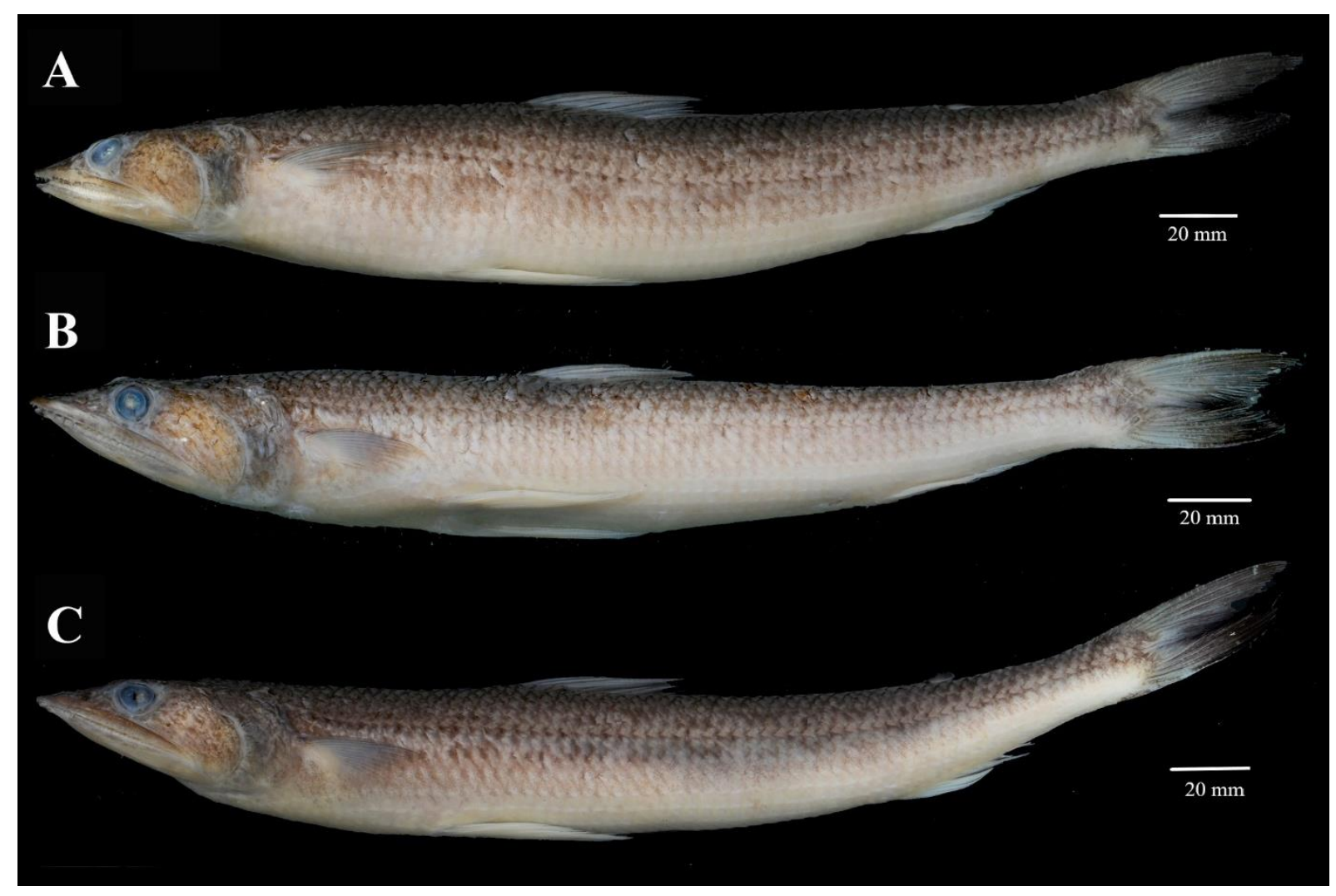

Figura 5. Synodus bondi. A. MPEG 35608, 239.5 mm CP; B. MPEG 35672, 247.5 mm CP; C. MPEG 35747 , $249.5 \mathrm{~mm} \mathrm{CP}$.

\section{Descrição}

Dados morfométricos listados na Tabela 4. Corpo alongado e cilíndrico, afunilando no pedúnculo caudal. Boca terminal. Focinho pontudo em vista lateral, triangular em vista dorsal com visualização dos lábios; comprimido dorso-ventralmente. Ponta do focinho se entendendo além da sínfise do dentário. Margem distal dos ossos maxilares se entendendo além da margem posterior da órbita. Duas fileiras de dentes na pré-maxila; maxila edêntula. Três fileiras de dentes no dentário, maiores medialmente; dentes posteriores direcionados anteriormente. Todos os dentes cônicos, com uma cúspide. Narinas de mesmo tamanho; narina anterior com membrana triangular afunilada; narina posterior sem membrana.

Nadadeiras peitorais curtas, com formato triangular, posicionadas lateralmente no corpo, na altura da órbita. Nadadeiras pélvicas ventrais em posição anterior à vertical que passa sobre a origem da nadadeira dorsal. Nadadeira adiposa presente. Nadadeira caudal furcada; lobo superior ligeiramente maior ou igual ao lobo inferior. 
Raios da nadadeira dorsal ii,8 (2), ii,9 (13), ii,10 (41) e ii,11 (1); raios da nadadeira anal ii,8 (1), ii,9 (16) e ii,10 (34); raios da nadadeira peitoral ii,9,i (6), ii,10,i (40) e ii,11,i (11); raios da nadadeira pélvica i,6,i (57); raios da nadadeira caudal i,8,9,i (33) e i,9,9,i (24); vértebras 63 (2); vértebras pré-dorsais 18 (2) (Figura 6); raios branquiostégios 16 (1); raios procurrentes dorsais 11 (1); raios procurrentes ventrais 10 (1); escamas ctenóides; escamas da linha lateral 59 (2); 61 (8); 62 (16), 63 (23) e 64 (8); escamas pré-dorsais 24 (14), 25 (21), 26 (13), 27 (5) e 28 (4); fileiras de escamas acima da linha lateral até base da nadadeira dorsal 4,5 (44) e 5,5 (13); fileiras de escamas abaixo da linha lateral até base da nadadeira anal 5,5 (39) e 6,5 (18).

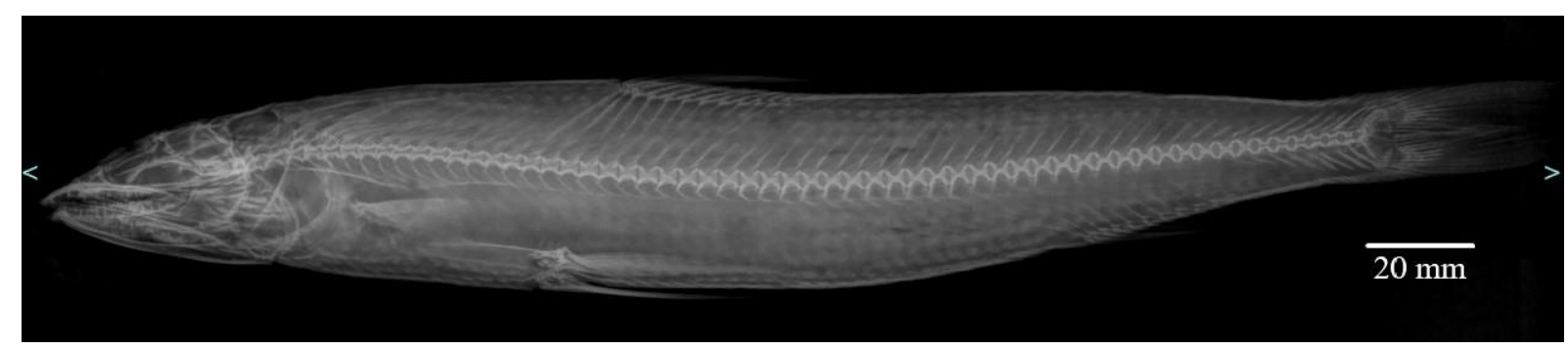

Figura 6. Radiografia de Synodus bondi, MPEG 35608, 239.5 mm CP.

Tabela 4. Dados morfométricos obtidos em Synodus bondi.

\begin{tabular}{lcccc}
\hline \hline Medição & $\begin{array}{c}\text { Range } \\
(\%)\end{array}$ & $\begin{array}{c}\text { Média } \\
(\%)\end{array}$ & $\begin{array}{c}\text { Desvio } \\
\text { padrão }\end{array}$ & N \\
Porcentagem em relação ao CP (Figura 1) & & & & \\
Comprimento cabeça (CC) & $19.9-24.3$ & 22.2 & 1.10 & 54 \\
Comprimento focinho-nadadeira anal deprimida & $83.2-97.3$ & 92.8 & 2.09 & 54 \\
Comprimento pré-adiposa & $77.5-86.0$ & 81.2 & 1.44 & 54 \\
Comprimento pré-anal & $74.0-83.4$ & 76.9 & 1.45 & 54 \\
Comprimento pré-dorsal & $42.1-47.0$ & 44.2 & 1.14 & 54 \\
Comprimento pré-pélvica & $33.4-40.9$ & 37.1 & 1.75 & 54 \\
Comprimento pré-peitoral & $22.1-26.0$ & 23.9 & 0.98 & 54 \\
Comprimento base da nadadeira dorsal & $10.6-13.9$ & 11.9 & 0.83 & 54 \\
Comprimento raio mais longo da nadadeira dorsal & $13.4-15.7$ & 14.5 & 0.64 & 54 \\
Comprimento base da nadadeira anal & $10.7-15.1$ & 12.5 & 1.01 & 54 \\
Comprimento raio mais longo da nadadeira anal & $6.5-10.2$ & 8.4 & 0.81 & 54 \\
Comprimento base da nadadeira adiposa & $1.0-2.3$ & 1.4 & 0.31 & 54 \\
Largura do corpo origem nadadeira peitoral & $10.4-16.1$ & 13.6 & 1.12 & 54 \\
Altura do corpo origem nadadeira dorsal & $10.1-17.1$ & 13.2 & 1.80 & 54 \\
Altura do corpo origem nadadeira adiposa & $6.5-9.8$ & 8.3 & 0.75 & 54 \\
\hline \hline
\end{tabular}




\begin{tabular}{lcccc}
\hline \hline Altura do corpo origem nadadeira pélvica & $8.0-16.2$ & 12.4 & 1.77 & 54 \\
Altura do corpo origem nadadeira anal & $7.8-11.4$ & 9.4 & 0.85 & 54 \\
Altura do corpo no pedúnculo caudal & $4.4-6.3$ & 5.4 & 0.45 & 54 \\
Largura do corpo origem nadadeira dorsal & $9.2-15.2$ & 13.4 & 1.15 & 54 \\
Comprimento nadadeira peitoral & $10.4-13.8$ & 12.2 & 0.67 & 54 \\
Comprimento nadadeira pélvica & $17.5-21.9$ & 19.6 & 1.26 & 54 \\
Comprimento nadadeira caudal & $12.4-20.9$ & 18.5 & 1.37 & 47 \\
Distância ponta do focinho-ponta da maxila & $13.8-16.6$ & 15.2 & 0.74 & 54 \\
Comprimento focinho & $6.5-8.1$ & 7.2 & 0.40 & 54 \\
Comprimento pedúnculo caudal & $9.3-14.2$ & 12.2 & 1.03 & 54 \\
Diâmetro da órbita & $3.3-4.8$ & 3.8 & 0.32 & 54 \\
Porcentagem em relação ao CC (Figura 2) & & & & \\
Distância ponta do focinho-ponta da maxila & $63.8-74.3$ & 68.3 & 2.21 & 54 \\
Comprimento focinho & $30.7-36.9$ & 32.6 & 1.41 & 54 \\
Distância narina anterior-margem anterior da órbita & $7.4-10.8$ & 8.9 & 0.80 & 54 \\
Distância narina posterior-margem anterior da órbita & $4.4-8.0$ & 5.5 & 0.75 & 54 \\
Comprimento membrana narina anterior & $2.0-6.2$ & 3.8 & 1.00 & 45 \\
Largura tampa adiposa em volta da órbita & $1.3-3.6$ & 2.5 & 0.62 & 54 \\
Diâmetro da órbita & $14.5-21.1$ & 17.3 & 1.53 & 54 \\
\hline \hline
\end{tabular}

Coloração em vida. Corpo esverdeado escuro com ventre mais claro. Presença de 7-8 manchas em formato de cruz principalmente em exemplares menores que $100 \mathrm{~mm}$ (FRABLE et al., 2013). Nadadeira dorsal marrom com membrana translúcida entre raios. Nadadeiras peitorais, pélvicas e anal transparentes ou pálidas. Nadadeiras caudais com pigmentação mais escura nas bordas.

Coloração em álcool. Pigmentação geral do corpo acinzentada com 7-8 manchas sutis em formato de diamante, distribuídas lateralmente ao longo de todo o comprimento do corpo. Coloração marrom avermelhada e manchas mais claras em exemplares antigos em coleções. Coloração mais clara ou até mesmo branca no ventre. Nadadeiras dorsal, anal, pélvicas e peitorais claras. Nadadeiras caudais com pigmentação mais escura nas bordas. Nadadeira adiposa pigmentada. Cabeça mais alaranjada que o restante do corpo.

\section{Distribuição}

Synodus bondi está distribuído desde a América Central, incluindo Jamaica, Haiti, Belize, Honduras, Panamá; e se estende até América do Sul, no norte do Brasil (FRABLE et al., 2013). A espécie aparentemente possui uma distribuição disjunta no Sul e Sudeste brasileiro, nos 
estados do Rio de Janeiro, São Paulo, Paraná e Santa Catarina. Curiosamente, não foram examinados exemplares dessa espécie nos estados do Nordeste brasileiro, entre o Maranhão e norte do Espírito Santo (Figura 7).

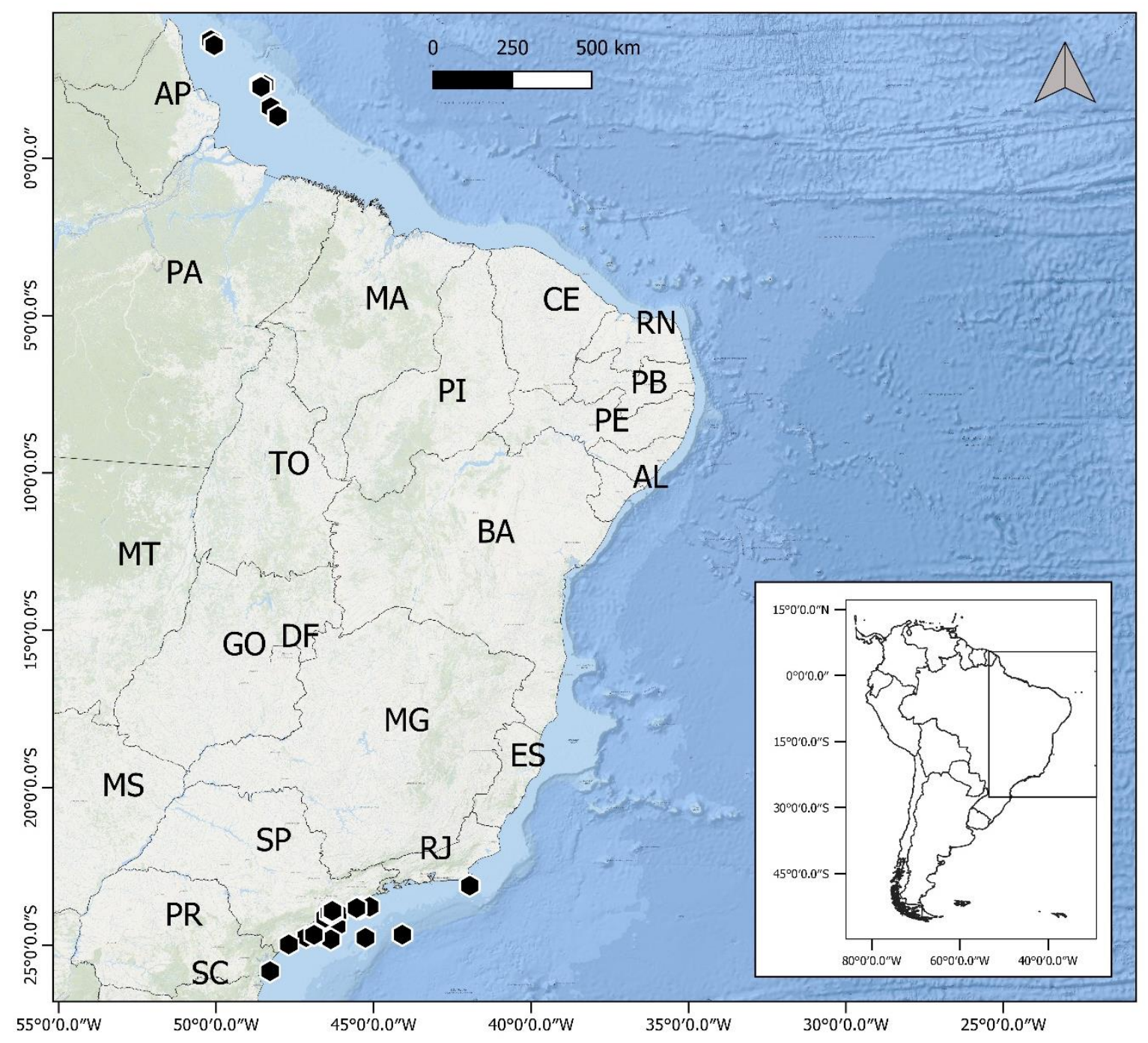

Figura 7. Área de distribuição dos lotes de S. bondi provenientes de coleções brasileiras.

Comentário. Synodus bondi pode chegar a $30 \mathrm{~cm}$ de comprimento total (FOWLER, 1939; FRABLE et al., 2013). Teve sua ocorrência registrada no Brasil por Frable et al. (2013), com um espécime coletado em 1963 no Maranhão, previamente identificado como S. foetens. 


\section{Synodus foetens (Linnaeus, 1766)}

Peixe-lagarto, Peixe-lagarto-costeiro; tira-vira, catinguento [português]; Inshore Lizardfish [inglês].

(Figs. 8, 9, 10, 11, 25 B, 28, 31, 32, 33 C, 34 C-D, 35 E-H, 36 C-D, 41 A; Tabelas 5, 10, 11).

Salmo foetens Linnaeus, 1766: 513 [descrição original baseada em Catesby, 1743:2, Pl. 2, fig. 2 (v. 2), espécimes enviados por Dr. Alexander Garden de Charleston, localidade tipo: Carolina do Sul, Estados Unidos]; sem tipos designados.

Osmerus albidus Lacepède, 1803: 229, 235. [Histoire naturelle des poissons (Lacepède) v. 5, nome baseado em descrições de Catesby e Linnaeus, localidade tipo: Carolina do Sul; sem tipos designados]; McAllister, 1963:42 [revisão da família Osmeridae, sinonimizada a Synodus foetens]

Coregonus ruber Lacepède, 1803: 243, Pl. 4 (fig. 3) [Histoire naturelle des poissons (Lacepède) v. 5, nome baseado em descrições de Plumier, localidade tipo: Martinique; sem tipos designados].

Esox salmoneus Mitchill, 1815: 442 [descrição dos peixes de Nova York, localidade tipo: Baía de Nova York; descrito de espécimes, 203-229 mm CT; sem tipos deignados]; Smith, 1986:399 [catálogo de peixes de Nova York, sinonimizada a Synodus foetens]

Saurus longirostris Agassiz in Spix and Agassiz, 1829: 80, pl. 43 [catálogo de peixes do Brasil, localidade tipo: Salvador, Bahia, Brasil; descrito de espécimes, 178-216 mm CT; potenciais síntipos: MHNN 793 (2) e MNHN B-0977 (1)]; Kottelat, 1984:146 [catálogo dos exemplares tipo do Musée d'Historie Naturelle de Neuchâtel, sinonimizada a Synodus foetens]

Saurus mexicanus Cuvier, 1829: 314 [catálogo do reino animal com descrições e anatomia, localidade tipo: Golfo do México; sem tipos designados].

Saurus spixianus Poey, 1860: 304 [catálogo das espécie de Isla de Cuba, localidade tipo: Cuba; holótipo - MCZ 6884, 330 mm CT]; Howell Rivero, 1938:176 [catálogo de exemplares tipos do Museum of Comparative Zoölogy, sinonimizada a Synodus foetens]

Synodus foetens Uyeno \& Aizawa in Uyeno et al., 1983:164 [Peixes coletados com rede de arrastado no Suriname e Guiana Francesa]; Smith, 1986:399 [catálogo de peixes interior do estado de Nova York]; Robins \& Ray, 1986:80 [guia de campo para peixes da costa Atlântica da América do Norte]; Cervigón, 1991:149 [catálogo de peixes marinhos da Venezuela]; 
Boschung, 1992:70 [catálogo de peixes do Alabama]; Cervigón, 1992:446 [guia de identificação de espécies pesqueiras]; Andreata \& Séret, 1996:583 [catálogo de peixes coletados nos limites da plataforma continental e nas montanhas submarinas de Vitória, Trindade e Martin Vaz]; Murdy et al., 1997:79 [catálogo de peixes da baía de Chesapeake]; McEachran \& Fechhelm, 1998:610 [catálogo de peixes do Golfo do México]; Aguilera, 1998:47 [catálogo de peixes marinhos do ocidente da Venezuela]; Smith-Vaniz et al., 1999:149 [catálogo, zoogeografia e chaves de identificação dos peixes de Bermuda]; Schmitter-Soto, et al., 2000:151 [catálogo de peixes marinhos do caribe mexicano]; Camargo \& Isaac, 2001:139 [catálogo de peixes estuarinos da região norte do Brasil]; Figueiredo \& Menezes in Menezes et al., 2003:49 [catálogo de peixes marinhos do Brasil]; Russell in Carpenter, 2003:928 [guia de identificação de peixes ósseos do Atlântico leste central]; Smith et al., 2003:11 [catálogo de peixes de Pelican Cays, Belize]; Nelson et al., 2004:88 [peixes do Canadá, Estados Unidos e México]; García-Hernández et al., 2009:91 [catálogo de larvas e juvenis da Penínsual de Yucatán, México]; Carvalho-Filho et al., 2010:33 [chave de identificação de espécies de Aulopoidei do Atlântico ocidental]; Frable et al., 2013:134, Figs 1, 2 C, 5 A-B, 6; Tab. 1, 4, 5 [revisão taxonômica e designação de neótipo USNM 405413, 205 mm CP, Carolina do Sul, $32^{\circ} 47^{\prime} 34.80^{\prime} \mathrm{N}, 7^{\circ} 39^{\prime} 46.80^{\prime}$ O]; Page et al., 2013:88 [catálogo de peixes do Canadá, Estados Unidos e México]; Pinheiro et al., 2015:8 [catálogo de peixes da cadeia montanhosa de VitóriaTrindade]; Raz-Guzmán et al., 2018:345 [catálogo e identificação de peixes da Laguna de Tamiahua, Veracruz, México]; Spier et al., 2018:8 [catálogo e caracterização de peixes da plataforma continental do Paraná]; Ribeiro et al., 2019:4 [catálogo de peixes de Santa Catarina].

Neótipo. USNM 405413, 205 mm CP, Carolina do Sul, 3247'34.80’ N, 79³9’46.80' O (Figura 8).

Material analisado: Apêndice A. 


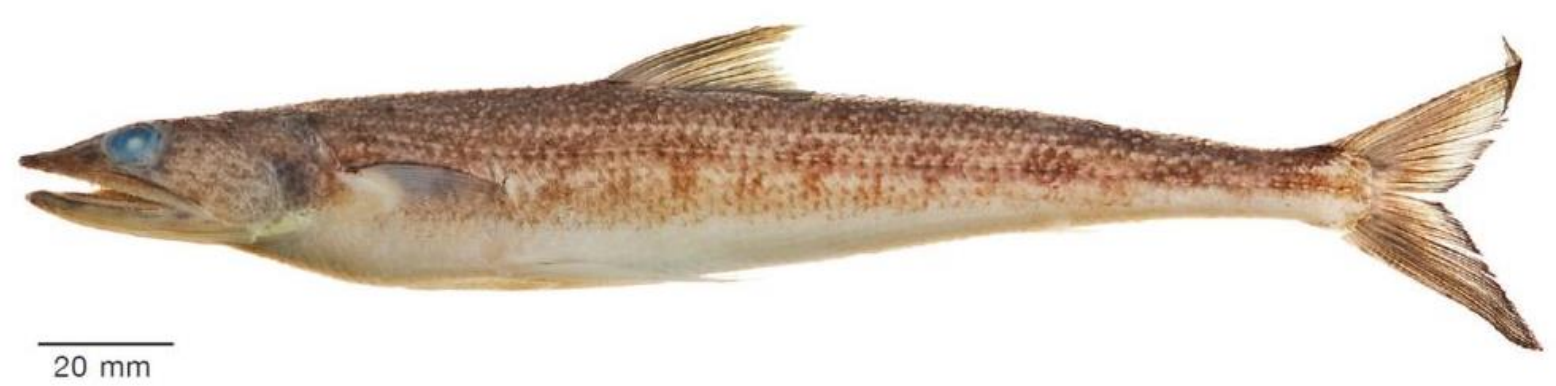

Figura 8. Neótipo de Synodus foetens. USNM 405413, 205 mm CP. Retirado de Frable et al. (2013).

\section{Diagnose}

Synodus foetens pode ser diferenciado de seus congêneres pela presença das seguintes características: 60-64 escamas na linha lateral (vs. 43-52 em S. poeyi, S. intermedius, S. macrostigmus e Synodus sp. N); 20-30 escamas pré-dorsais (vs. 15-18 em S. poeyi, S. macrostigmus, S. intermedius, S. synodus e Synodus sp. N); 4,5-5,5 escamas da linha lateral à base da nadadeira dorsal (vs. 3,5 em S. intermedius e $S$. macrostigmus); 12-14 raios na nadadeira anal (vs. 8-10 em S. synodus e 10-12 em S. bondi); raios anteriores da nadadeira dorsal longos, ultrapassando os posteriores quando deprimida ( $v s$. raios curtos, não ultrapassando os posteriores quando deprimida em S. intermedius, S. macrostigmus e Synodus synodus); extremidade distal da nadadeira peitoral não ultrapassando a origem da nadadeira pélvica (vs. ultrapassando em S. intermedius, S. macrostigmus, S. poeyi, S. synodus e Synodus sp. N); comprimento do focinho maior que o diâmetro do olho ( $v s$. menor ou igual em Synodus sp. N); membrana da narina anterior triangular com ponta arredondada ( $v s$. em formato de colher em S. synodus, e afunilada em $S$. bondi e $S$. macrostigmus); focinho triangular arredondado quando visto dorsalmente ( $v s$. triangular muito pontudo com lábio supramaxilar visto dorsalmente em $S$. bondi). 


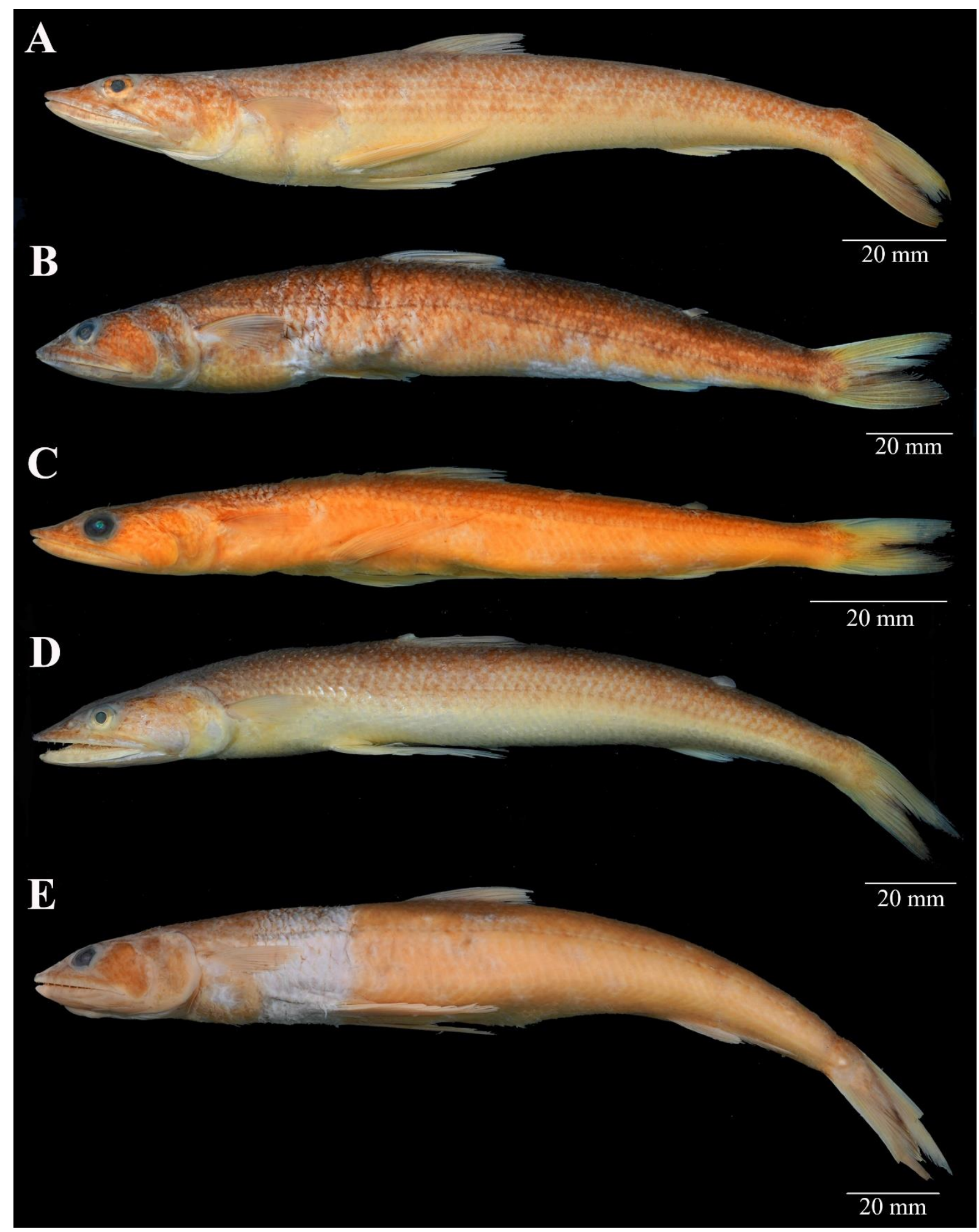

Figura 9. Synodus foetens. A. MZUSP 18299, 177 mm CP; B. MCP 16248, 203.5 mm CP; C. MNRJ 46453, 131.7 mm CP; D. MNRJ 37114, 196 mm CP; E. MCP 5025, 204 mm CP. 


\section{Descrição}

Dados morfométricos listados na Tabela 5. Corpo alongado e cilíndrico, afunilando no pedúnculo caudal. Boca terminal. Focinho pontudo em vista lateral, triangular em vista dorsal; comprimido dorso-ventralmente. Ponta do focinho se entendendo além da sínfise do dentário. Margem distal dos ossos maxilares se entendendo além da margem posterior da órbita. Duas fileiras de dentes na pré-maxila; maxila edêntula. Três fileiras de dentes no dentário, maiores medialmente; dentes posteriores direcionados anteriormente. Todos os dentes cônicos, com uma cúspide. Narinas de mesmo tamanho; narina anterior com membrana triangular; narina posterior sem membrana.

Nadadeiras peitorais curtas, com formato triangular, posicionadas lateralmente no corpo, na altura da órbita. Nadadeiras pélvicas ventrais em posição anterior à vertical que passa sobre a origem da nadadeira dorsal. Nadadeira adiposa presente. Nadadeira caudal furcada; lobo superior ligeiramente maior ou igual ao lobo inferior.

Raios da nadadeira dorsal ii,9 (2), ii,10 (111) e ii,11 (4); raios da nadadeira anal ii,10 (69), ii,11 (46) e ii,12 (2); raios da nadadeira peitoral ii,9,i (7), ii,10,i (103) e ii,11,i (7); raios da nadadeira pélvica i,6,i (117); raios da nadadeira caudal i,8,8,i (15), i,8,9,i (88) e i,9,9,i (14); vértebras 56 (1), 59 (2), 60 (1), 61 (1) e 62 (1); vértebras pré-dorsais 14 (2), 15 (1), 16 (1), 17 (1) e 18 (1) (Figura 10); raios branquiostégios 17 (2); raios procurrentes dorsais 11 (1) e 13 (1); raios procurrentes ventrais 10 (1) e 12 (1); escamas ctenóides; escamas da linha lateral 60 (4); 61 (6), 62 (46); 63 (56) e 64 (5); escamas pré-dorsais 21 (4), 22 (5), 23 (9); 24 (8); 25 (37); 26 (28); 27 (20); 28 (5) e 30 (1); fileiras de escamas acima da linha lateral até base da nadadeira dorsal 4,5 (56) e 5,5 (61) ; fileiras de escamas abaixo da linha lateral até base da nadadeira anal 5,5 (39) e 6,5 (78); duas fileiras de dentes na pré-maxila; três fileiras de dentes no dentário; lobo caudal superior ligeiramente maior ou igual lobo caudal inferior. 


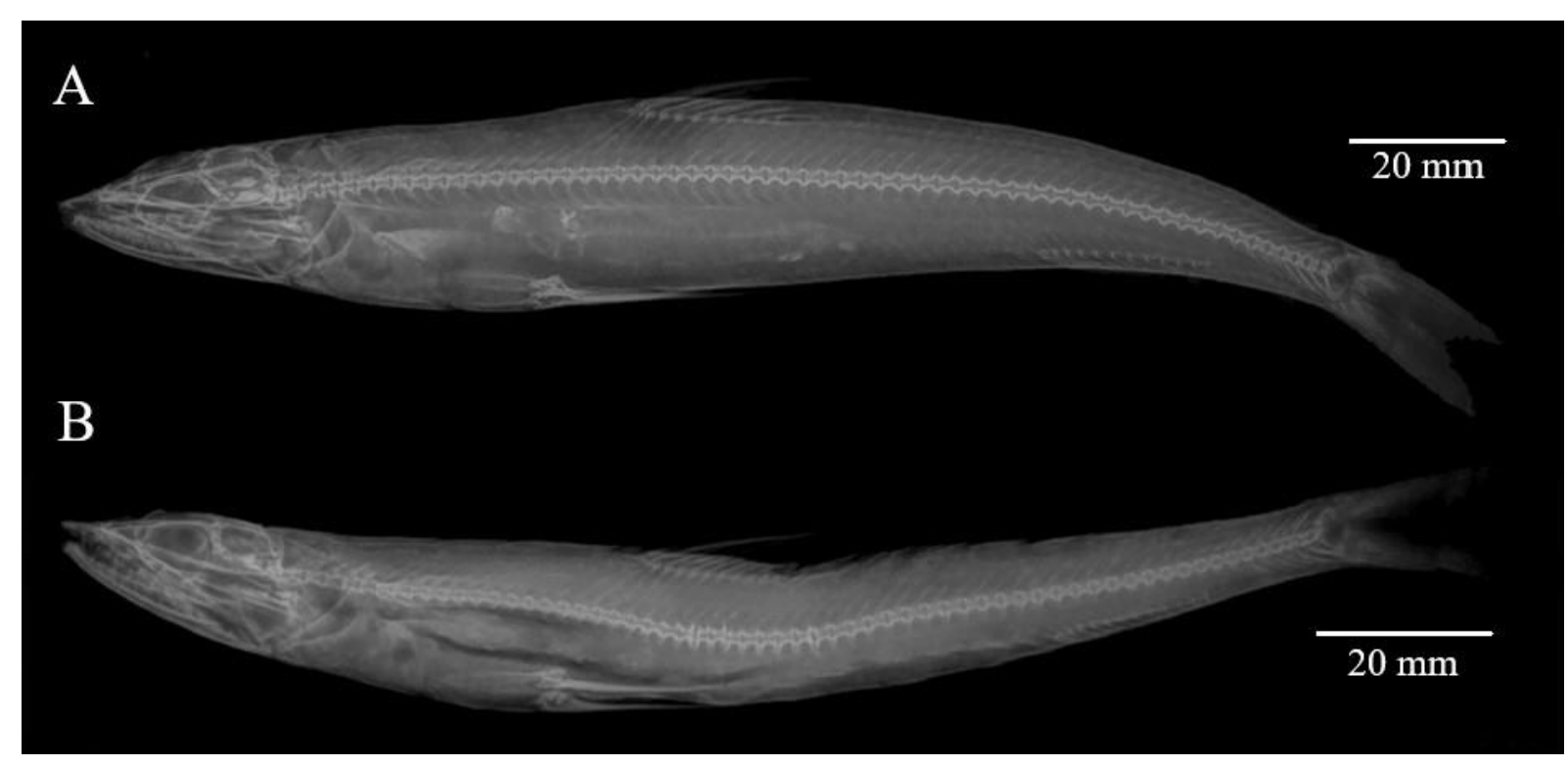

Figura 10. Radiografias de Synodus foetens. A. MZUSP 18299, 177.8 mm CP; B. MZUSP 55465, 160.8 mm CP.

Tabela 5. Dados morfométricos obtidos em Synodus foetens.

\begin{tabular}{lcccc}
\hline \hline Medição & $\begin{array}{c}\text { Range } \\
(\boldsymbol{\%})\end{array}$ & $\begin{array}{c}\text { Média } \\
(\boldsymbol{\%})\end{array}$ & $\begin{array}{c}\text { Desvio } \\
\text { padrão }\end{array}$ & N \\
Porcentagem em relação ao CP (Figura 1) & & & & \\
Comprimento cabeça (CC) & $19.6-23.6$ & 21.9 & 0.94 & 87 \\
Comprimento até nadadeira anal deprimida & $87.3-96.2$ & 92.9 & 1.92 & 87 \\
Comprimento pré-adiposa & $76.7-85.1$ & 80.6 & 1.46 & 87 \\
Comprimento pré-anal & $72.7-78.9$ & 75.9 & 1.59 & 87 \\
Comprimento pré-dorsal & $37.3-46.2$ & 43.8 & 1.50 & 87 \\
Comprimento pré-pélvica & $32.6-39.6$ & 36.4 & 1.47 & 87 \\
Comprimento pré-peitoral & $20.7-27.5$ & 23.9 & 1.20 & 87 \\
Comprimento base da nadadeira dorsal & $10.0-14.5$ & 11.9 & 0.90 & 87 \\
Comprimento raio mais longo da nadadeira dorsal & $11.9-16.3$ & 14.2 & 0.78 & 83 \\
Comprimento base da nadadeira anal & $10.7-16.6$ & 12.9 & 0.99 & 87 \\
Comprimento raio mais longo da nadadeira anal & $4.9-9.4$ & 7.7 & 0.83 & 85 \\
Comprimento base da nadadeira adiposa & $1.1-2.3$ & 1.6 & 0.28 & 87 \\
Largura do corpo origem nadadeira peitoral & $8.5-14.5$ & 12.7 & 1.23 & 87 \\
Altura do corpo origem nadadeira dorsal & $7.6-14.8$ & 11.6 & 1.67 & 87 \\
Altura do corpo origem nadadeira adiposa & $6.3-8.9$ & 7.7 & 0.59 & 87 \\
Altura do corpo origem nadadeira pélvica & $7.5-14.3$ & 11.2 & 1.57 & 87 \\
Altura do corpo origem nadadeira anal & $6.8-10.2$ & 8.8 & 0.85 & 87 \\
Altura do corpo no pedúnculo caudal & $4.4-5.9$ & 5.1 & 0.30 & 87 \\
Largura do corpo origem nadadeira dorsal & $7.8-15.4$ & 12.6 & 1.56 & 87 \\
Comprimento nadadeira peitoral & $10.5-13.8$ & 12.0 & 0.62 & 87 \\
\hline \hline
\end{tabular}




\begin{tabular}{lcccc}
\hline \hline Comprimento nadadeira pélvica & $18.4-23.1$ & 20.4 & 1.12 & 87 \\
Comprimento nadadeira caudal & $15.4-20.8$ & 18.1 & 1.16 & 78 \\
Distância ponta do focinho-ponta da maxila & $12.8-17.0$ & 14.9 & 0.71 & 87 \\
Comprimento focinho & $5.7-8.4$ & 7.3 & 0.55 & 87 \\
Comprimento pedúnculo caudal & $7.3-14.6$ & 11.4 & 1.12 & 87 \\
Diâmetro da órbita & $2.8-5.4$ & 3.9 & 0.62 & 87 \\
Porcentagem em relação ao CC (Figura 2) & & & & \\
Distância ponta do focinho-ponta da maxila & $61.8-78.2$ & 68.3 & 2.61 & 87 \\
Comprimento focinho & $28.8-38.8$ & 33.4 & 2.00 & 87 \\
Distância narina anterior-margem anterior da órbita & $7.7-12.5$ & 9.5 & 1.03 & 87 \\
Distância narina posterior-margem anterior da órbita & $4.2-8.9$ & 5.9 & 1.05 & 87 \\
Comprimento membrana narina anterior & $2.0-6.4$ & 4.1 & 1.08 & 86 \\
Largura tampa adiposa em volta da órbita & $1.3-5.8$ & 3.0 & 0.80 & 87 \\
Diâmetro da órbita & $13.0-24.8$ & 18.1 & 2.40 & 87 \\
\hline \hline
\end{tabular}

Coloração em vida. Padrão de coloração semelhante à $S$. bondi. Corpo esverdeado, com o ventre mais claro e manchas em formato de cruz ao longo do corpo em exemplares menores que $100 \mathrm{~mm}$, que desaparecem ou passam a ter formato indistinto conforme o crescimento (FRABLE et al., 2013). Nadadeira dorsal marrom, peitoral com mancha escura na parte dorsal. Oito ou mais manchas em formato de diamante ao longo do corpo e manchas escuras ao longo da base da nadadeira anal (Robins et al. 1986).

Coloração em álcool. Alaranjada ou marrom avermelhada, ventre amarelo pálido. Exemplares menores que 100 mm mais claros. Nadadeiras sem coloração, com exceção da nadadeira caudal que ainda pode manter pigmentação mais escura nas bordas. Nadadeira adiposa pigmentada. Alguns exemplares ainda apresentam manchas ao longo do corpo, enquanto outros já possuem o padrão de cor uniforme.

\section{Distribuição}

Apesar de Frable et al. (2013) terem limitado a distribuição de Synodus foetens ao Atlântico Norte, esta espécie é amplamente distribuída ao longo da costa leste de todo o continente americano, ocorrendo desde Massachusetts nos Estados Unidos, até o Sul do Brasil, incluindo América Central (ANDERSON et al., 1966; RIBEIRO et al., 2019) (Figura 11).

Comentários. Synodus foetens pode chegar a $45 \mathrm{~cm}$ de comprimento total (RUSSELL, 2002). A espécie ocorre em baías rasas e águas costeiras e pode ser encontrada até os $200 \mathrm{~m}$ de profundidade. Os juvenis têm hábitos pelágicos e são facilmente coletados no oceano aberto, 
geralmente perto da costa e em águas rasas. (JONES et al., 1978; ROBINS et al., 1986; RUSSELL, 2002; SAMPAIO \& NOTTINGHAM, 2008). Em Meek (1884), a espécie já era documentada na Bahia e no Rio de Janeiro. Synodus foetens foi descrita da Carolina do Sul (EUA) e de acordo com Frable et al. (2013), não existiam materiais tipos nem mesmo em coleções de espécies descritas por Linnaeus. Desta forma, um espécime coletado na Carolina do Sul em 2011 foi designado como neótipo por Frable et al. (2013).

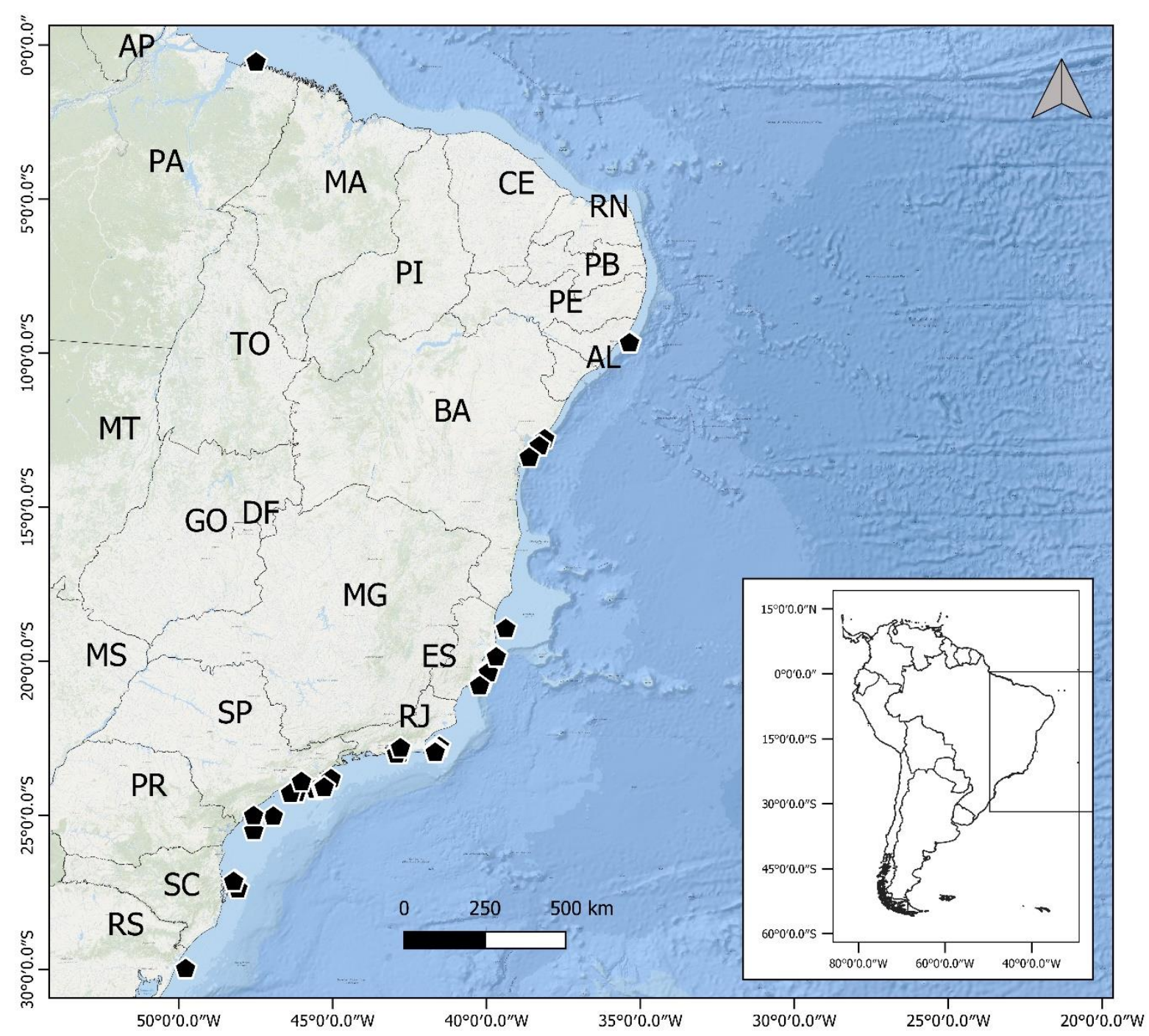

Figura 11. Área de distribuição dos lotes de S. foetens provenientes de coleções brasileiras. 


\section{Synodus intermedius (Agassiz, 1829)}

Peixe-lagarto; tira-vira, mergulhador-de-areia-comum [português]; Sand Diver [inglês]. (Figs. 12, 13, 14, 15, 25 C, 33 D, 37 A-B, 38 A-B; Tabelas 6, 10, 11).

Saurus intermedius Agassiz in Spix \& Agassiz, 1829: 81, pl. 44 [descrição original, Selecta genera et species piscium quos in itinere per Brasiliam, localidade tipo: nordeste do Brasil, 216 $\mathrm{mm} \mathrm{CT}]$.

Saurus anolis Valenciennes in Cuvier \& Valenciennes, 1850: 483 [Histoire naturelle des poissons v. 22, localidade tipo: Martinique, Guadalupe, e Bahia, Brasil; 2 síntipos - MNHN A.8611, 390 mm CT; MNHN B.1022, 400 mm CT]; Bertin \& Estève, 1950:6-7 [catálogo dos exemplares tipo do Muséum National d'Histoire Naturelle, sinonimizada a Synodus intermedius].

Synodus cubanus Poey, 1876: 185 [143] [Anales de la Sociedad Española de Historia Natural, Madrid v. 5, localidade tipo: Cuba]

Synodus intermedius Uyeno \& Aizawa in Uyeno et al., 1983:163 [Peixes coletados com rede de arrastado no Suriname e Guiana Francesa]; Robins \& Ray, 1986:80 [guia de campo para peixes da costa Atlântica da América do Norte]; Cervigón, 1991:146 [catálogo de peixes marinhos da Venezuela]; Boschung, 1992:70 [catálogo de peixes do Alabama]; Cervigón, 1992:446 [guia de identificação de espécies pesqueiras]; Andreata \& Séret, 1996:583 [catálogo de peixes coletados nos limites da plataforma continental e nas montanhas submarinas de Vitória, Trindade e Martin Vaz]; Spix, McEachran \& Fechhelm, 1998:611 [catálogo de peixes do Golfo do México]; Smith-Vaniz et al., 1999:149 [catálogo, zoogeografia e chaves de identificação dos peixes de Bermuda]; Afonso et al., 1999:83 [catálogo de peixes costeiros da Ilha de São Tomé, Açores]; Schmitter-Soto et al., 2000:151 [catálogo de peixes marinhos do caribe mexicano]; Rocha \& Rosa, 2001:989 [catálogo de peixes do parque marinho Parcel Manuel Luiz Marine, Maranhão]; Figueiredo \& Menezes in Menezes et al., 2003:50 [catálogo de peixes marinhos do Brasil]; Russell in Carpenter, 2003:928 [guia de identificação de peixes ósseos do Atlântico leste central]; Smith et al., 2003:11 [catálogo de peixes de Pelican Cays, Belize]; Nelson et al., 2004:88 [peixes do Canadá, Estados Unidos e México]; Wirtz et al., 2007:25 [catálogo de peixes das Ilhas de São Tomé e Príncipe]; Carvalho-Filho et al., 2010:33 [chave de identificação de espécies de Aulopoidei do Atlântico ocidental]; Frable et al., 2013:131, figs 1, 2 B, 3 C-D, 4; tab. 1-3 [revisão taxonômica e designação de neótipo USNM 398292, 285 mm CP, nordeste do Brasil, 001'48.00" S, 444947.99" O]; Page et al., 2013:88 
[catálogo de peixes do Canadá, Estados Unidos e México]; Smith-Vaniz \& Jelks, 2014:27 [catálogo de peixes das Ilhas Virgínia]; Pinheiro et al., 2015:8 [catálogo de peixes da cadeia montanhosa de Vitória-Trindade].

Neótipo. USNM 398292, 285 mm CP, Nordeste do Brasil, 001'48.00" S, 444947.99" O (Figura 12).

Material analisado: Apêndice A.
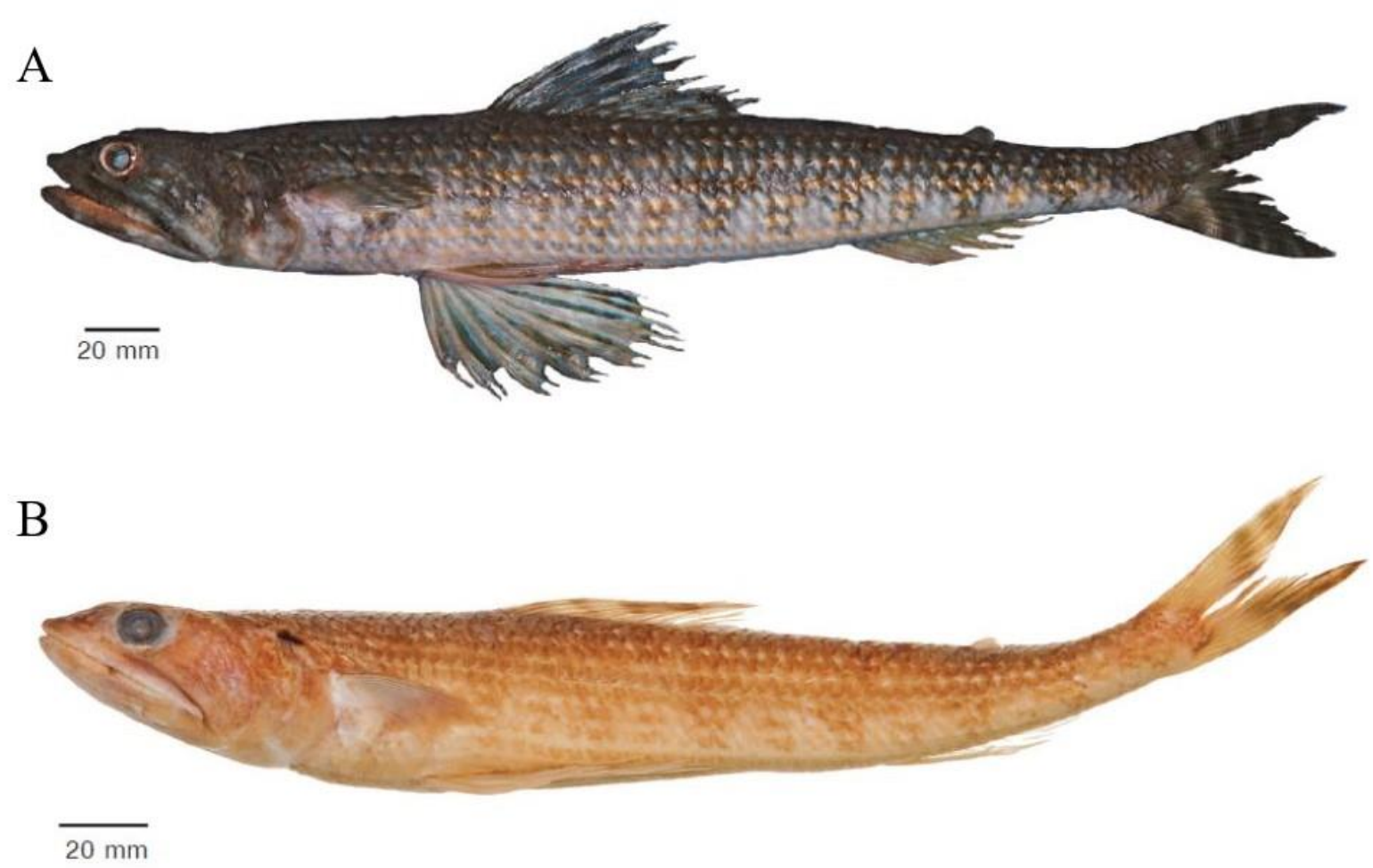

Figura 12. Neótipo de Synodus intermedius. USNM 398292, 285 mm CP. A. Em vida. B. Em álcool. Retirado de Frable et al. (2013).

\section{Diagnose}

Synodus intermedius pode ser diferenciada dos demais congêneres pela presença de: 49-52 escamas na linha lateral (vs. 45-48 em S. macrostigmus; 54-65 em S. bondi, S. foetens e $S$. synodus); 15-18 escamas pré-dorsais (vs. 20-30 em S. foetens e S. bondi); 3,5 escamas da linha lateral à base da nadadeira dorsal (vs. 4,5 em S. foetens, S. bondi e $S$. synodus); 11-13 raios na nadadeira anal (vs. 8-10 em S. synodus e 10-11 em S. bondi); raios anteriores da nadadeira dorsal curtos, não ultrapassando os posteriores quando deprimida ( $v s$. raios longos, ultrapassando os posteriores quando deprimida em S. foetens, S. bondi, S. poeyi e Synodus sp. 
$\mathrm{N}$ ); extremidade distal da nadadeira peitoral ultrapassando a origem da nadadeira pélvica ( $v$. não ultrapassando em $S$. foetens e $S$. bondi); comprimento do focinho maior que o diâmetro do olho (vs. menor ou igual em Synodus sp. N); membrana da narina anterior curta e triangular, não ultrapassando a extremidade posterior da narina posterior ( $v s$. longa, ultrapassando a extremidade posterior da narina posterior em S. macrostigmus), mancha escapular pequena 5.1$11.6 \%$ CC (7.6\%) (vs. grande em S. macrostigmus 12.0-17.2\% CC (14.6\%)); 3-6 barras verticais na nadadeira caudal (vs. ausência em nas demais espécies).

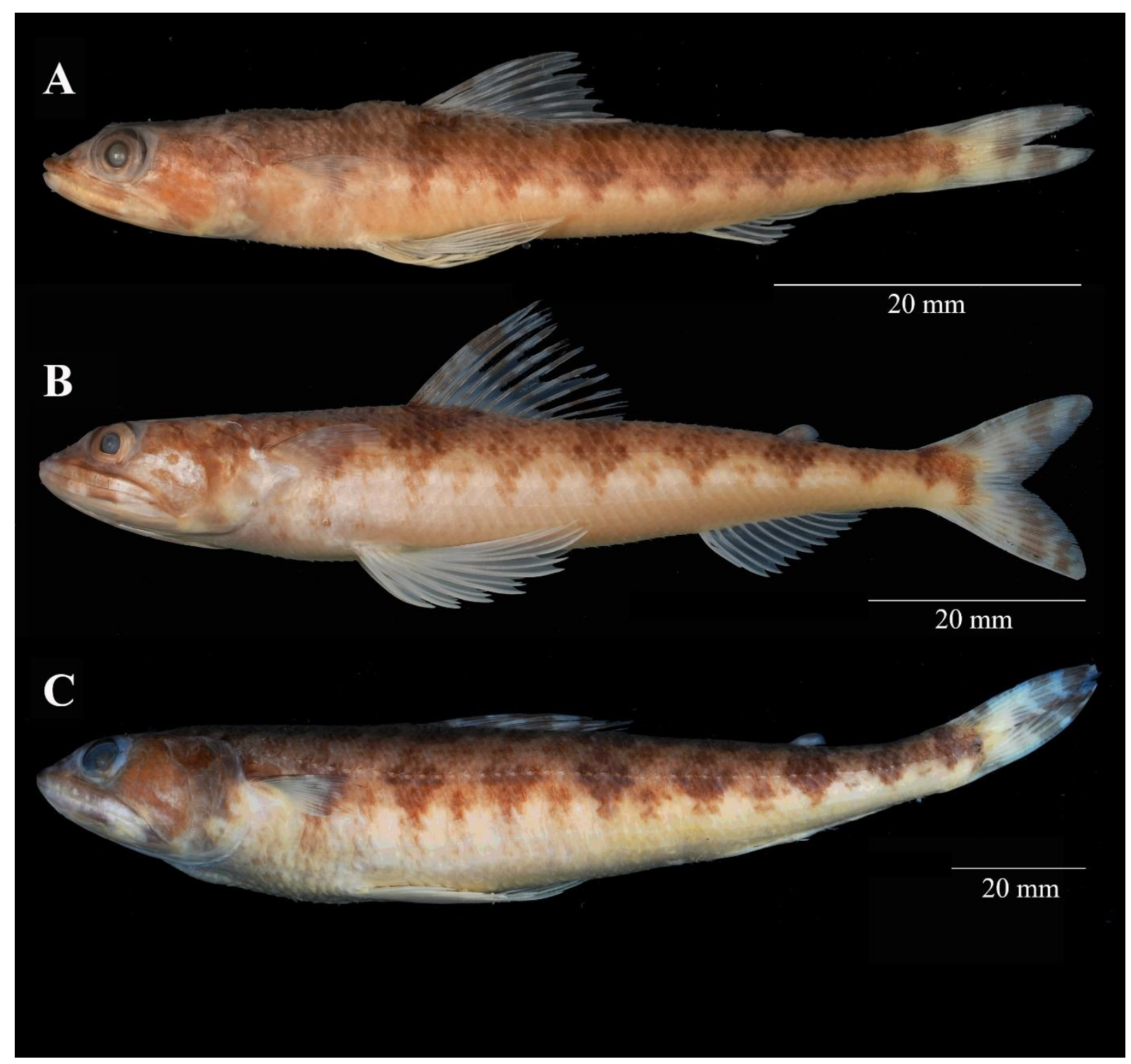

Figura 13. Synodus intermedius. A. MZUSP 52870, 68.5 mm CP; B. UFPB 4269, 94.2 mm CP; C. MZUSP 60547, $153.8 \mathrm{~mm} \mathrm{CP}$. 


\section{Descrição}

Dados morfométricos listados na Tabela 6. Corpo alongado e cilíndrico, afunilando no pedúnculo caudal. Boca terminal. Focinho ligeiramente arredondado em vista lateral, triangular arredondado em vista dorsal. Ponta do focinho se entendendo além da sínfise do dentário. Margem distal dos ossos maxilares se entendendo além da margem posterior da órbita. Duas fileiras de dentes na pré-maxila; maxila edêntula. Três fileiras de dentes no dentário, maiores medialmente; dentes posteriores direcionados anteriormente. Todos os dentes cônicos, com uma cúspide. Narinas de mesmo tamanho; narina anterior com membrana triangular curta; narina posterior sem membrana.

Nadadeiras peitorais arredondadas, se estendendo além da pélvica, posicionadas lateralmente no corpo, na altura da órbita. Nadadeiras pélvicas ventrais em posição anterior à vertical que passa sobre a origem da nadadeira dorsal. Nadadeira adiposa presente. Nadadeira caudal furcada; lobo superior ligeiramente menor ou igual ao lobo inferior.

Raios da nadadeira dorsal ii,10 (29) e ii,11 (4); raios da nadadeira anal ii,10 (28), ii,9 (3) e ii,11 (2); raios da nadadeira peitoral ii,10,i (30) e ii,9,i (3); raios da nadadeira pélvica i,6,i (33); raios da nadadeira caudal i,8,8,i (4), i,8,9,i (14) e i,9,9,i (15); vértebras 51 (1) e 57 (1); vértebras prédorsais 12 (1) e 15 (1) (Figura 14); raios branquiostégios 17 (1); raios procurrentes dorsais 12 (1); raios procurrentes ventrais 11 (1); escamas ctenóides; escamas da linha lateral 50 (1), 51 (5) e 52 (27); escamas pré-dorsais 15 (5), 16 (5), 17 (21) e 18 (2); fileiras de escamas acima da linha lateral até base da nadadeira dorsal 3,5 (33); fileiras de escamas abaixo da linha lateral até base da nadadeira anal 5,5 (33).

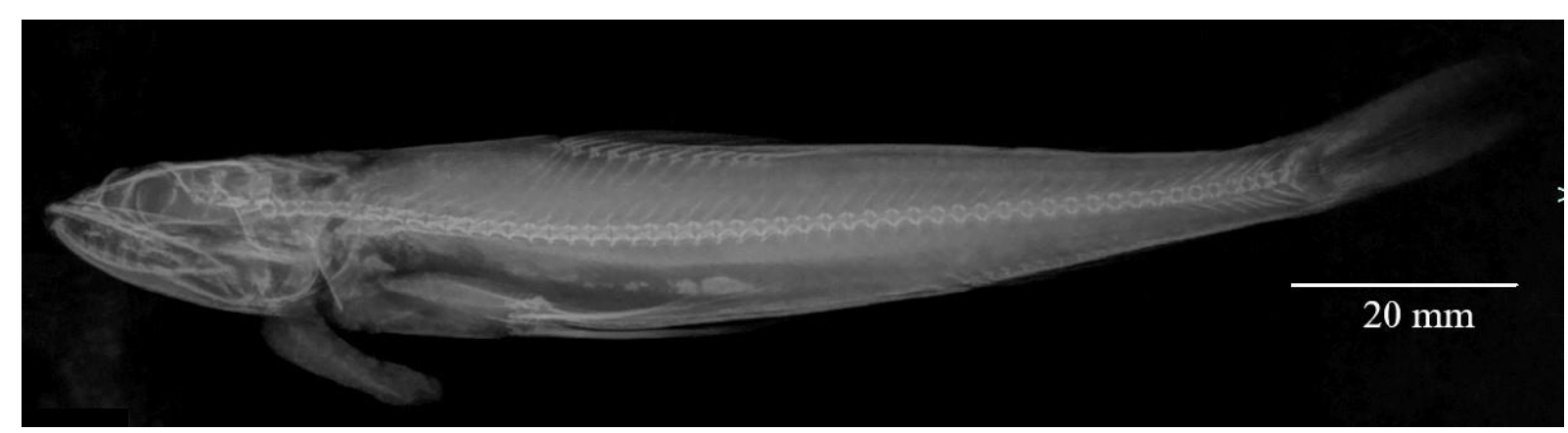

Figura 14. Radiografia de Synodus intermedius, MZUSP 52828, 127.6 mm CP. 
Tabela 6. Dados morfométricos obtidos em Synodus intermedius.

Medição

Porcentagem em relação ao CP (Figura 1)

Comprimento cabeça (CC)

Comprimento até nadadeira anal deprimida

Comprimento pré-adiposa

Comprimento pré-anal

Comprimento pré-dorsal

Comprimento pré-pélvica

Comprimento pré-peitoral

Comprimento base da nadadeira dorsal

Comprimento raio mais longo da nadadeira dorsal

Comprimento base da nadadeira anal

Comprimento raio mais longo da nadadeira anal

Comprimento base da nadadeira adiposa

Largura do corpo origem nadadeira peitoral

Altura do corpo origem nadadeira dorsal

Altura do corpo origem nadadeira adiposa

Altura do corpo origem nadadeira pélvica

Altura do corpo origem nadadeira anal

Altura do corpo no pedúnculo caudal

Largura do corpo origem nadadeira dorsal

Comprimento nadadeira peitoral

Comprimento nadadeira pélvica

Comprimento nadadeira caudal

Distância ponta do focinho-ponta da maxila

Comprimento focinho

Comprimento pedúnculo caudal

Diâmetro da órbita

\section{Porcentagem em relação ao CC (Figura 2)}

Distância ponta do focinho-ponta da maxila

Comprimento focinho

Distância narina anterior-margem anterior da órbita

Distância narina posterior-margem anterior da órbita

Comprimento membrana narina anterior

Largura tampa adiposa em volta da órbita

Diâmetro da órbita

Comprimento mancha escapular (se houver)

\section{$\begin{array}{cccc}\text { Range } & \text { Média } & \text { Desvio } & \\ (\%) & (\%) & \text { padrão } & N\end{array}$}

$\begin{array}{llll}22.3-26.8 & 24.0 & 1.06 & 33\end{array}$

$\begin{array}{llll}86.8-93.9 & 91.3 & 2.25 & 33\end{array}$

$\begin{array}{llll}76.5-82.8 & 80.5 & 1.47 & 33\end{array}$

$\begin{array}{llll}67.3-79.7 & 71.2 & 2.57 & 33\end{array}$

$37.8-41.8 \quad 40.4 \quad 1.13 \quad 33$

$\begin{array}{llll}31.8-39.2 & 35.3 & 1.98 & 33\end{array}$

$23.5-28.0 \quad 25.6 \quad 1.11 \quad 33$

$14.9-21.2 \quad 17.3 \quad 1.56 \quad 33$

$\begin{array}{llll}15.2-19.3 & 17.3 & 1.10 & 32\end{array}$

$13.5-16.0 \quad 14.6 \quad 2.75 \quad 33$

$\begin{array}{llll}8.1-12.3 & 9.5 & 1.56 & 33\end{array}$

$\begin{array}{llll}1.5-3.6 & 2.0 & 0.47 & 33\end{array}$

$\begin{array}{llll}10.5-17.0 & 14.4 & 1.53 & 33\end{array}$

$\begin{array}{llll}11.1-16.5 & 14.4 & 1.39 & 33\end{array}$

$\begin{array}{llll}7.2-9.6 & 8.6 & 0.55 & 33\end{array}$

$11.6-16.4 \quad 13.9 \quad 1.38 \quad 33$

$\begin{array}{llll}9.1-11.8 & 10.7 & 0.83 & 33\end{array}$

$\begin{array}{llll}5.3-6.3 & 5.8 & 0.30 & 33\end{array}$

$10.4-17.9 \quad 14.7 \quad 1.90 \quad 33$

$11.4-15.8 \quad 13.5 \quad 1.03 \quad 33$

$\begin{array}{llll}22.7-28.0 & 25.4 & 1.39 & 33\end{array}$

$18.7-24.4 \quad 21.2 \quad 1.41 \quad 29$

$13.9-17.4 \quad 15.6 \quad 1.16 \quad 33$

$\begin{array}{llll}6.2-8.0 & 7.1 & 0.85 & 33\end{array}$

$12.1-15.6 \quad 14.0 \quad 1.46 \quad 33$

$\begin{array}{llll}3.7-6.7 & 5.4 & 0.83 & 33\end{array}$

$60.5-71.2 \quad 64.9 \quad 3.66 \quad 33$

$\begin{array}{llll}27.3-33.7 & 29.7 & 2.28 & 33\end{array}$

$\begin{array}{llll}8.6-13.9 & 10.5 & 1.51 & 33\end{array}$

$\begin{array}{llll}5.2-10.4 & 7.3 & 1.58 & 33\end{array}$

$\begin{array}{llll}1.9-5.0 & 3.0 & 0.95 & 33\end{array}$

$\begin{array}{llll}1.8-5.1 & 3.7 & 0.93 & 33\end{array}$

$\begin{array}{llll}14.9-27.9 & 22.6 & 3.75 & 33\end{array}$

\begin{tabular}{llll}
$5.1-11.6$ & $7.6 \quad 1.87 \quad 33$ \\
\hline
\end{tabular} 
Coloração em vida. Corpo esverdeado a marrom, pálido ventralmente. 9-13 barras escuras ao longo do corpo em exemplares maiores que $200 \mathrm{~mm}$. Barras se assemelham a cruzes em exemplares jovens. Tronco com várias listras do dorso ao ventre, com hiato ao longo da linha lateral. Mancha escapular preta e pequena, coberta parcialmente pelo opérculo. Nadadeiras amarelas pálidas. Nadadeira caudal com 3-6 barras verticais (ROBINS et al, 1986; FRABLE et al, 2013).

Coloração em álcool. Corpo alaranjado, mais claro ventralmente. Manchas em forma de diamante ao longo do corpo, intercaladas com manchas menores na lateral do corpo, que desaparecem na linha lateral e na parte ventral. Barras verticais na nadadeira caudal. Nadadeiras dorsal e anal translúcidas, a dorsal ainda apresenta barras verticais marrons que atravessam diagonalmente os raios. Manchas escuras nos lábios e na cabeça. Nadadeira adiposa pigmentada. Mancha escapular pequena. Menores exemplares com o mesmo padrão de coloração.

\section{Distribuição}

Synodus intermedius é amplamente distribuída ao longo de toda a costa leste do continente americano, da Carolina do Norte nos Estados Unidos ao Sudeste do Brasil (ANDERSON et al., 1966; FRABLE et al., 2013) (Figura 15).

Comentário. Synodus intermedius pode chegar a $45 \mathrm{~cm}$ de comprimento total, e, ao contrário de $S$. foetens, não é muito comum em águas costeiras, podendo ser encontrado até $320 \mathrm{~m}$ de profundidade (ROBINS et al.,1986; RUSSELL, 2002). 


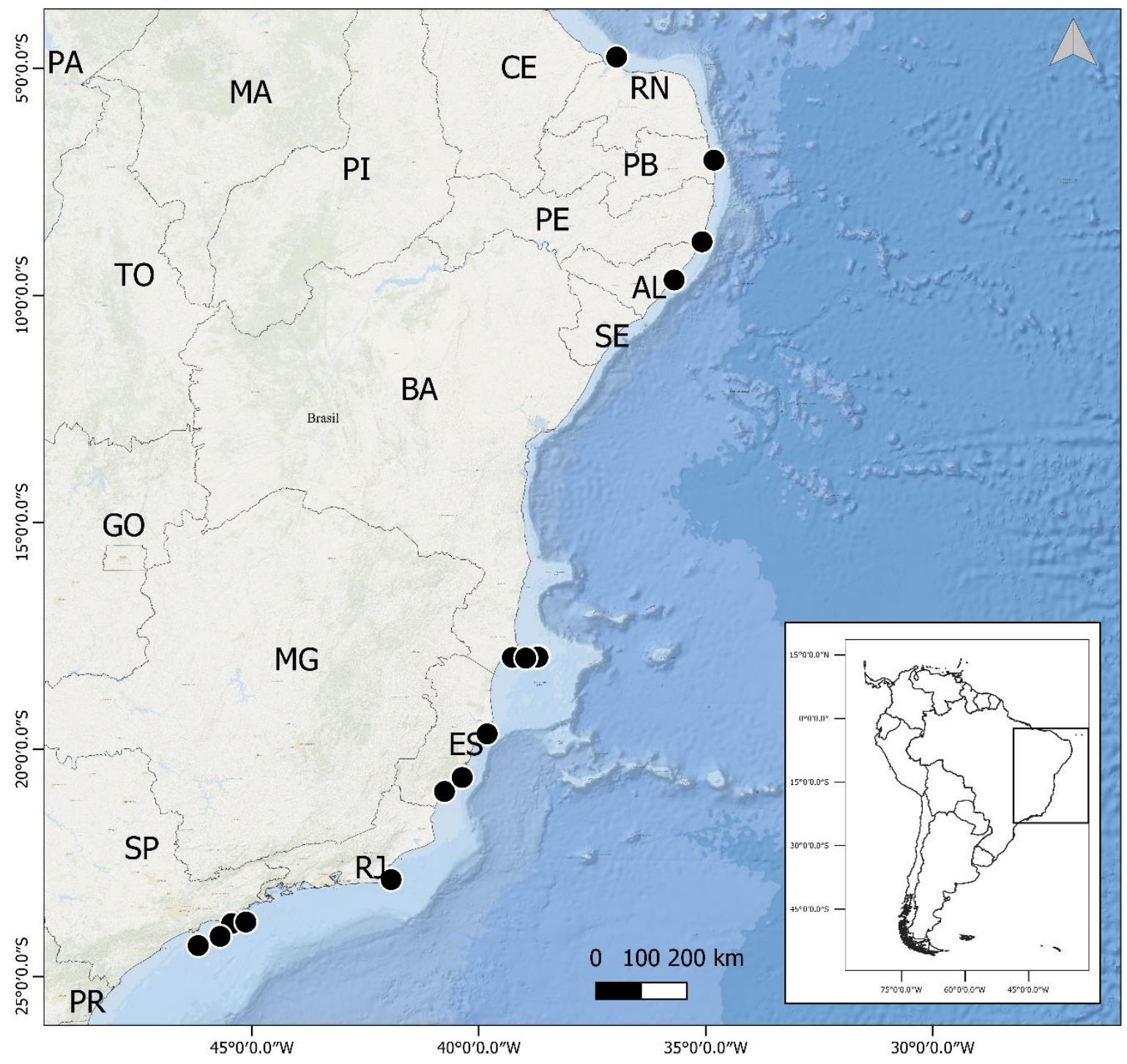

Figura 15. Área de distribuição dos lotes de S. intermedius provenientes de coleções brasileiras..

\section{Synodus macrostigmus Frable, Luther \& Baldwin, 2013}

Peixe-lagarto-de-ponto-grande; peixe-lagarto [português]; Largespot Lizardfish [inglês] (Frable et al., 2013).

(Figs. 16, 17, 18, 37 C-D, 38 C-D; Tabelas 7, 10, 11).

Synodus macrostigmus Frable, Luther \& Baldwin, 2013: 111(2), pl. 124, Figs. 2 A, 3 A-B, localidade tipo: Panama City, Florida, $29^{\circ} 16^{\prime} 59.95^{\prime} \mathrm{N}, 85^{\circ} 53^{\prime} 12.94^{\prime} \mathrm{O}$; holótipo: UF 182810, 189 mm CP, parátipos: UF 182811 (1), 182812 (5) e USNM 358546 (1).

Holótipo. UF 182810, 189.0 mm CP. Panama City, Florida, $29^{\circ} 16^{\prime} 59.95^{\prime} \mathrm{N}, 85^{\circ} 53^{\prime} 12.94^{\prime} \mathrm{O}$ (Figura 16). 
Parátipos. UF 182811 (1), 182812 (5) e USNM 358546 (1).

Material analisado: Apêndice A.

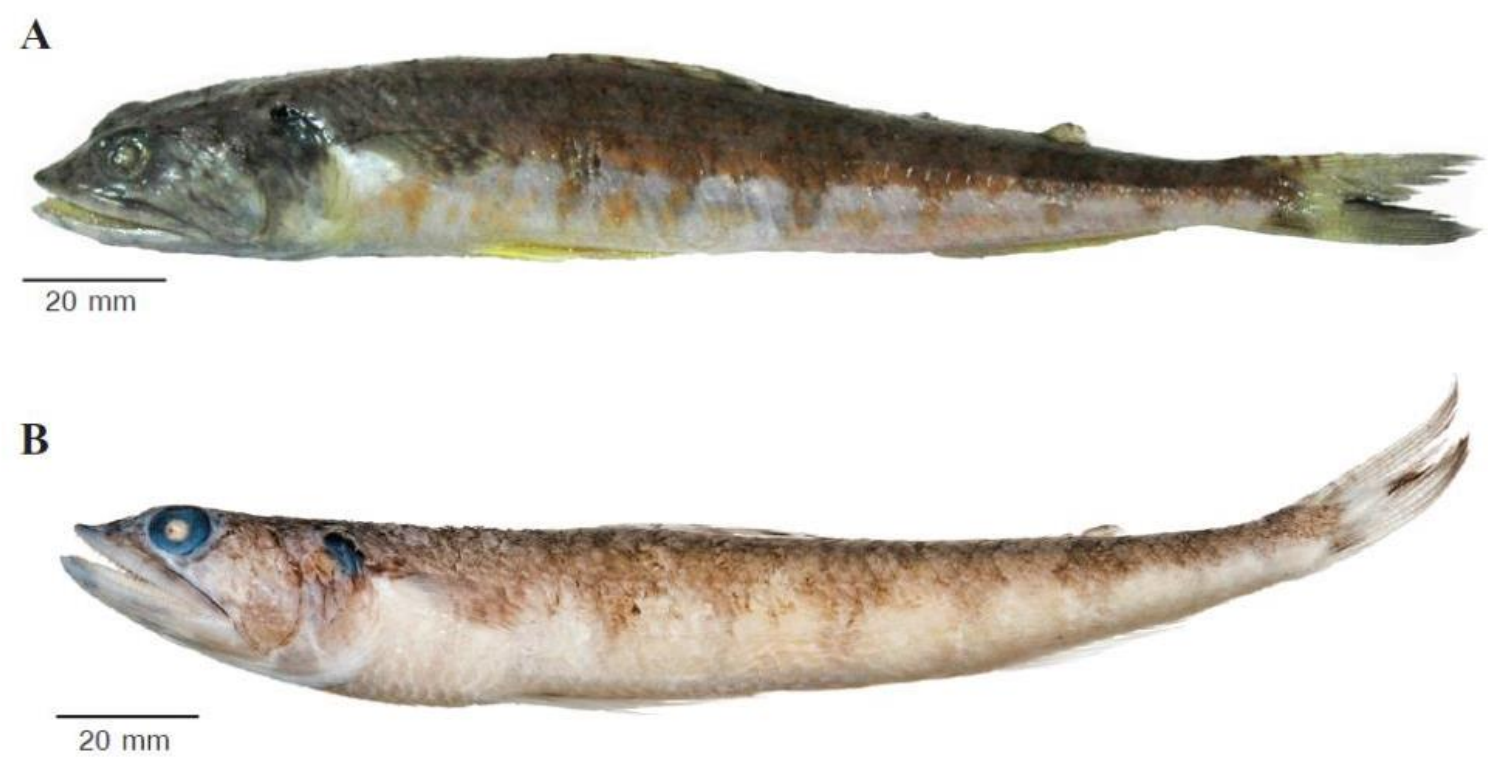

Figura 16. Neótipo de Synodus macrostigmus. USNM 182810, 189 mm CP. A. Em vida. B. Em álcool. Retirado de Frable et al. (2013).

\section{Diagnose}

Synodus macrostigmus pode ser diferenciado de seus congêneres pela presença das seguintes características: 45-48 escamas na linha lateral (vs. 49-52 em S. intermedius e 54-65 em $S$. bondi, S. foetens e S. synodus); 15-18 escamas pré-dorsais (vs. 20-30 em S. foetens e S. bondi); 3,5 escamas da linha lateral à base da dorsal (vs. 4,5 em S. foetens, S. bondi e S. synodus); 1112 raios na nadadeira anal (vs. 8-10 em S. synodus e 10-11 em S. bondi); raios anteriores da nadadeira dorsal curtos, não ultrapassando os posteriores quando deprimida ( $v s$. raios longos, ultrapassando os posteriores quando deprimida em S. foetens, S. bondi, S. poeyi e Synodus sp. $\mathrm{N}$ ); extremidade distal da nadadeira peitoral ultrapassando a origem da nadadeira pélvica ( $v s$. não ultrapassando em $S$. foetens e $S$. bondi); comprimento do focinho maior ou igual ao diâmetro do olho ( $v s$. menor ou igual em Synodus sp. N); membrana da narina anterior longa e triangular, ultrapassando a extremidade posterior da narina posterior ( $v s$. curta, não ultrapassando a extremidade posterior da narina posterior em S. intermedius); mancha escapular grande e oval 12.0-17.2\% CC (14.6\%) (vs. pequena em S. intermedius 5.1-11.6\% CC (7.6\%)); 
pigmento escuro no lobo inferior da nadadeira caudal ( $v$ s. ausência em $S$. intermedius, $S$. foetens, S. bondi, S. synodus, S. poeyi e Synodus sp. N).

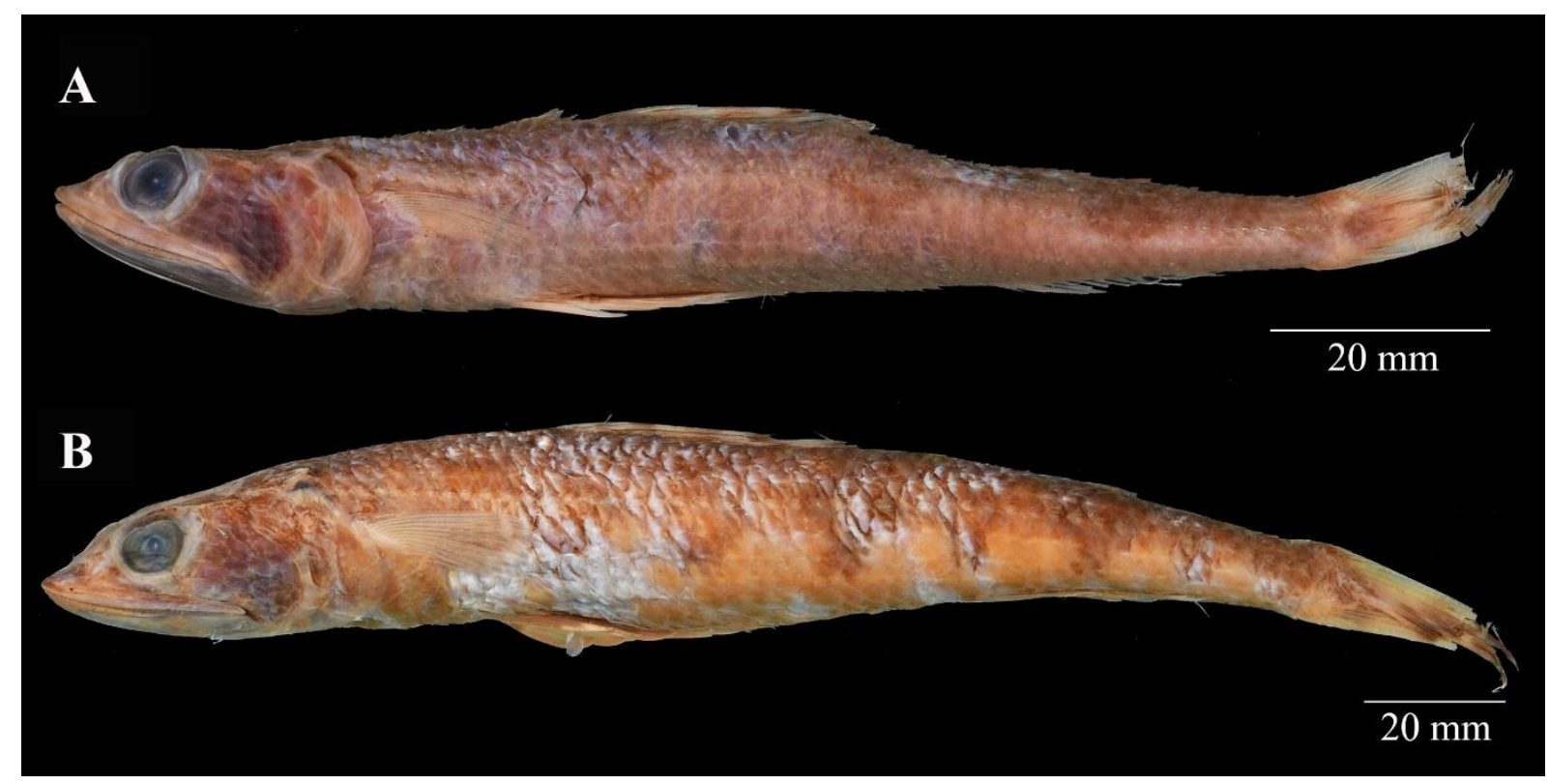

Figura 17. Synodus macrostigmus. A. MNRJ 18209, 131.4 mm CP; B. MNRJ 49610, 197.1 mm CP.

\section{Descrição}

Dados morfométricos listados na Tabela 7. Corpo alongado e cilíndrico, afunilando no pedúnculo caudal. Boca terminal. Focinho ligeiramente pontudo em vista lateral e dorsal. Ponta do focinho se entendendo além da sínfise do dentário. Margem distal dos ossos maxilares se entendendo além da margem posterior da órbita. Duas fileiras de dentes na pré-maxila; maxila edêntula. Três fileiras de dentes no dentário, maiores medialmente; dentes posteriores direcionados anteriormente. Todos os dentes cônicos, com uma cúspide. Narinas de mesmo tamanho; narina anterior com membrana triangular longa afunilada; narina posterior sem membrana.

Nadadeiras peitorais se estendendo além da pélvica, posicionadas lateralmente no corpo, na altura da órbita. Nadadeiras pélvicas ventrais em posição anterior à vertical que passa sobre a origem da nadadeira dorsal. Nadadeira adiposa presente. Nadadeira caudal furcada; lobo superior ligeiramente menor ou igual ao lobo inferior. 
Raios da nadadeira dorsal ii,10 (3); raios da nadadeira anal ii,9 (2) e ii,10 (1); raios da nadadeira peitoral ii,9,i (3); raios da nadadeira pélvica i,6,i (3); raios da nadadeira caudal i,8,9,i (3); escamas ctenóides; escamas da linha lateral 48 (3); escamas pré-dorsais 15 (1), 16 (1) e 18 (1); fileiras de escamas acima da linha lateral até base da nadadeira dorsal 3,5 (3); fileiras de escamas abaixo da linha lateral até base da nadadeira anal 4,5 (2) e 5,5 (1). Não foi possível realizar a contagem de vértebras já que nenhum exemplar foi radiografado ou diafanizado. A espécie possui 47-49 vértebras e 12-13 vértebras pré-dorsais (FRABLE et al., 2013).

Tabela 7. Dados morfométricos obtidos em Synodus macrostigmus.

Medição

Porcentagem em relação ao CP (Figura 1)

Comprimento cabeça (CC)

Comprimento até nadadeira anal deprimida

Comprimento pré-adiposa

Comprimento pré-anal

Comprimento pré-dorsal

Comprimento pré-pélvica

Comprimento pré-peitoral

Comprimento base da nadadeira dorsal

Comprimento raio mais longo da nadadeira dorsal

Comprimento base da nadadeira anal

Comprimento raio mais longo da nadadeira anal

Comprimento base da nadadeira adiposa

Largura do corpo origem nadadeira peitoral

Altura do corpo origem nadadeira dorsal

Altura do corpo origem nadadeira adiposa

Altura do corpo origem nadadeira pélvica

Altura do corpo origem nadadeira anal

Altura do corpo no pedúnculo caudal

Largura do corpo origem nadadeira dorsal

Comprimento nadadeira peitoral

Comprimento nadadeira pélvica

Comprimento nadadeira caudal

Distância ponta do focinho-ponta da maxila

Comprimento focinho

Comprimento pedúnculo caudal

Diâmetro da órbita

\begin{tabular}{cccc}
\hline Range & Média & Desvio \\
$(\%)$ & $(\%)$ & padrão & $N$
\end{tabular}

$24.9-26.0 \quad 25.2 \quad 0.63 \quad 3$

$91.0-91.9 \quad 91.5 \quad 0.46 \quad 3$

$80.7-81.8 \quad 81.4 \quad 0.61 \quad 3$

$\begin{array}{llll}72.2-75.0 & 73.2 & 1.55 & 3\end{array}$

$\begin{array}{llll}40.9-43.1 & 41.7 & 1.20 & 3\end{array}$

$\begin{array}{llll}34.6-36.0 & 35.4 & 0.73 \quad 3\end{array}$

$\begin{array}{llll}25.1-27.5 & 26.2 & 1.22 & 3\end{array}$

$\begin{array}{llll}14.7-19.5 & 17.0 & 2.42 & 3\end{array}$

$10.9-17.4 \quad 14.3 \quad 2.64 \quad 3$

$\begin{array}{llll}10.9-14.7 & 13.3 & 2.08 & 3\end{array}$

$\begin{array}{llll}6.9-10.0 & 8.6 & 1.60 & 3\end{array}$

$\begin{array}{llll}1.9-2.1 & 2.0 & 0.12 & 3\end{array}$

$14.0-15.3 \quad 14.4 \quad 0.72 \quad 3$

$11.6-14.4 \quad 13.3 \quad 1.50 \quad 3$

$\begin{array}{llll}7.1-9.5 & 8.2 & 1.22 & 3\end{array}$

$\begin{array}{llll}11.1-14.1 & 13.0 & 1.67 & 3\end{array}$

$\begin{array}{llll}8.7-11.2 & 10.3 & 1.38 & 3\end{array}$

$\begin{array}{llll}5.5-6.2 & 5.8 & 0.37 & 3\end{array}$

$\begin{array}{llll}13.4-14.2 & 13.9 & 1.28 & 3\end{array}$

$13.5-14.6 \quad 14.0 \quad 0.59 \quad 3$

$\begin{array}{llll}22.3-23.8 & 22.8 & 0.82 & 3\end{array}$

$* \quad * \quad * \quad 0$

$\begin{array}{llll}15.6-16.3 & 16.0 & 0.39 & 3\end{array}$

$\begin{array}{llll}6.4-6.8 & 6.5 & 0.24 & 3\end{array}$

$\begin{array}{llll}11.8-14.0 & 12.9 & 1.10 & 3\end{array}$

$\begin{array}{llll}5.4-6.6 & 6.1 & 0.62 \quad 3\end{array}$

\section{Porcentagem em relação ao CC (Figura 2)}




\begin{tabular}{lcccc}
\hline \hline Distância ponta do focinho-ponta da maxila & $62.4-65.7$ & 63.6 & 1.87 & 3 \\
Comprimento focinho & $24.6-27.5$ & 26.0 & 1.46 & 3 \\
Distância narina anterior-margem anterior da órbita & $8.2-10.8$ & 9.1 & 1.48 & 3 \\
Distância narina posterior-margem anterior da órbita & $5.3-6.2$ & 5.6 & 0.51 & 3 \\
Comprimento membrana narina anterior & $3.7-7.9$ & 5.4 & 2.19 & 3 \\
Largura tampa adiposa em volta da órbita & $2.8-4.1$ & 3.6 & 0.75 & 3 \\
Diâmetro da órbita & $21.8-25.6$ & 24.1 & 2.01 & 3 \\
Comprimento mancha escapular & $12.0-17.2$ & 14.6 & 3.62 & 3 \\
\hline \hline
\end{tabular}

*não mensurado (danificada em todos os exemplares).

Coloração em vida. Corpo marrom esverdeado com o ventre pálido. 6-9 manchas escuras ao longo do corpo. Região escapular com uma grande mancha preta coberta parcialmente pelo opérculo. Nadadeira peitoral com barras marrons irregulares. Nadadeiras pélvicas amarelas. Nadadeira caudal sem barras verticais, mas com uma mancha escura na porção interna do lobo ventral. 2-3 minúsculas barras nos raios procurrentes dorsais (FRABLE et al., 2013).

Coloração em álcool. Coloração amarronzada, mais claro ventralmente. Barras verticais ao longo do corpo, mas mais pálidas e não tão evidentes como em S. intermedius. Pigmento escuro na região escapular se mantém, assim como a mancha escura na porção interna do lobo ventral. Mancha escapular com formato oval e maior que a mancha de S. intermedius. Nadadeira adiposa pigmentada.

\section{Distribuição}

Synodus macrostigmus está sendo registrada pela primeira vez no Atlântico Sul ocidental e era conhecida desde a Carolina do Sul, nos Estados Unidos, até o Golfo do México (Frable et al., 2013). O exemplar mais antigo está depositado no Museu Nacional do Rio de Janeiro e foi coletado em 1968 na foz do Rio Amazonas, no Amapá; além deste, há um outro registro em Atafona, litoral norte do Rio de Janeiro. Sendo assim é plausível que a espécie tam. bém ocorra nos estados do Norte e Nordeste do Brasil compreendidos entre esses registros. Desta forma, a distribuição da espécie passa a ser ampliada até o Rio de Janeiro (Figura 18). Novas coletas ou a revisão de espécimes depositados em um maior número de coleções do nordeste brasileiro talvez aumentem a área de ocorrência da espécie.

Comentário. Synodus macrostigmus pode chegar a $25 \mathrm{~cm}$ de comprimento quando adulto e habitar profundidades de até $194 \mathrm{~m}$, mas é mais comumente encontrada abaixo dos $30 \mathrm{~m}$ (FRABLE et al., 2013). 


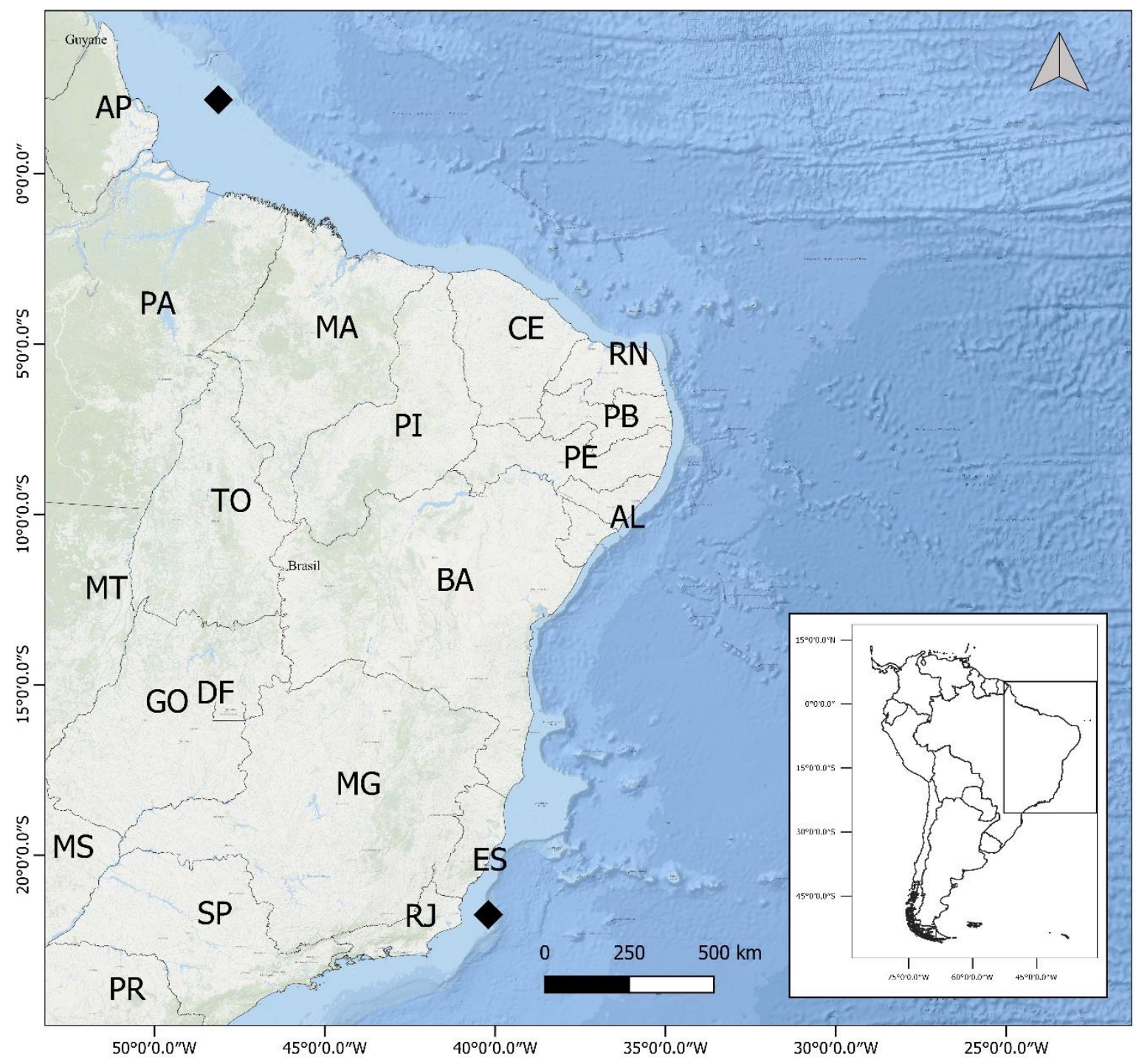

Figura 18. Área de distribuição dos lotes de S. macrostigmus provenientes de coleções brasileiras.

\section{Synodus synodus Linnaeus, 1758}

Peixe-lagarto, peixe-lagarto-vermelho [português]; Atlantic Lizardfish, Bluestripe Lizardfish, Diamond Lizardfish [inglês].

(Figs. 19, 20, 21, 25 D, 30, 33 B, 34 B, 39, 40, 41 B; Tabelas 8, 10, 11).

Esox synodus Linnaeus, 1758:313 [descrição original, Systema Naturae, Ed. X v. 1, localidade tipo: América, sem tipos conhecidos.

Synodus gronovii Walbaum, 1792:655 [baseado em Gronovius, Mus. Ichthyol, n. 155, sem localização]. 
Synodus fasciatus Lacepède, 1803: 318, 321. v. 5 [Histoire naturelle des poissons (Lacepède), localidade tipo: América do Norte]; Nielsen, 1973:161 in Hureau \& Monod, 1973 [catálogo de peixes do Atlântico norte oriental e Mediterrâneo, sinonimizada a Synodus synodus].

Saurus meleagrides Valenciennes 1834:Pl. 11, fig 3 [Voyage dans l'Amérique méridionale, localidade tipo: Buenos Aires, Argentina, síntipos incorretos: MNHN 0000-3416 (3, estado de conservação ruim), nome disponível]; Bertin \& Estève, 1950:7 [catálogo de exemplares tipo do Muséum National d'Histoire Naturelle]; Sulak in Whitehead et al., 1984:411 [catálogo de peixes do Atlântico norte oriental e Mediterrâneo, sinonimizada a Synodus synodus]; Sulak in Quéro et al. 1990:369 [catálogo de peixes do Atlântico oriental tropical].

Saurus atlanticus Johnson, 1863: 41 [descrição de cinco espécies de Madeira, localidade tipo: Madeira, Portugal, holótipo: BMNH 1862.2.5.1]; Nielsen, 1973:161 in Hureau \& Monod, 1973 [catálogo de peixes do Atlântico norte oriental e Mediterrâneo, sinonimizada a Synodus synodus]; Sulak in Whitehead et al., 1984:411 [catálogo de peixes do Atlântico norte oriental e Mediterrâneo]; Edwards \& Glass, 1987:629 [catálogo de peixes da Ilha de Santa Helena, Atlântico Sul]; Sulak in Quéro et al. 1990:369 [catálogo de peixes do Atlântico oriental tropical]; Wirtz et al., 2014:4 [catálogo de peices de Ascension Island, atlântico central];

Synodus nicholsi Breder, 1927:13 [resultados de uma expedição oceanográfica em "Pawnee", localidade tipo: Royal Island, Eleuthera, Bahamas, holótipo: YPM 56]; Sulak in Whitehead et al., 1984:411 [catálogo de peixes do Atlântico norte oriental e Mediterrâneo, sinonimizada a Synodus synodus]; Sulak in Quéro et al. 1990:369 [catálogo de peixes do Atlântico oriental tropical]; catalogada em Moore \& Boardman, 1991:26 [lista de exemplares tipo de Yale Peabody Museum].

Synodus synodus Nielsen, 1973:161 in Hureau \& Monod, 1973 [catálogo de peixes do Atlântico norte oriental e Mediterrâneo, sinonimizada a Synodus synodus]; Sulak in Whitehead et al., 1984:411 [catálogo de peixes do Atlântico norte oriental e Mediterrâneo]; Robins \& Ray, 1986:80 [guia de campo para peixes da costa Atlântica da América do Norte]; Edwards \& Glass, 1987:629 [catálogo de peixes da Ilha de Santa Helena, Atlântico Sul]; Scott \& Scott, 1988:190 [peixes do Canadá, Atlântico]; McAllister, 1990:99 [lista de peixes do Canadá]; Sulak in Quéro et al. 1990:369 [catálogo de peixes do Atlântico oriental tropical]; Cervigón, 1991:148 [catálogo de peixes marinhos da Venezuela]; Boschung, 1992:70 [catálogo de peixes do Alabama]; Boschung, 1992:71 [catálogo de peixes do Alabama]; Cervigón, 1992:447 [guia 
de identificação de espécies pesqueiras]; Arruda, 1997:42 [catálogo de peixes marinhos de Açores]; McEachran \& Fechhelm, 1998:613 [catálogo de peixes do Golfo do México]; Aguilera, 1998:47 [catálogo de peixes marinhos do ocidente da Venezuela]; Smith-Vaniz et al., 1999:150 [catálogo, zoogeografia e chaves de identificação dos peixes de Bermuda]; Afonso, et al. 1999:70 [catálogo de peixes das Ilhas de São Tomé]; Schmitter-Soto, et al., 2000:151 [catálogo de peixes marinhos do caribe mexicano]; Gasparini \& Floeter, 2001:1643 [peixes da Ilha de Trindade, atlântico sul ocidental]; Collette et al., 2003:99 [catálogo de peixes das Ilhas Navassa, Índias orientais]; Figueiredo \& Menezes in Menezes et al., 2003:50 [catálogo de peixes marinhos do Brasil]; Russell in Carpenter, 2003:929 [guia de identificação de peixes ósseos do Atlântico leste central]; Smith et al., 2003:11 [catálogo de peixes de Pelican Cays, Belize]; Nelson et al., 2004:88 [peixes do Canadá, Estados Unidos e México]; Wirtz et al., 2007:26 [peixes da Ilha de São Tomé e Princípe]; Carvalho-Filho et al., 2010:33 [chave de identificação de espécies de Aulopoidei do Atlântico ocidental]; Frable et al., 2013:141, [chave taxonômica e revisão das espécies de Synodus do Atlântico Norte]; Page et al., 2013:89 [catálogo de peixes do Canadá, Estados Unidos e México]; Wirtz et al., 2013:119 [catálogo de peixes de Cape Verde Islands]; Smith-Vaniz \& Jelks, 2014:28 [catálogo de peixes das ilhas Virgínia]; Pinheiro et al., 2015:8 [catálogo de peixes da cadeia montanhosa de VitóriaTrindade]; Russell in Carpenter \& De Angelis, 2016:1828 [peixes marinhos do Atlântico central oriental]; Nión et al., 2016:37 [catálogo de peixes do Uruguai]; Spier et al., 2018:8 [catálogo e caracterização de peixes da plataforma continental do Paraná]; Brown et al., 2019:159 [catálogo de peixes da ilha de Santa Helena, atlântico central].

\section{Designação do Neótipo}

Synodus synodus foi descrita originalmente como Esox synodus, por Linnaeus (1758) baseado em Gronow (1763). A descrição é bastante simplificada, e não incluiu a designação de tipos. Como localidade tipo, Linnaeus (1758) listou apenas "habitat in America", sem especificar a localidade exata. Em trabalhos subsquententes (e.g., Nielsen, 1973; Frable et al., 2013), também foi feita a designação de nenhum neótipo. A espécie é frequentemente confundida com $S$. foetens, portanto, verificou-se a necessidade de designar um neótipo para fixar a localidade tipo e dar estabilidade ao nome. 
Neótipo (NOVA DESIGNAÇÃO). MZUSP 45590, 206.0 mm CP, Arquipélago de Alcatrazes, São Paulo, Brasil, Atlântico Sul ocidental, 2407'01” S, 4541'59” O [coordenadas inferidas], $10 \mathrm{~m}$ de profundidade, 31 de outubro de 1992, número de campo RLO92103101, Col. R.L. Moura (Figura 23 A).

Material examinado: Apêndice A.

\section{Diagnose}

Synodus synodus pode ser diferenciada de seus congêneres por possuir 55-60 escamas na linha lateral (vs. 45-48 em S. macrostigmus e 49-52 em S. poeyi e Synodus sp. N); 15-18 escamas pré-dorsais (vs. 20-30 em S. foetens e S. bondi); 4,5-5,5 escamas da linha lateral à base da dorsal (vs. 3,5 em S. macrostigmus e S. intermedius); 8-10 raios na nadadeira anal (vs. 10-11 em S. bondi, 12-13 em S. foetens, S. intermedius, S. macrostigmus, S. poeyi e Synodus sp. N); raios anteriores da nadadeira dorsal curtos, não ultrapassando os posteriores quando deprimida (vs. raios longos, ultrapassando os posteriores quando deprimida em S. foetens, S. bondi, $S$. poeyi e Synodus sp. N); base da nadadeira anal muito menor que a nadadeira dorsal (vs. pouco menor ou aproximadamente igual que a nadadeira dorsal nas outras espécies); extremidade distal da nadadeira peitoral ultrapassando a origem da nadadeira pélvica ( $v s$. não ultrapassando em $S$. foetens e $S$. bondi); comprimento do focinho maior que diâmetro do olho (vs. menor ou igual em Synodus sp. N); membrana da narina anterior longa e em formato de colher, ultrapassando a extremidade posterior da narina posterior ( $v s$. em formato triangular nas demais espécies); mancha preta na extremidade superior do focinho ( $v s$. ausência em todas as outras espécies). 


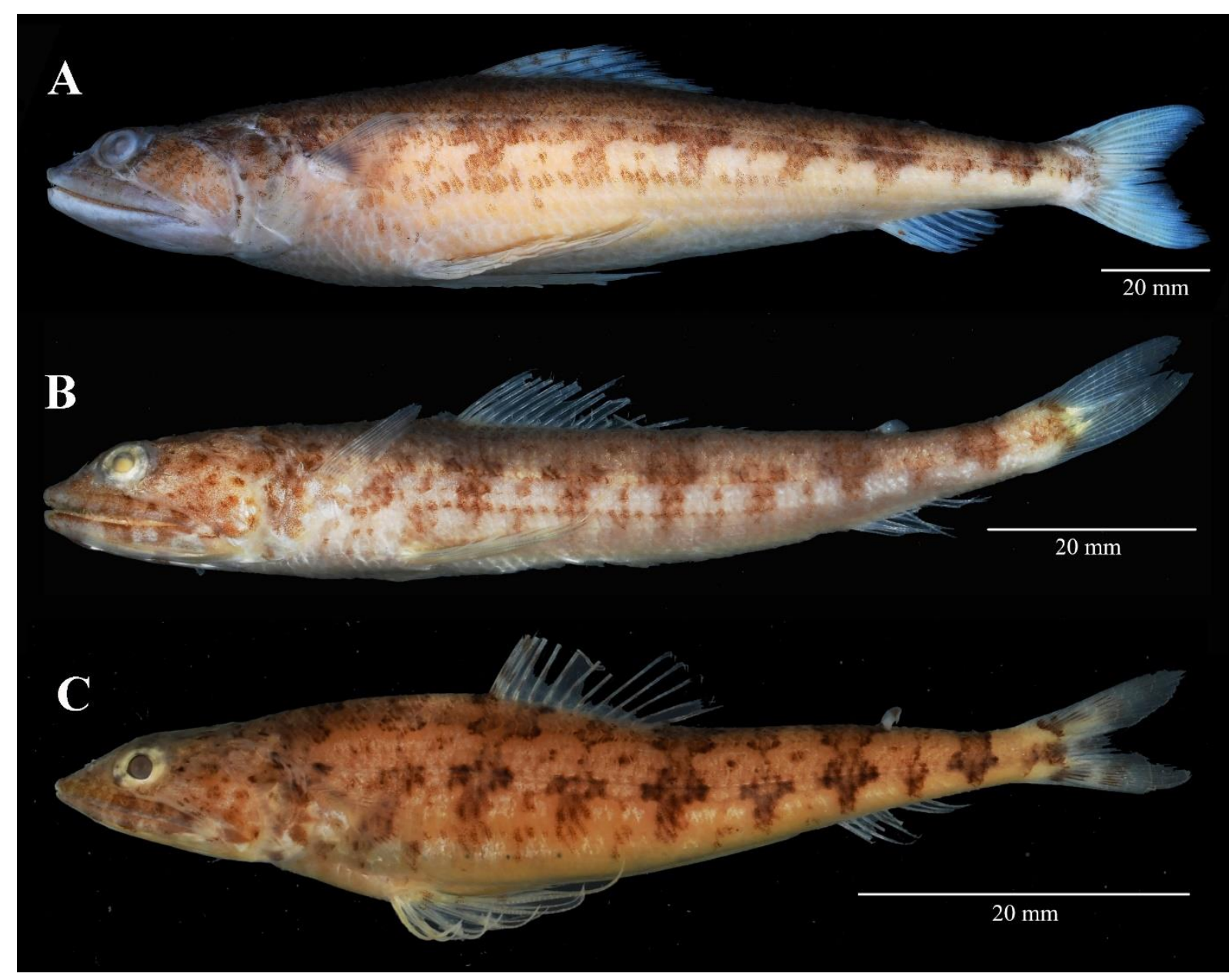

Figura 19. Synodus synodus. A. MS Néotipo MZUSP 45590, 206.0 mm CP; B. MZUSP 110433, 84.2 mm CP; C. MZUSP 75284, $59.9 \mathrm{~mm} \mathrm{CP.}$

\section{Descrição}

Dados morfométricos listados na Tabela 8. Corpo alongado e cilíndrico, afunilando no pedúnculo caudal. Boca terminal. Focinho ligeiramente arredondado em vista lateral e dorsal. Ponta do focinho se entendendo além da sínfise do dentário. Margem distal dos ossos maxilares se entendendo além da margem posterior da órbita. Duas fileiras de dentes na pré-maxila; maxila edêntula. Três fileiras de dentes no dentário, maiores medialmente; dentes posteriores direcionados anteriormente. Todos os dentes cônicos, com uma cúspide. Narinas de mesmo tamanho; narina anterior com membrana longa e em formato de colher; narina posterior sem membrana.

Nadadeiras peitorais se estendendo além da pélvica, posicionadas lateralmente no corpo, na altura da órbita. Nadadeiras pélvicas ventrais em posição anterior à vertical que passa sobre a 
origem da nadadeira dorsal. Nadadeira adiposa presente. Nadadeira caudal furcada; lobo superior ligeiramente maior ou igual ao lobo inferior.

Raios da nadadeira dorsal ii,10 (26), ii,11 (14) e ii,12 (4); raios da nadadeira anal ii,6 (2), ii,7 (16) e ii,8 (26); raios da nadadeira peitoral ii,9,i (34) e ii,10,i (10); raios da nadadeira pélvica i,6,i (44); raios da nadadeira caudal i,8,8,i (4), i,8,9,i (29), i,9,9,i (11); vértebras 56 (1) e 57 (2); vértebras pré-dorsais 12 (1) e 14 (2) (Figura 24); raios branquiostégios 15 (1); raios procurrentes dorsais 18 (1); raios procurrentes ventrais 16 (1); escamas ctenóides; escamas da linha lateral 55 (1), 56 (5), 57 (1), 58 (14), 59 (14), 60 (6), 61 (1) e 62 (2); escamas pré-dorsais 15 (6), 16 (14), 17 (9) e 18 (15); fileiras de escamas acima da linha lateral até base da nadadeira dorsal 4,5 (43) e 5,5 (1); fileiras de escamas abaixo da linha lateral até base da nadadeira anal 5,5 (42) e $6,5(2)$.

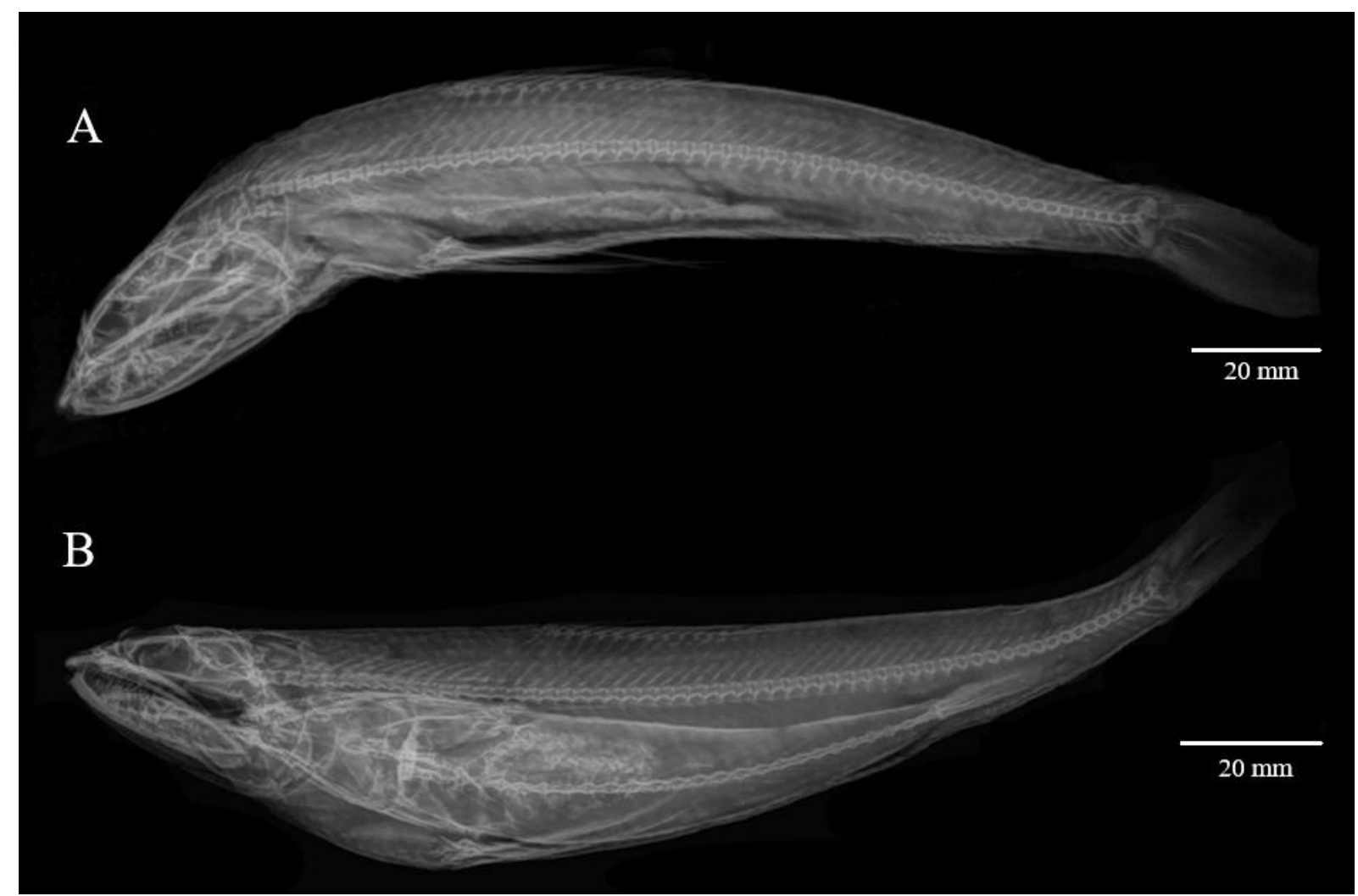

Figura 20. Radiografias de Synodus synodus. A. MZUSP 69282, 190.4 mm CP; B. Synodus synodus, MZUSP 43483, $168.7 \mathrm{~mm} \mathrm{CP}$. 
Tabela 8. Dados morfométricos obtidos em Synodus synodus.

Medição

Porcentagem em relação ao CP (Figura 1)

Comprimento cabeça (CC)

Comprimento até nadadeira anal deprimida

Comprimento pré-adiposa

Comprimento pré-anal

Comprimento pré-dorsal

Comprimento pré-pélvica

Comprimento pré-peitoral

Comprimento base da nadadeira dorsal

Comprimento raio mais longo da nadadeira dorsal

Comprimento base da nadadeira anal

Comprimento raio mais longo da nadadeira anal

Comprimento base da nadadeira adiposa

Largura do corpo origem nadadeira peitoral

Altura do corpo origem nadadeira dorsal

Altura do corpo origem nadadeira adiposa

Altura do corpo origem nadadeira pélvica

Altura do corpo origem nadadeira anal

Altura do corpo no pedúnculo caudal

Largura do corpo origem nadadeira dorsal

Comprimento nadadeira peitoral

Comprimento nadadeira pélvica

Comprimento nadadeira caudal

Distância ponta do focinho-ponta da maxila

Comprimento focinho

Comprimento pedúnculo caudal

Diâmetro da órbita

\section{Porcentagem em relação ao CC (Figura 2)}

Distância ponta do focinho-ponta da maxila

Comprimento focinho

Distância narina anterior-margem anterior da órbita

Distância narina posterior-margem anterior da órbita

Comprimento membrana narina anterior

Largura tampa adiposa em volta da órbita

Diâmetro da órbita

$\begin{array}{cccc}\text { Range } & \text { Média } & \text { Desvio } \\ (\%) & (\%) & \text { padrão } & N\end{array}$

$\begin{array}{cccc}20.4-27.9 & 25.1 & 1.59 & 39 \\ 85.8-96.0 & 92.7 & 2.07 & 39 \\ 80.0-85.0 & 82.4 & 1.12 & 39 \\ 76.0-81.1 & 78.8 & 1.34 & 39 \\ 39.0-45.3 & 41.9 & 1.43 & 39 \\ 30.4-38.9 & 34.9 & 1.73 & 39 \\ 21.3-29.9 & 26.7 & 1.64 & 39 \\ 13.2-22.0 & 17.1 & 1.51 & 39 \\ 11.5-16.8 & 14.5 & 1.24 & 37 \\ 7.7-12.1 & 9.7 & 0.94 & 39 \\ 5.0-11.9 & 8.1 & 1.10 & 38 \\ 1.1-4.2 & 2.0 & 0.62 & 39 \\ 12.1-19.2 & 15.3 & 1.92 & 39 \\ 10.2-19.5 & 15.4 & 2.28 & 39 \\ 7.3-10.0 & 8.8 & 0.61 & 39 \\ 9.9-19.6 & 14.9 & 2.25 & 39 \\ 7.9-11.2 & 9.9 & 0.76 & 39 \\ 5.0-6.3 & 5.7 & 0.29 & 39 \\ 10.3-18.7 & 15.1 & 1.98 & 39 \\ 11.0-15.1 & 13.2 & 1.05 & 39 \\ 22.2-29.3 & 25.7 & 1.57 & 39 \\ 15.2-22.0 & 18.3 & 1.66 & 38 \\ 11.9-20.4 & 18.0 & 1.62 & 39 \\ 5.7-7.9 & 7.0 & 0.46 & 39 \\ 6.7-13.7 & 11.4 & 1.50 & 39 \\ 4.0-7.1 & 5.4 & 0.86 & 39\end{array}$

\begin{tabular}{cccc}
$63.8-83.2$ & 72.1 & 4.70 & 39 \\
$23.2-32.8$ & 28.0 & 1.91 & 39 \\
$7.5-14.2$ & 10.3 & 1.47 & 39 \\
$5.2-9.8$ & 6.8 & 1.02 & 39 \\
$3.3-10.8$ & 6.6 & 2.00 & 38 \\
$1.0-5.7$ & 3.3 & 1.02 & 39 \\
$14.8-29.1$ & 21.6 & 3.99 & 39 \\
\hline
\end{tabular}


Coloração em vida. Barras verticais avermelhadas ao longo do corpo e nadadeiras dorsal e caudal, além de uma mancha escura na parte superior do focinho (ANDERSON et al., 1966; ROBINS et al., 1986).

Coloração em álcool. Corpo alaranjado com o ventre mais claro. Várias manchas grandes e escuras ao longo do corpo, intercaladas com manchas e pontos escuros de tamanhos variados, inclusive na cabeça e lábios. Barras verticais nas nadadeiras dorsal e caudal. Nadadeiras peitorais, pélvicas e anal translúcidas. Mancha negra na parte superior do focinho. Nadadeira adiposa pigmentada.

\section{Distribuição}

A espécie tem distribuição do Golfo do México até o Uruguai, e é a única que também tem ocorrência no Atlântico oriental (ANDERSON et al., 1966; NIÓN et al., 2016). A espécie parece ter uma maior propensão a ser encontrada em ilhas, já que dos 33 lotes analisados, 13 eram provenientes de ilhas continentais, oito de ilhas oceânicas (Atol das Rocas e Arquipélago de Fernando de Noronha e Vitória-Trindade) e 12 de praias continentais. Brown et al., 2019 reportaram a ocorrência da espécie na Ilha de Santa Helena, no Atlântico Central. Dos lotes analisados em coleções brasileiras, apenas Synodus synodus foi encontrada em ilhas oceânicas do Atlântico Sul ocidental (Figura 25).

Comentários. Descrita da América, a espécie não possui tipos conhecidos. A descrição original de Esox synodus por Linnaeus (1758) é bastante breve, com poucas informações. Não há menção sobre contagem de escamas na linha lateral, escamas pré-dorsais ou mesmo padrão de cores. Uma descrição subsequente realizada por Nielsen (1973), classificou a espécie como Synodus synodus, sem designar tipos. Os trabalhos seguintes também não designaram tipos, porém, as análises mostraram que cerca de 15 lotes de Synodus synodus estavam identificados erroneamente como Synodus foetens. A confusão de identificação entre as duas espécies provavelmente ocorre pelo número semelhante de escamas na linha lateral. Entretanto, as duas espécies apresentam diferenças no número de escamas pré-dorsais, número de raios na nadadeira anal, formato da membrana da narina anterior, comprimento dos raios anteriores da nadadeira dorsal e extremidade da nadadeira peitoral em relação à origem da nadadeira pélvica. Synodus synodus também apresenta uma mancha preta na parte dorsal do focinho, característica ausente em Synodus foetens.

Synodus synodus possui seis a oito manchas quatro avermelhadas no dorso e na lateral do corpo e nas nadadeiras dorsal e anal (SAMPAIO \& NOTTINGHAM, 2008). O focinho é mais 
arredondado que as demais espécies (FRABLE et al., 2013). Pode chegar a $25 \mathrm{~cm}$ de comprimento total, mas raramente ultrapassa os $11 \mathrm{~cm}$. Habita litorais em áreas rochosas e de recifes de coral, podendo ultrapassar os $90 \mathrm{~m}$ de profundidade (ROBINS et al., 1986; RUSSELL, 2002). A primeira ocorrência da espécie em águas brasileiras foi registrada no estado da Bahia (NORMAN, 1935).

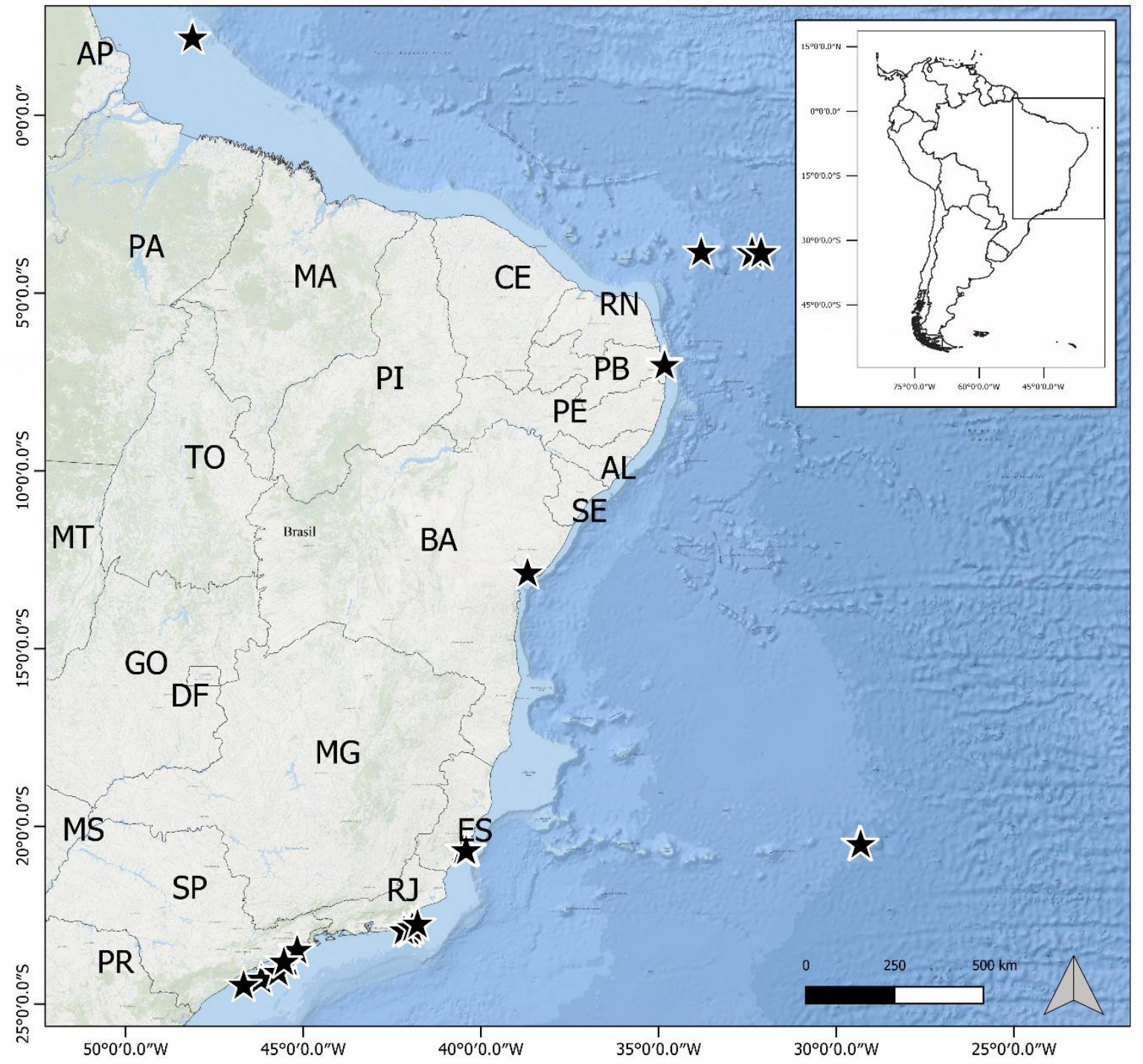

Figura 21. Área de distribuição dos lotes de S. synodus provenientes de coleções brasileiras. 


\section{Synodus sp. N, nova espécie}

Nome proposto: Peixe-lagarto-olhudo [português];

(Figs. 22, 23, 24; Tabelas 9, 10, 11)

Synodus poeyi Camargo \& Isaac, 2001:139 [catálogo de peixes estuarinos da região norte do Brasil e distribuição geográfica]; Moraes et al. 2009: 165 [lista de espécies encontradas na plataforma continental ao largo de Ilhéus, Bahia]; Carvalho-Filho et al., 2010:33 [chave de identificação de espécies de Aulopoidei do Atlântico ocidental].

MS Holótipo. MNRJ 44976 (2), 81.8 mm CP, Talude continental da Bahia, Brasil, Atlântico Sul ocidental, $16^{\circ} 24^{\prime} 00^{\prime}$ ' S, 38²4'53”' O, 64.4 m de profundidade, 14 de junho de 1999, número de campo REVIZEE D-439, Col. Navio Oceanográfico Thalassa (Figura 19 A).

MS Parátipos: AZUSC 5814 (1, 129.4 mm CP), Ao largo dos recifes amazônicos, Pará, 3³5'27" N, 5003’30" O; CIUFES 1266 (1, 25.2 mm CP), Ilhas Rasas, Guarapari, Espírito Santo, 2040’38.5" S, 40²1'56" O [coordenadas inferidas]; CIUFES 3720 (1, $49.8 \mathrm{~mm} \mathrm{CP})$, Piraquê-Açu, Espírito Santo, 1951'55" S, 4002’26" O [coordenadas inferidas]; MNRJ 44976 (4, 74.0-104.4 mm CP), talude continental do estado da Bahia, 16²4’00” S, 38²4'53" O; MZUSP 95441 (1, 71.8 mm CP), Ilhéus, Bahia, 1449’12." S, 390’14." O; MZUSP 95442 (1, 58.8 mm CP), Ilhéus, Bahia, 14²9’12." S, 390’14." O. Apêndice A.

\section{Diagnose}

Synodus sp. n pode ser diferenciada de seus congêneres por possuir comprimento do focinho menor ou igual ao diâmetro do órbita, focinho $24.8-27.9 \%$ do comprimento da cabeça e diâmetro da órbita 26.0-33.9\% (vs. comprimento do focinho maior que o diâmetro da órbita em S. foetens, S. bondi, S. intermedius, S. macrostigmus, S. synodus e S. poeyi); ponta do dentário com projeção carnosa (vs. ausência de projeção em S. foetens, S. bondi, S. intermedius, $S$. macrostigmus e $S$. synodus). Adicionalmente, a nova espécie pode ser diagnosticada das demais por possuir 44-52 escamas na linha lateral (vs. 54-65 em S. bondi, S. foetens e S. synodus); 1518 escamas pré-dorsais (vs. 20-30 em S. foetens e S. bondi); 10-12 raios na nadadeira anal (vs. 8-10 em S. synodus); raios anteriores da nadadeira dorsal longos, ultrapassando os posteriores quando deprimida (vs. raios curtos, não ultrapassando os posteriores quando deprimida em $S$. macrostigmus, S. intermedius e S. synodus); extremidade distal da nadadeira peitoral ultrapassando a origem da nadadeira pélvica ( $v$ s. não ultrapassando em $S$. foetens e $S$. bondi). 


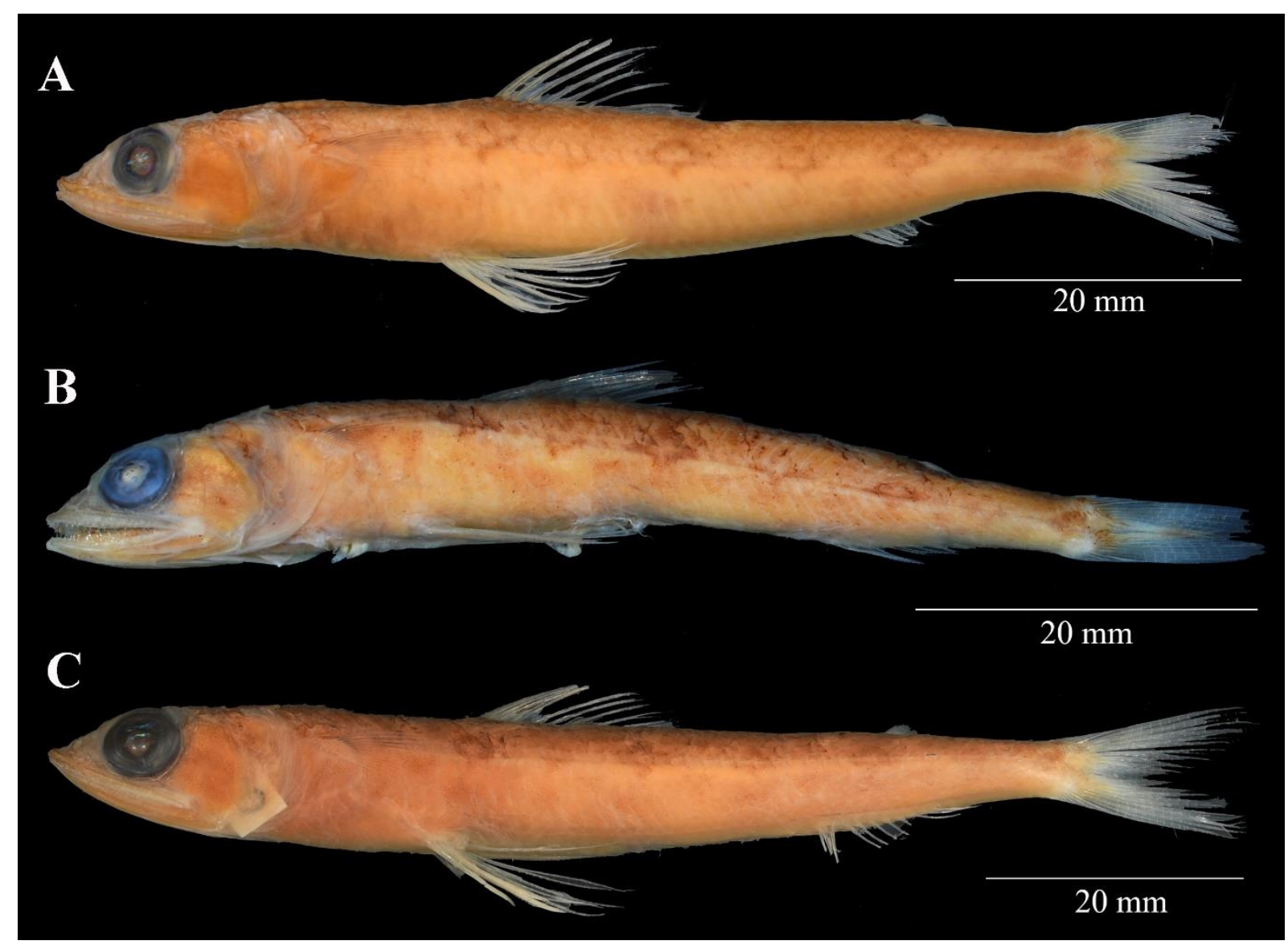

Figura 22. Synodus sp. n. A. MS Holótipo MNRJ 44976 (2), 81.8 mm CP; B. MZUSP 95441, 71.0 mm CP; C. MNRJ 44976 (3), $75.4 \mathrm{~mm} \mathrm{CP.}$

\section{Descrição}

Dados morfométricos listados na Tabela 9. Corpo alongado e cilíndrico, afunilando no pedúnculo caudal. Boca terminal. Focinho pontudo em vista lateral e dorsal. Ponta do focinho se entendendo além da sínfise do dentário. Margem distal dos ossos maxilares se entendendo além da margem posterior da órbita. Duas fileiras de dentes na pré-maxila; maxila edêntula. Três fileiras de dentes no dentário, maiores medialmente; dentes posteriores direcionados anteriormente. Todos os dentes cônicos, com uma cúspide. Narinas de mesmo tamanho; narina anterior com membrana na maior parte das vezes muito danificada, não sendo possível caracterização; narina posterior sem membrana.

Nadadeiras peitorais se estendendo além da pélvica, posicionadas lateralmente no corpo, na altura da órbita. Nadadeiras pélvicas ventrais em posição anterior à vertical que passa sobre a origem da nadadeira dorsal. Nadadeira adiposa presente. Nadadeira caudal furcada; lobo superior ligeiramente menor ou igual ao lobo inferior. 
Raios da nadadeira dorsal ii,8 (1), ii,10 (7) e ii,11 (1); raios da nadadeira anal ii,8 (5), ii,9 (2) e ii,10 (2); raios da nadadeira peitoral ii,9,i (7) e ii,10,i (2); raios da nadadeira pélvica i,6,i (9); raios da nadadeira caudal i,8,8,i (5), i,9,9,i (1) e i,9,10,i (3); vértebras 50 (1); vértebras prédorsais 14 (1) (Figura 21); escamas ctenóides; escamas da linha lateral 44 (3), 45 (2), 49 (1), 50 (2) e 51 (1); escamas pré-dorsais 15 (6) e 16 (3); fileiras de escamas acima da linha lateral até base da nadadeira dorsal 3,5 (7) e 4,5 (2); fileiras de escamas abaixo da linha lateral até base da nadadeira anal 4,5 (7) e 5,5 (2).

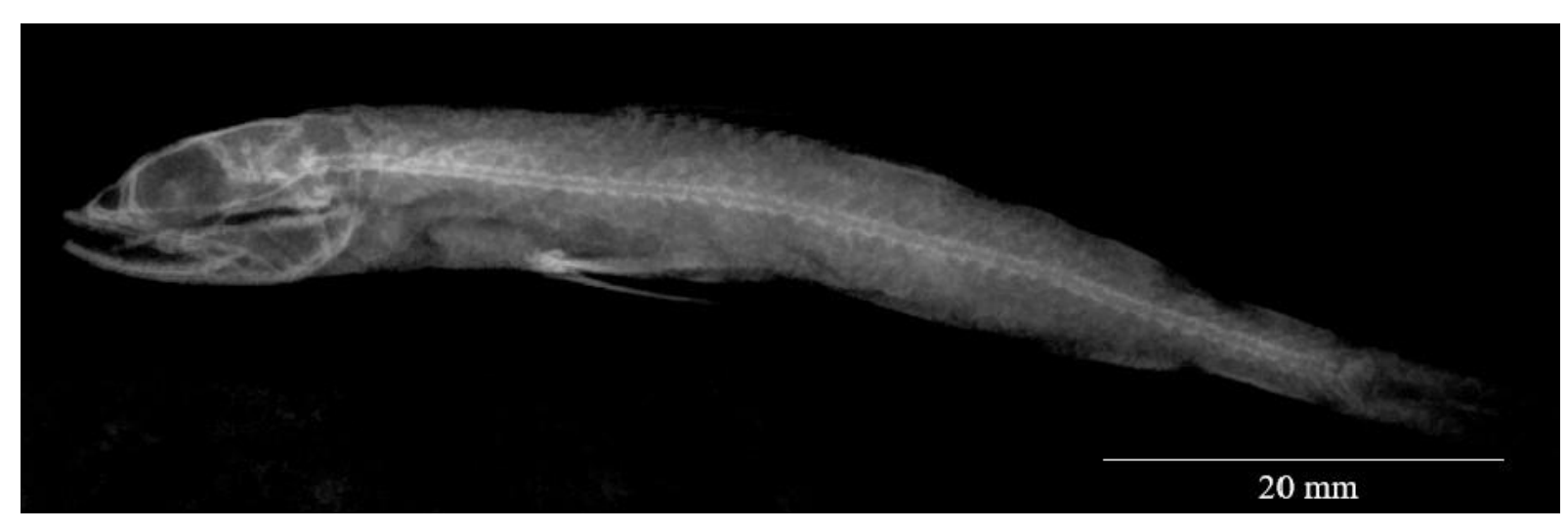

Figura 23. Radiografia de Synodus sp. N, MZUSP 95441, 71.8 mm CP.

Tabela 9. Dados morfométricos obtidos em Synodus sp. N.

\section{Medição}

\section{Porcentagem em relação ao CP (Figura 1)}

Comprimento cabeça (CC)

Comprimento até nadadeira anal deprimida

Comprimento pré-adiposa

Comprimento pré-anal

Comprimento pré-dorsal

Comprimento pré-pélvica

Comprimento pré-peitoral

Comprimento base da nadadeira dorsal

Comprimento raio mais longo da nadadeira dorsal

Comprimento base da nadadeira anal

Comprimento raio mais longo da nadadeira anal

Comprimento base da nadadeira adiposa

Largura do corpo origem nadadeira peitoral

\section{Range \\ (\%)

$\begin{array}{ccc}\text { Média } & \text { Desvio } \\ (\%) & \text { padrão }\end{array}$

\begin{tabular}{cccc}
$22.8-26.4$ & 24.7 & 1.08 & 9 \\
$89.6-93.0$ & 91.1 & 1.25 & 9 \\
$81.3-85.3$ & 82.8 & 1.28 & 9 \\
$74.0-76.5$ & 75.6 & 0.84 & 9 \\
$41.8-44.4$ & 43.1 & 0.87 & 9 \\
$35.6-38.1$ & 37.3 & 0.73 & 9 \\
$25.8-28.7$ & 27.1 & 1.05 & 9 \\
$14.3-17.1$ & 15.2 & 1.00 & 9 \\
$15.6-18.1$ & 17.2 & 1.08 & 5 \\
$10.7-13.6$ & 12.3 & 1.03 & 9 \\
$7.5-10.8$ & 9.6 & 1.31 & 6 \\
$1.5-2.8$ & 2.1 & 0.47 & 9 \\
$11.6-13.8$ & 12.7 & 0.75 & 9 \\
\hline
\end{tabular}




\begin{tabular}{lcccc}
\hline \hline Altura do corpo origem nadadeira dorsal & $11.8-14.2$ & 13.2 & 0.93 & 9 \\
Altura do corpo origem nadadeira adiposa & $7.4-8.7$ & 8.1 & 0.50 & 9 \\
Altura do corpo origem nadadeira pélvica & $11.5-14.2$ & 12.8 & 0.96 & 9 \\
Altura do corpo origem nadadeira anal & $8.8-10.3$ & 9.6 & 0.61 & 9 \\
Altura do corpo no pedúnculo caudal & $4.9-5.9$ & 5.4 & 0.35 & 9 \\
Largura do corpo origem nadadeira dorsal & $11.3-13.6$ & 12.4 & 0.92 & 9 \\
Comprimento nadadeira peitoral & $13.8-16.4$ & 14.5 & 0.86 & 9 \\
Comprimento nadadeira pélvica & $21.3-25.8$ & 23.1 & 1.33 & 9 \\
Comprimento nadadeira caudal & $18.8-22.2$ & 20.6 & 1.07 & 9 \\
Distância ponta do focinho-ponta da maxila & $15.1-16.7$ & 15.8 & 0.51 & 9 \\
Comprimento focinho & $6.3-6.9$ & 6.5 & 0.24 & 9 \\
Comprimento pedúnculo caudal & $12.3-15.2$ & 13.9 & 1.04 & 9 \\
Diâmetro da órbita & $6.3-8.4$ & 7.6 & 0.70 & 9 \\
Porcentagem em relação ao CC (Figura 2) & & & & \\
Distância ponta do focinho-ponta da maxila & $60.5-68.9$ & 64.1 & 2.82 & 9 \\
Comprimento focinho & $24.8-27.9$ & 26.6 & 1.12 & 9 \\
Distância narina anterior-margem anterior da órbita & $8.6-13.6$ & 10.3 & 1.51 & 9 \\
Distância narina posterior-margem anterior da órbita & $4.7-11.2$ & 7.2 & 2.04 & 9 \\
Comprimento membrana narina anterior & $3.5-5.1$ & 4.6 & 0.95 & 3 \\
Largura tampa adiposa em volta da órbita & $2.4-5.3$ & 4.0 & 1.00 & 9 \\
Diâmetro da órbita & $27.0-33.9$ & 30.8 & 2.59 & 9 \\
\hline \hline
\end{tabular}

Coloração em vida. Não foram coletados exemplares em vida. Synodus poeyi apresenta oito manchas escuras ao longo da linha lateral em formato de diamante (ROBINS et al., 1986), característica provavelmente semelhante em Synodus sp. n.

Coloração em álcool. Corpo alaranjado uniforme dorso e ventralmente. Nadadeiras translúcidas. Região do opérculo ligeiramente mais escura. Manchas ao longo da linha lateral em formato de diamante, desaparecendo em alguns exemplares.

\section{Distribuição}

A espécie possui ocorrência no Norte, Nordeste e Sudeste do Brasil, com registros no Amapá, Bahia e Espírito Santo, porém possivelmente ocorre nos demais estados do Norte e Nordeste Brasileiro (Figura 22). 


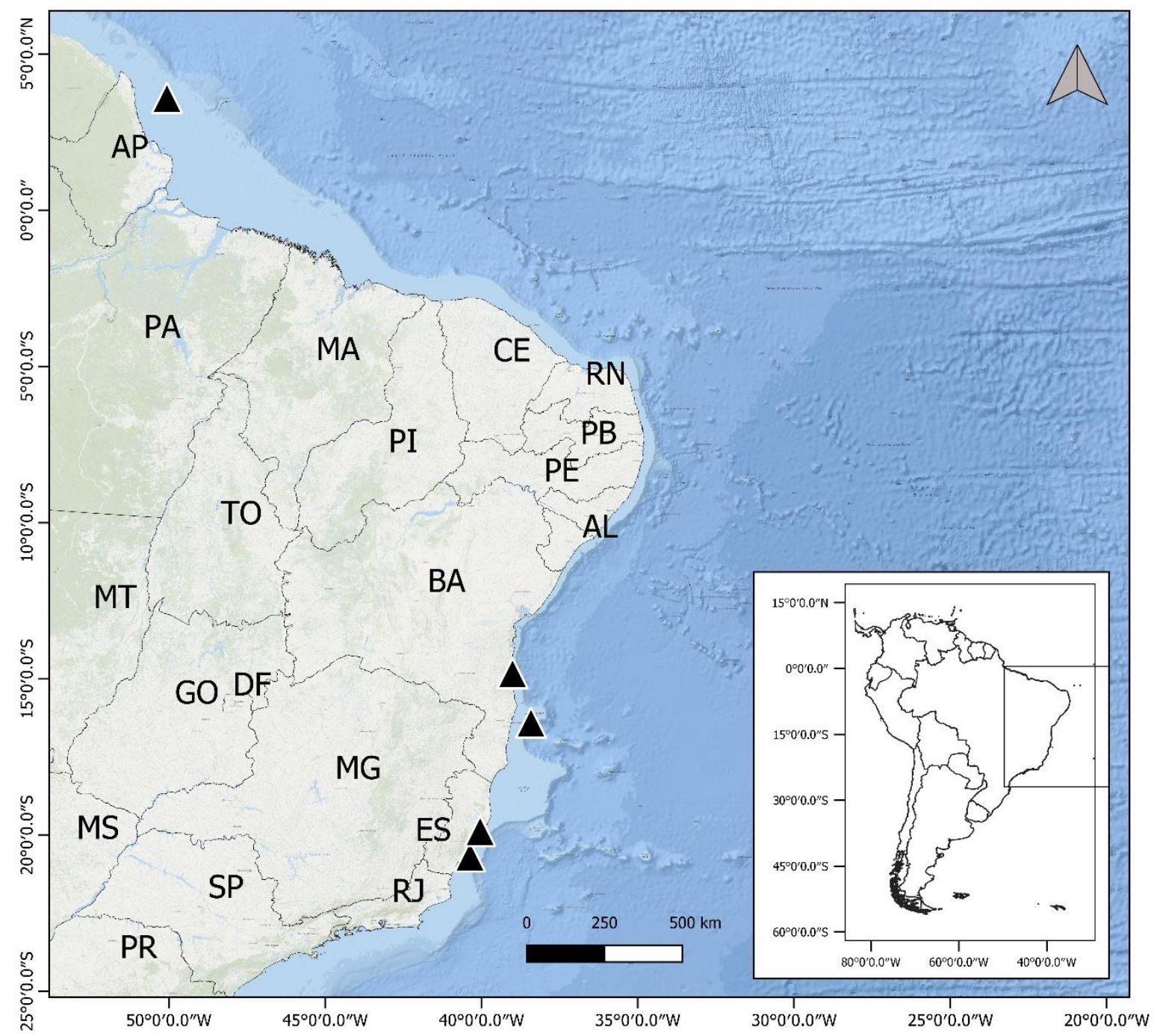

Figura 24. Área de distribuição dos lotes de Synodus sp. N provenientes de coleções brasileiras.

\subsection{Comparação entre as espécies}

A Tabela 10 separa por espécie as médias obtidas em cada medida morfométrica. É possível observar algumas informações como o diâmetro da órbita em Synodus sp. N; a grande diferença entre as medidas de comprimento da mancha escapular em $S$. intermedius e $S$. macrostigmus; menor comprimento da base da nadadeira dorsal em $S$. bondi e $S$. foetens; e o menor comprimento da base da nadadeira anal em S. synodus. As principais características descritivas e dados merísticos usadas na diagnose de cada espécie são mostradas na Tabela 11. 
Tabela 10. Médias obtidas em cada medição morfométrica, separadas por espécie.

\begin{tabular}{|c|c|c|c|c|c|c|}
\hline & $\begin{array}{c}S . \\
\text { bondi }\end{array}$ & $\begin{array}{c}S . \\
\text { foetens }\end{array}$ & $\begin{array}{c}S . \\
\text { intermedius }\end{array}$ & $\begin{array}{c}S . \\
\text { macrostigmus }\end{array}$ & $\begin{array}{l}\text { S. sp. } \\
N\end{array}$ & $\begin{array}{c}\text { S. } \\
\text { synodus }\end{array}$ \\
\hline \multicolumn{7}{|c|}{ Porcentagem em relação ao CP (Figura 1) } \\
\hline $\begin{array}{l}\text { Comprimento cabeça } \\
\text { (CC) }\end{array}$ & 22.2 & 21.9 & 24 & 25.2 & 24.7 & 25.1 \\
\hline $\begin{array}{l}\text { Comprimento até } \\
\text { nadadeira anal deprimida }\end{array}$ & 92.8 & 92.9 & 91.3 & 91.5 & 91.1 & 92.7 \\
\hline Comprimento pré-adiposa & 81.2 & 80.6 & 80.5 & 81.4 & 82.8 & 82.4 \\
\hline Comprimento pré-anal & 76.9 & 75.9 & 71.2 & 73.2 & 75.6 & 78.8 \\
\hline Comprimento pré-dorsal & 44.2 & 43.8 & 40.4 & 41.7 & 43.1 & 41.9 \\
\hline Comprimento pré-pélvica & 37.1 & 36.4 & 35.3 & 35.4 & 37.3 & 34.9 \\
\hline Comprimento pré-peitoral & 23.9 & 23.9 & 25.6 & 26.2 & 27.1 & 26.7 \\
\hline $\begin{array}{l}\text { Comprimento base da } \\
\text { nadadeira dorsal }\end{array}$ & 11.9 & 11.9 & 17.3 & 17 & 15.2 & 17.1 \\
\hline $\begin{array}{l}\text { Comprimento raio mais } \\
\text { longo da nadadeira dorsal }\end{array}$ & 14.5 & 14.2 & 17.3 & 14.3 & 17.2 & 14.5 \\
\hline $\begin{array}{l}\text { Comprimento base da } \\
\text { nadadeira anal }\end{array}$ & 12.5 & 12.9 & 14.6 & 13.3 & 12.3 & 9.7 \\
\hline $\begin{array}{l}\text { Comprimento raio mais } \\
\text { longo da nadadeira anal }\end{array}$ & 8.4 & 7.7 & 9.5 & 8.6 & 9.6 & 8.1 \\
\hline $\begin{array}{l}\text { Comprimento base da } \\
\text { nadadeira adiposa }\end{array}$ & 1.4 & 1.6 & 2 & 2 & 2.1 & 2 \\
\hline $\begin{array}{l}\text { Largura do corpo origem } \\
\text { nadadeira peitoral }\end{array}$ & 13.6 & 12.7 & 14.4 & 14.4 & 12.7 & 15.3 \\
\hline $\begin{array}{l}\text { Altura do corpo origem } \\
\text { nadadeira dorsal }\end{array}$ & 13.2 & 11.6 & 14.4 & 13.3 & 13.2 & 15.4 \\
\hline $\begin{array}{l}\text { Altura do corpo origem } \\
\text { nadadeira adiposa }\end{array}$ & 8.3 & 7.7 & 8.6 & 8.2 & 8.1 & 8.8 \\
\hline $\begin{array}{l}\text { Altura do corpo origem } \\
\text { nadadeira pélvica }\end{array}$ & 12.4 & 11.2 & 13.9 & 13 & 12.8 & 14.9 \\
\hline $\begin{array}{l}\text { Altura do corpo origem } \\
\text { nadadeira anal }\end{array}$ & 9.4 & 8.8 & 10.7 & 10.3 & 9.6 & 9.9 \\
\hline $\begin{array}{l}\text { Altura do corpo no } \\
\text { pedúnculo caudal }\end{array}$ & 5.4 & 5.1 & 5.8 & 5.8 & 5.4 & 5.7 \\
\hline $\begin{array}{l}\text { Largura do corpo origem } \\
\text { nadadeira dorsal }\end{array}$ & 13.4 & 12.6 & 14.7 & 13.9 & 12.4 & 15.1 \\
\hline $\begin{array}{l}\text { Comprimento nadadeira } \\
\text { peitoral }\end{array}$ & 12.2 & 12 & 13.5 & 14 & 14.5 & 13.2 \\
\hline $\begin{array}{l}\text { Comprimento nadadeira } \\
\text { pélvica }\end{array}$ & 19.6 & 20.4 & 25.4 & 22.8 & 23.1 & 25.7 \\
\hline
\end{tabular}




\begin{tabular}{|c|c|c|c|c|c|c|}
\hline $\begin{array}{l}\text { Comprimento nadadeira } \\
\text { caudal }\end{array}$ & 18.5 & 18.1 & 21.2 & $*$ & 20.6 & 18.3 \\
\hline $\begin{array}{l}\text { Distância ponta do } \\
\text { focinho-ponta da maxila }\end{array}$ & 15.2 & 14.9 & 15.6 & 16 & 15.8 & 18 \\
\hline Comprimento focinho & 7.2 & 7.3 & 7.1 & 6.5 & 6.5 & 7 \\
\hline $\begin{array}{l}\text { Comprimento pedúnculo } \\
\text { caudal }\end{array}$ & 12.2 & 11.4 & 14 & 12.9 & 13.9 & 11.4 \\
\hline Diâmetro da órbita & 3.8 & 3.9 & 5.4 & 6.1 & 7.6 & 5.4 \\
\hline \multicolumn{7}{|c|}{ Porcentagem em relação ao CC (Figura 2) } \\
\hline $\begin{array}{l}\text { Distância ponta do } \\
\text { focinho-ponta da maxila }\end{array}$ & 68.3 & 68.3 & 64.9 & 63.6 & 64.1 & 72.1 \\
\hline Comprimento focinho & 32.6 & 33.4 & 29.7 & 26 & 26.6 & 28 \\
\hline $\begin{array}{l}\text { Distância narina anterior- } \\
\text { margem anterior da órbita }\end{array}$ & 8.9 & 9.5 & 10.5 & 9.1 & 10.3 & 10.3 \\
\hline $\begin{array}{l}\text { Distância narina } \\
\text { posterior-margem anterior } \\
\text { da órbita }\end{array}$ & 5.5 & 5.9 & 7.3 & 5.6 & 7.2 & 6.8 \\
\hline $\begin{array}{l}\text { Comprimento membrana } \\
\text { narina anterior }\end{array}$ & 3.8 & 4.1 & 3 & 5.4 & 4.6 & 6.6 \\
\hline $\begin{array}{l}\text { Largura tampa adiposa } \\
\text { em volta da órbita }\end{array}$ & 2.5 & 3 & 3.7 & 3.6 & 4 & 3.3 \\
\hline Diâmetro da órbita & 17.3 & 18.1 & 22.6 & 24.1 & 30.8 & 21.6 \\
\hline $\begin{array}{l}\text { Comprimento mancha } \\
\text { escapular }\end{array}$ & $X$ & $X$ & 7.6 & 14.6 & $\mathrm{X}$ & $X$ \\
\hline
\end{tabular}

* todos os exemplares danificados. 
Tabela 11. Principais diferenças entre as espécies de Synodus.

\begin{tabular}{|c|c|c|c|c|c|c|}
\hline & S. bondi & S. foetens & $\begin{array}{c}S . \\
\text { intermedius }\end{array}$ & $\begin{array}{c}S . \\
\text { macrostigmus }\end{array}$ & S. sp. $N$ & S. synodus \\
\hline $\begin{array}{l}\text { Escamas na Linha } \\
\text { Lateral }\end{array}$ & $59-65$ & $60-64$ & $49-52$ & $45-48$ & $44-52$ & $55-60$ \\
\hline $\begin{array}{l}\text { Escamas da Linha } \\
\text { Lateral à base da } \\
\text { nadadeira dorsal }\end{array}$ & $4,5-5,5$ & $4,5-5,5$ & 3,5 & 3,5 & $3,5-4,5$ & $4,5-5,5$ \\
\hline $\begin{array}{l}\text { Escamas Pré- } \\
\text { Dorsais }\end{array}$ & $20-30$ & $20-30$ & 15-18 & $15-18$ & 15-18 & $15-18$ \\
\hline $\begin{array}{l}\text { Raios anteriores da } \\
\text { nadadeira dorsal }\end{array}$ & longos & longos & curtos & curtos & longos & curtos \\
\hline $\begin{array}{l}\text { Raios da nadadeira } \\
\text { anal }\end{array}$ & $10-12$ & $10-14$ & $11-13$ & $11-12$ & $10-12$ & $8-10$ \\
\hline $\begin{array}{l}\text { Nadadeira peitoral } \\
\text { ultrapassa a origem } \\
\text { da nadadeira } \\
\text { pélvica }\end{array}$ & não & não & $\operatorname{sim}$ & $\operatorname{sim}$ & $\operatorname{sim}$ & sim \\
\hline $\begin{array}{l}\text { Comprimento } \\
\text { focinho em relação } \\
\text { à órbita }\end{array}$ & maior & maior & maior & maior & $\begin{array}{l}\text { menor ou } \\
\text { igual }\end{array}$ & maior \\
\hline $\begin{array}{l}\text { Membrana Narina } \\
\text { Anterior }\end{array}$ & $\begin{array}{l}\text { triangular } \\
\text { afunilada }\end{array}$ & triangular & $\begin{array}{l}\text { triangular } \\
\text { curta }\end{array}$ & $\begin{array}{l}\text { triangular } \\
\text { longa }\end{array}$ & indefinida & colher longa \\
\hline $\begin{array}{l}\text { Outras } \\
\text { Características }\end{array}$ & $\begin{array}{l}\text { focinho } \\
\text { muito } \\
\text { pontudo }\end{array}$ & & $\begin{array}{c}\text { 3-6 barras } \\
\text { verticais na } \\
\text { nadadeira } \\
\text { caudal, } \\
\text { mancha } \\
\text { escapular } \\
\text { pequena }\end{array}$ & $\begin{array}{l}\text { pigmento } \\
\text { escuro no lobo } \\
\text { inferior da } \\
\text { nadadeira } \\
\text { caudal; } \\
\text { mancha } \\
\text { escapular } \\
\text { grande }\end{array}$ & $\begin{array}{l}\text { ponta da } \\
\text { maxila } \\
\text { inferior } \\
\text { com } \\
\text { projeção } \\
\text { carnosa }\end{array}$ & $\begin{array}{c}\text { mancha } \\
\text { preta na } \\
\text { extremidade } \\
\text { superior do } \\
\text { focinho }\end{array}$ \\
\hline
\end{tabular}

Para facilitar a identificação de Synodus do Atlântico Sul ocidental foi gerada uma nova chave de identificação utilizando algumas características já descritas em Anderson et al. (1966), Polanco (2006) e Frable et al. (2013). A chave possui novos dados e modificação de caracteres presentes em chaves anteriores. 


\section{Nova chave de identificação das espécies de Synodus do Atlântico Sul ocidental.}

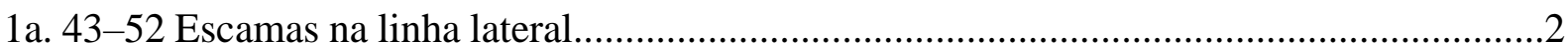

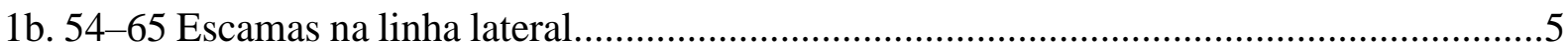

2a. Raios anteriores da nadadeira dorsal alcançando ou ultrapassando os raios posteriores quando deprimida; maxilar inferior terminando em projeção carnosa; ausência de mancha escapular na parte superior atrás do opérculo

3a. Diâmetro da órbita menor que o comprimento do focinho. Synodus poeyi

3b. Diâmetro da órbita maior ou igual ao comprimento do focinho

Synodus sp. $\mathbf{N}$

2b. Raios anteriores da nadadeira dorsal curtos, não ultrapassando os posteriores quando deprimida; maxilar inferior sem ponta carnosa; mancha escapular presente na parte superior atrás do opérculo; diâmetro do olho menor ou igual ao comprimento do focinho; 3,5 escamas da linha lateral à base da nadadeira dorsal. 4

4a. Nadadeira caudal com 3-6 barras verticais; 49-52 escamas na linha lateral; mancha escapular pequena e arredondada (média $7.6 \%$ do comprimento a cabeça); diâmetro do olho menor que o comprimento do focinho; membrana da narina anterior triangular e curta, não alcançando a extremidade posterior da narina posterior quando deprimida. Synodus

\section{intermedius}

4b. Nadadeira caudal sem barras verticais, com mancha escura no lobo ventral da nadadeira caudal; 45-48 escamas na linha lateral; mancha escapular grande e oval (média 14.6\% do comprimento a cabeça); diâmetro do olho igual ou pouco menor que o comprimento do focinho; membrana da narina anterior triangular e longa, alcançando ou ultrapassando a extremidade posterior da narina posterior quando deprimida.

Synodus macrostigmus

5a. Três fileiras de escamas entre linha lateral e base da nadadeira dorsal.

Synodus saurus

5b. Quatro a seis fileiras de escamas entre linha lateral e base da nadadeira dorsal.

6a. 15-18 escamas pré-dorsais; focinho arredondado; raios anteriores da nadadeira dorsal curtos, não ultrapassando os posteriores quando deprimida; base da nadadeira anal muito menor que a base da nadadeira dorsal; extremidade distal da nadadeira peitoral ultrapassando a origem da nadadeira pélvica; mancha na parte superior do focinho; membrana da narina anterior longa e em formato de colher, ultrapassando a extremidade posterior da narina posterior. Synodus synodus 
6b. 20-30 escamas pré-dorsais; focinho triangular; raios anteriores da nadadeira dorsal longos, ultrapassando os posteriores quando deprimida; nadadeiras peitorais curtas ou apenas alcançando a base da nadadeira pélvica; sem mancha na parte superior do focinho; membrana da narina anterior triangular......

7a. 11 raios na nadadeira anal (muito raramente 12); membrana da narina anterior com espessura fina e formato afunilado proximal-distal; focinho muito pontudo com sulco nas laterais em vista dorsal - lábio supramaxilar.

Synodus bondi

7b. 12-14 raios na nadadeira anal; membrana da narina anterior triangular arredondada; focinho triangular com ponta convexa em vista dorsal, sem visualização de sulcos laterais quando visto dorsalmente.

Synodus foetens

Synodus foetens, S. bondi e S. intermedius são amplamente distribuídos ao longo da costa atlântica do continente americano entre a Carolina do Norte ao Brasil, incluindo o Golfo do México, Bermudas e o Mar do Caribe (RUSSELL, 2002, FRABLE et al., 2013). Synodus synodus está distribuída no Atlântico ocidental entre o Golfo do México até o sul do Uruguai e no Atlântico oriental (ANDERSON et al., 1966; RUSSELL, 2002; RUSSELL, 2016). Synodus macrostigmus têm distribuição desde à Carolina do Sul (EUA) até o Rio de Janeiro, no Brasil. Synodus sp. N possui distribuição na costa brasileira, do Amapá ao Espírito Santo.

Em relação à profundidade em que as espécies do gênero são encontradas, Polanco (2006) afirma que Synodus do Atlântico podem ser encontrados desde os 10 até 412 m, com algumas diferenças entre as espécies. Muitas coleções científicas brasileiras não forneceram a profundidade em que os exemplares foram coletados. Entretanto, dentre os dados fornecidos, as menores profundidades foram de Synodus foetens, coletado a $1 \mathrm{~m}$ de profundidade em área de estuário de Santos - SP; $S$. bondi, coletado a $3 \mathrm{~m}$ de profundidade em área de estuário de Guarujá - SP; S. intermedius, coletado na costa de Pernambuco a $5 \mathrm{~m}$ de profundidade; e $S$. synodus, coletado na Ilha de Queimada Grande, em Peruíbe - SP, a $10 \mathrm{~m}$ de profundidade. A maior profundidade foi a de S. bondi, coletado na Ilha Anchieta, Ubatuba - SP, a $135 \mathrm{~m}$ de profundidade. De acordo com Anderson et al. (1966), as maiores profundidades documentadas para as espécies de Synodus são: S. synodus, 91 m, norte do Brasil; S. foetens, 182 m, Flórida; S. intermedius, 320 m, Flórida, Honduras. Polanco (2006), documentou profundidade ainda maior para S. foetens, coletado a $208 \mathrm{~m}$ no Golfo do México. Por fim, em relação a $S$. macrostigmus, Frable et al. (2013) documentou um espécime coletado a 194 m, na Flórida. 
O exemplar mais antigo de Synodus analisado foi de S. foetens, coletado em 1950 na Praia da Siriúba em Ilhabela, SP e depositado no Museu de Zoologia da USP. Os exemplares mais recentes são de S. foetens e Synodus sp. N, ambos coletados em 2019 em Piraquê-Açu, ES e depositados na Coleção Ictiológica da Universidade Federal do Espírito Santo (CIUFES). Synodus foetens é a espécie mais abundante e comum nas coleções científicas brasileiras.

\subsection{Caracteres Osteológicos}

A diafanização dos exemplares permitiu a contagem de vértebras e a posterior dissecação das estruturas. A figura 25 mostra o resultado completo dos peixes diafanizados. Como é possível observar, exemplares grandes (e.g. MPEG 35586) retém muito tecido conjuntivo, sendo necessária a retirada para melhor visualização das estruturas. Exemplares menores, no entanto, (e.g. MZUSP 46254) ficam quase transparentes. Exemplares de Synodus sp. N e S. macrostigmus não foram diafanizados devido ao baixo número de espécimes disponíveis em coleções brasileiras. 

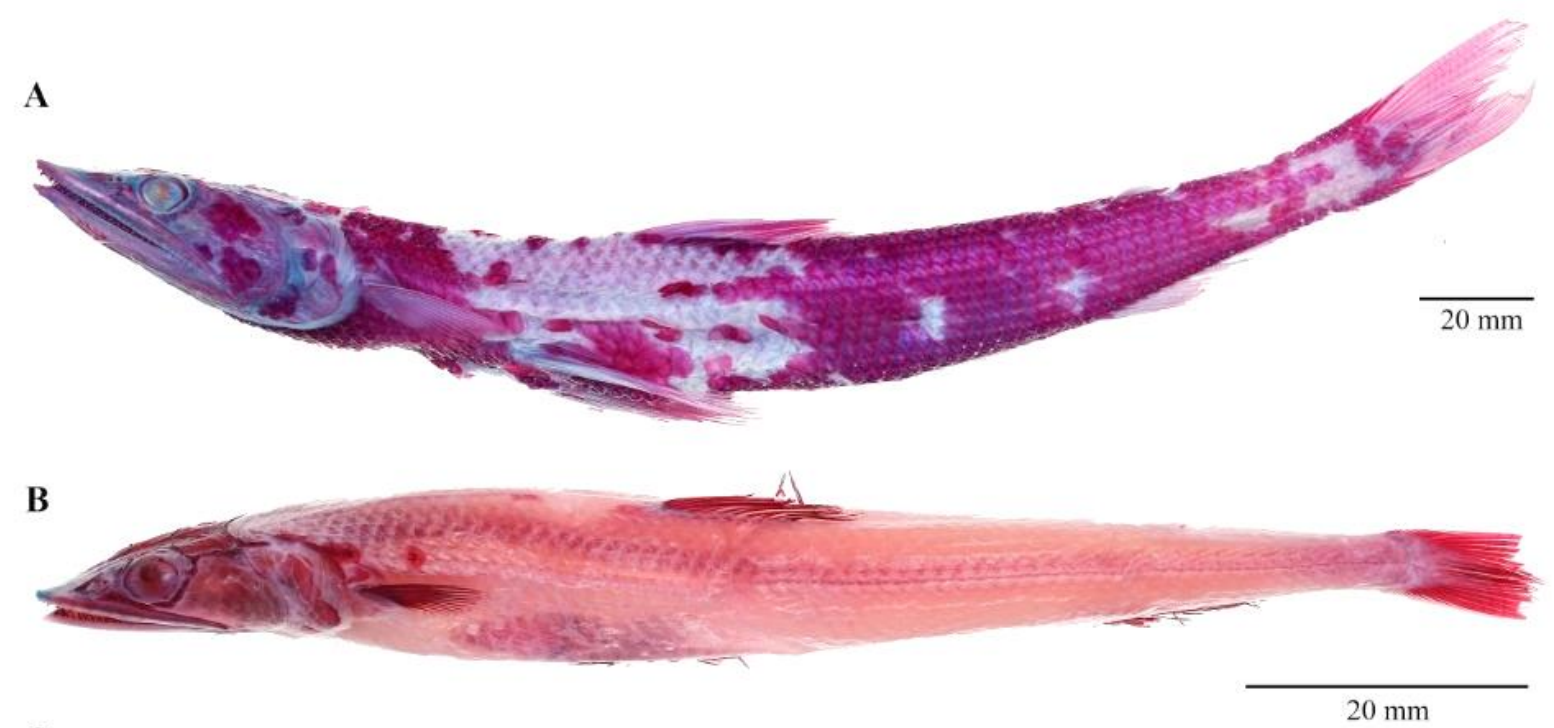

C

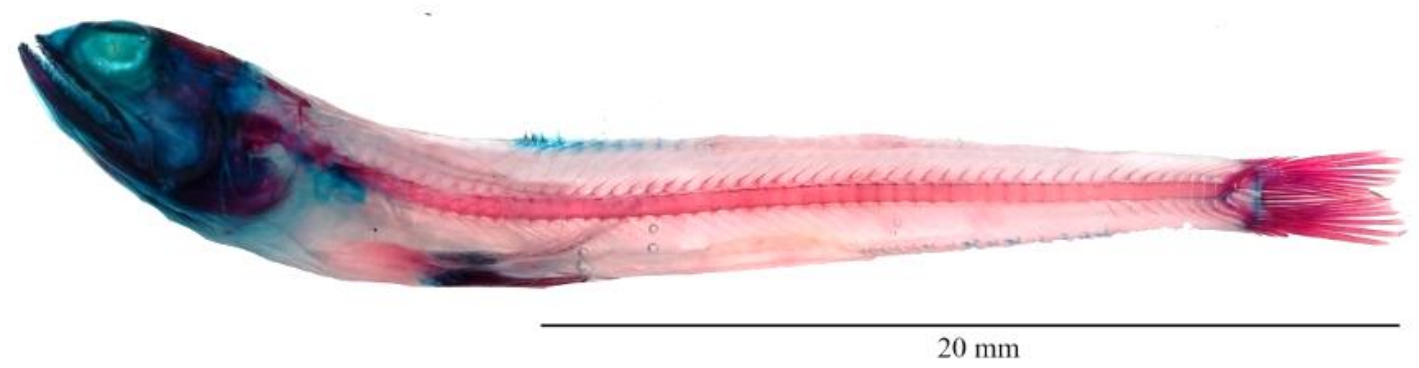

D

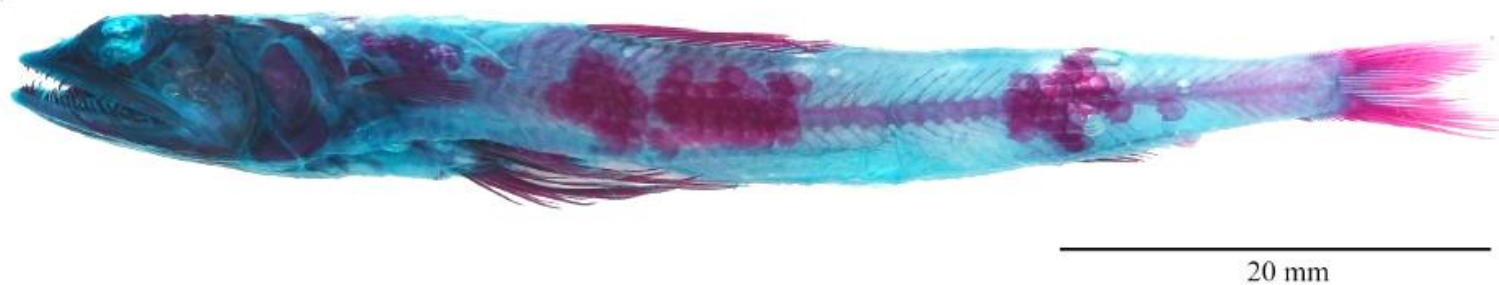

Figura 25. Exemplares de Synodus diafanizados. A. Synodus bondi, MPEG 35586, $252.5 \mathrm{~mm}$ CP; B. Synodus foetens, MZUSP 16472, $106.2 \mathrm{~mm}$ CP; C. Synodus intermedius, MZUSP 46254, $33.8 \mathrm{~mm}$ CP; D. Synodus synodus. MZUSP 110433, $69.2 \mathrm{~mm} \mathrm{CP.}$

De acordo com Russell (2002), os Synodontidae apresentam superfícies ósseas no topo da cabeça, visíveis a olho nu. Foi possível notar essa característica principalmente em exemplares de Synodus bondi em álcool e em todos os exemplares de Synodus diafanizados (Figura 26). 
A

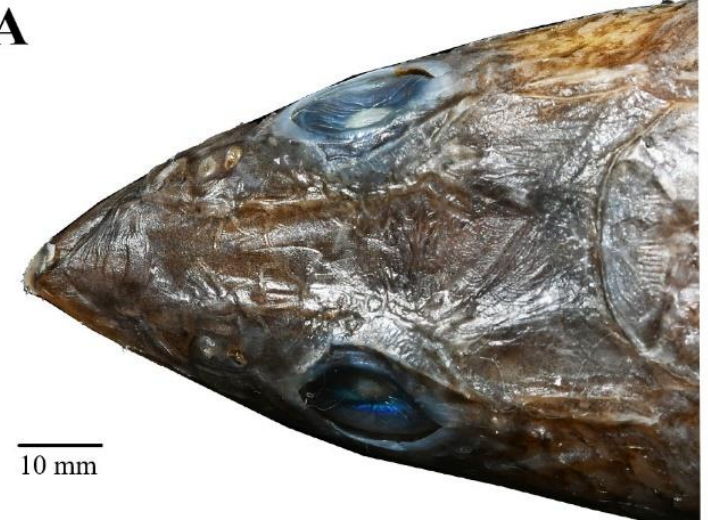

B

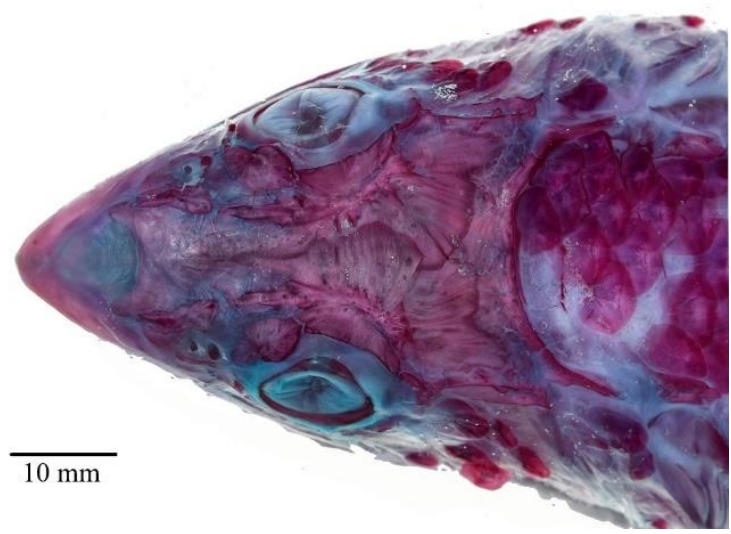

Figura 26. Cabeça de Synodus bondi em vista dorsal evidenciando os ossos do crânio formando placas ósseas. A. MPEG 35202(1), $255.0 \mathrm{~mm} \mathrm{CP}$; B. MPEG 35586, $252.5 \mathrm{~mm}$ CP.

Para identificação de estruturas ósseas e dissecação foi utilizado como referência Keivany (2014a;b;c;d). Os membros de Synodontidae possuem o endopterigóide estreito e conectado ao palatino; metapterigóide grande e triangular, acima do ectopterigóide; quadrado em formato de $\mathrm{U}$, separado em dois côndilos com uma grande cavidade entre eles; e simplético totalmente inserido no lado posterior do quadrado (Figura 27) (KEIVANY, 2014d). O côndilo posterior do quadrado articula com o hiomandibular. Também nota-se a presença de uma fileira de dentes no palatino, característica de todas as espécies do gênero Synodus, assim como em Trachinocephalus (vs. duas fileiras em Saurida) (BALDWIN \& JOHNSON, 1996; RUSSELL, 2002; NELSON et al., 2016). 


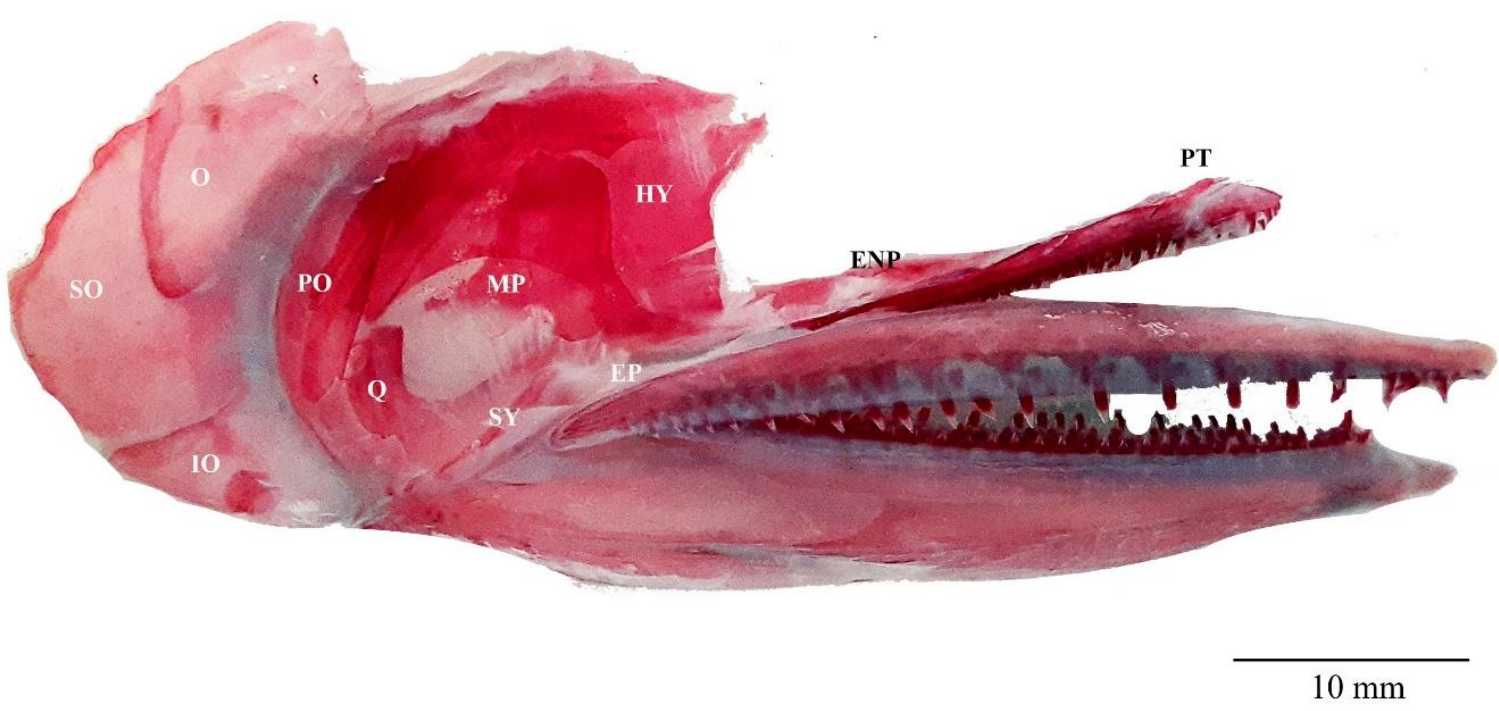

Figura 27. Suspensório direito de Synodus bondi em vista lateral (MPEG 35586, $252.5 \mathrm{~mm} \mathrm{CP).} \mathrm{Legenda:} \mathrm{O:}$ Opérculo; SO: Subopérculo; IO: Interopérculo; PO: Pré-opérculo; Q: Quadrado; SY: Simplético; MP: Metapterigóide; EP: Ectopterigóide; ENP: Endopterigóide; HY: Hiomandibular; PT: Palatino.

O pré-maxilar e o dentário de Synodus têm um comprimento que se estende por mais da metade do comprimento da cabeça, com numerosos dentes. O retroarticular tem formato esférico e o anguloarticular é bifurcado (Figura 28). Não há presença de supramaxila, diferentemente de Saurida (KEIVANY, 2014b).

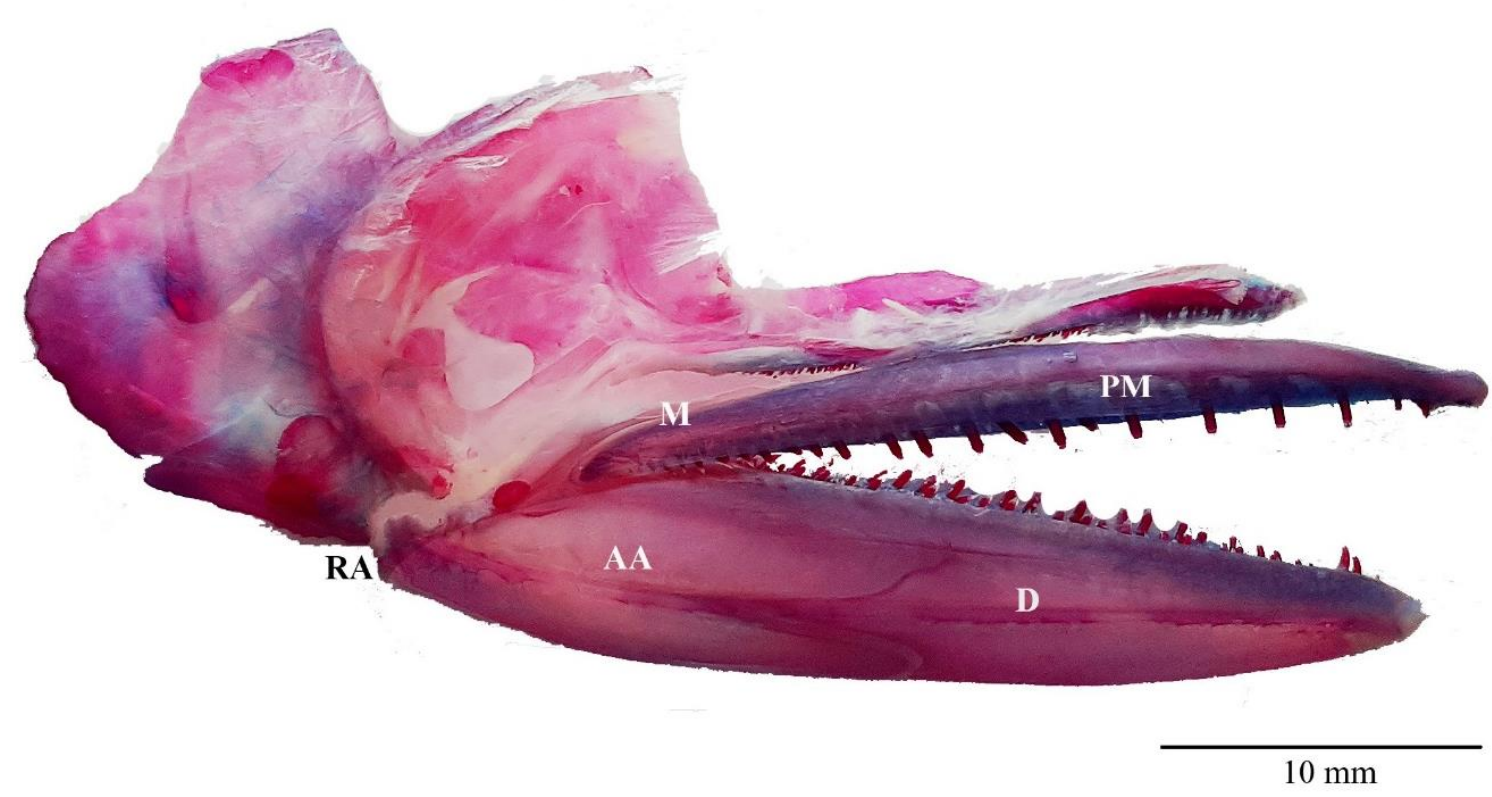

Figura 28. Suspensório, opérculo e arco mandibular direito de Synodus foetens, evidenciando ossos maxilares (MZUSP uncat., 222.0 mm CP). Legenda: RA: Retroarticular; AA: Anguloarticular; D: Dentário; M: Maxila; PM: Pré-maxila. 
As espécies de Synodus possuem quatro arcos branquiais, além da presença de 15-18 raios branquiostégios (vs. 12 em Trachinocephalus e 13 em Saurida) (RUSSELL, 2002). O basihial é dentado, os ceratohiais são grandes e separados entre si, e o interhial é longo e cilíndrico (Figura 29) (KEIVANY, 2014a). Os rastros branquiais estão presentes como placa de dentes (NELSON et al., 2016). Nas figuras 30 e 31 também é possível visualizar o quinto ceratobranquial em forma de $\mathrm{V}$ com membro mediano robusto, além de outras estruturas (BALDWIN \& JOHNSON, 1996).

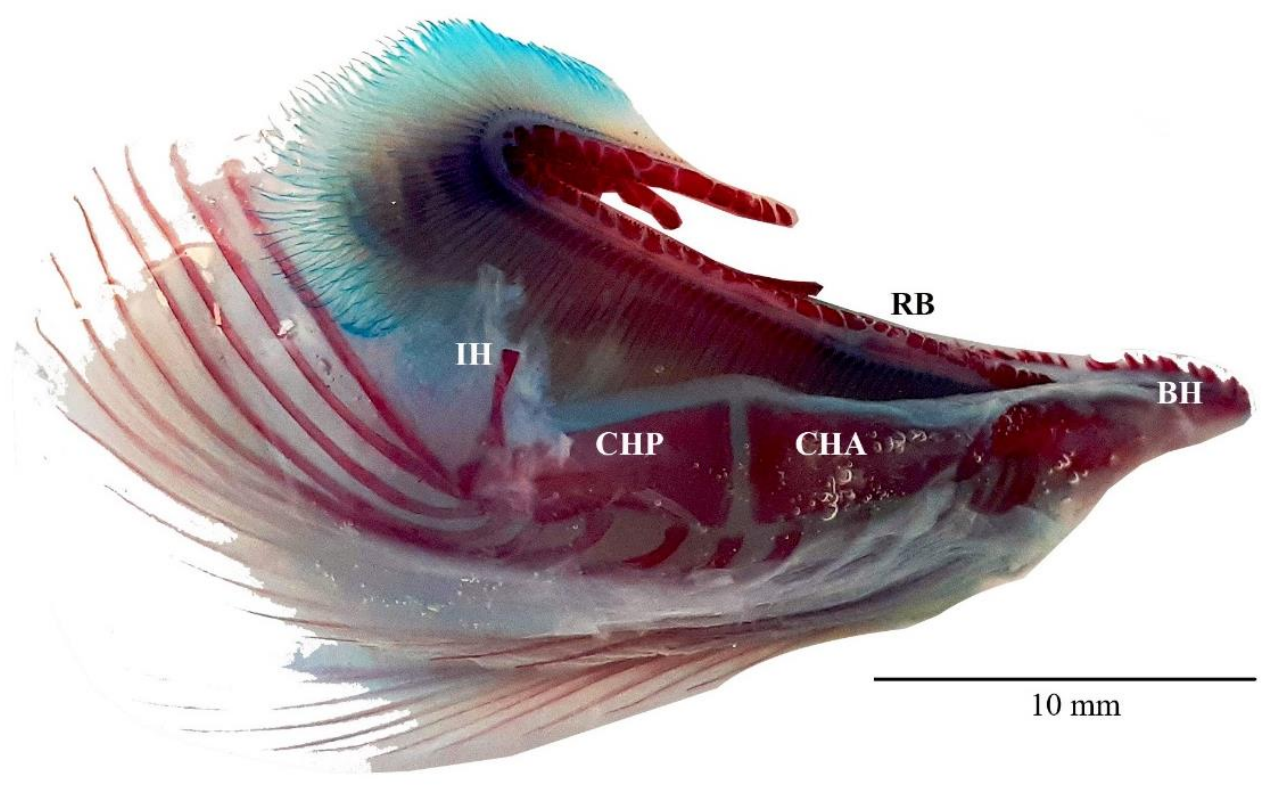

Figura 29. Arco branquial de Synodus bondi (MPEG 35586, $252.5 \mathrm{~mm} \mathrm{CP).} \mathrm{Legenda:} \mathrm{IH:} \mathrm{Interhial;} \mathrm{CHP:}$ Ceratohial posterior; CHA: Ceratohial anterior; $\mathrm{BH}$ : Basihial; RB: Rastros branquiais.

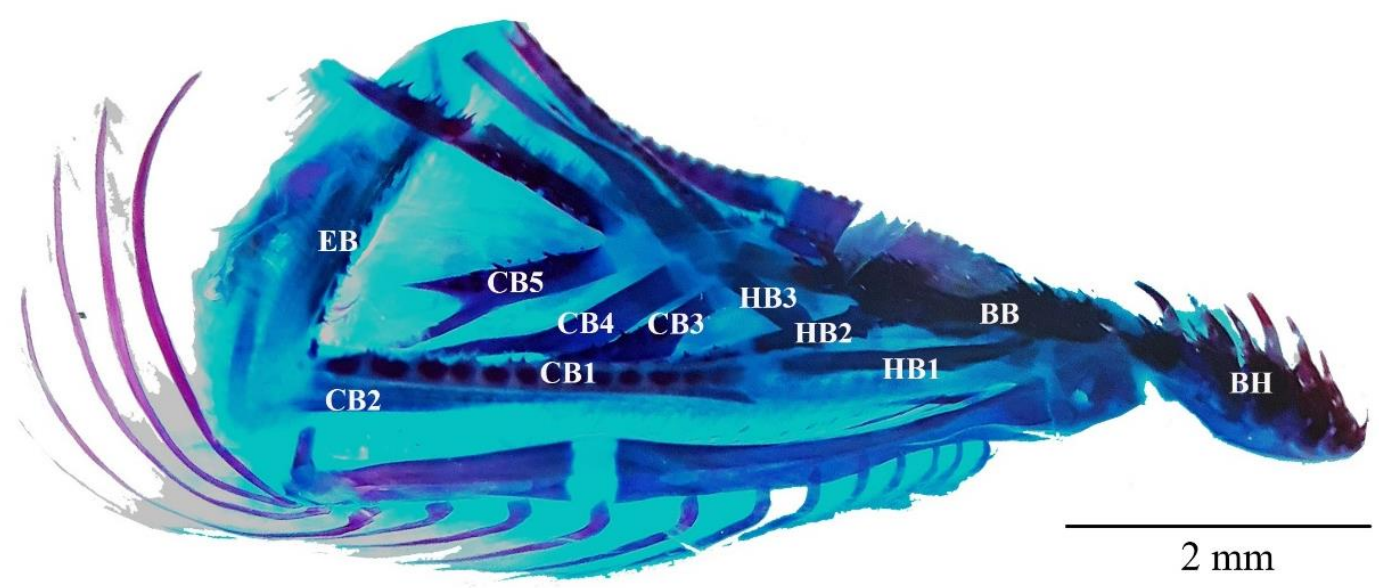

Figura 30. Arco branquial de Synodus synodus (MZUSP 110433, 69.2 mm CP). Legenda: BH: Basihial; BB: Basibranquial; HB: Hipobranquial; CB: Ceratobranquial; EB: Epibranquial. 


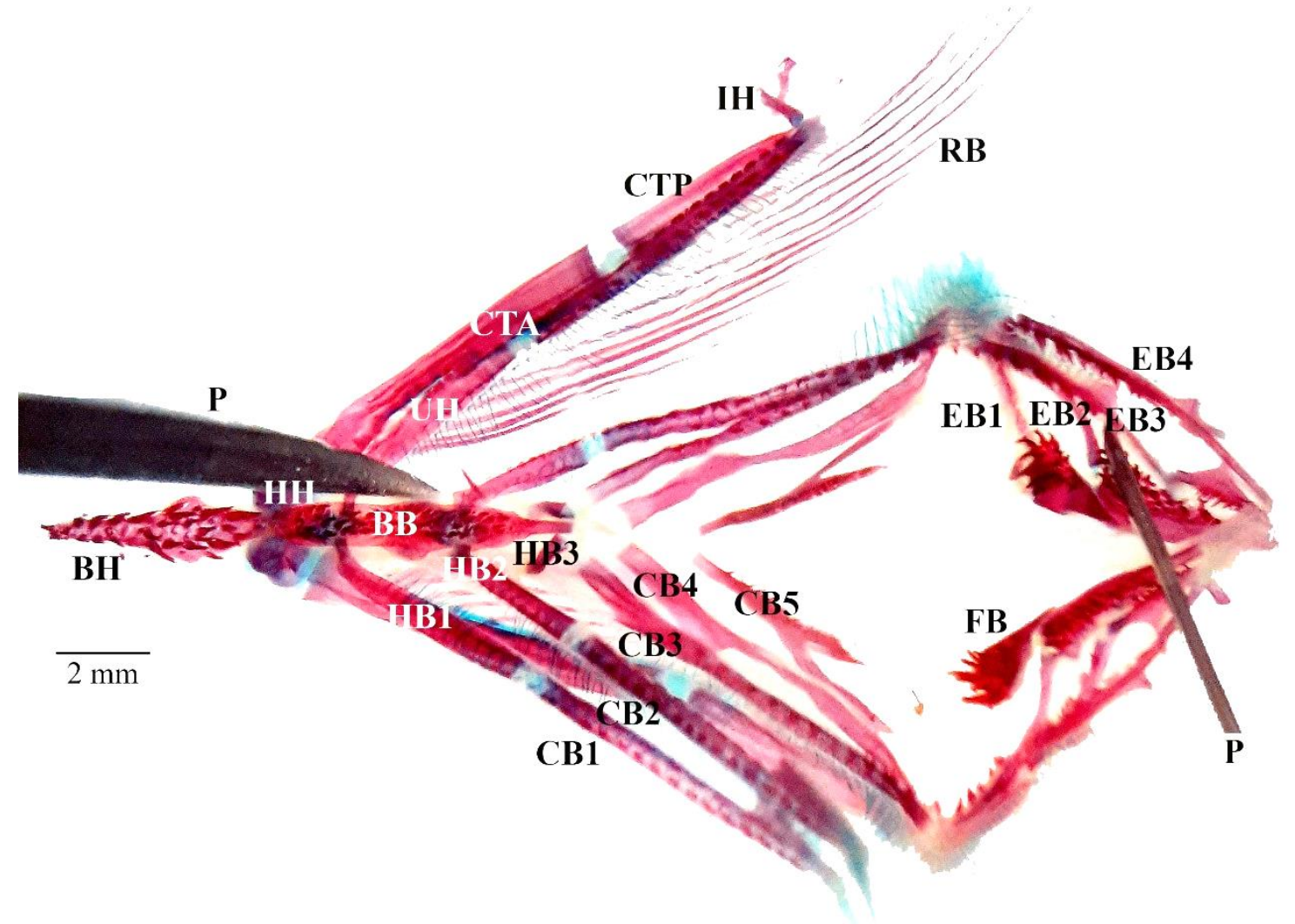

Figura 31. Arco branquial de Synodus foetens (MZUSP 16472, 106.2 mm CP). Legenda: BH: Basihial; HH: Hipohial; BB: Basibranquial; UH: Urohial; CTA: Ceratohial anterior; CTP: Ceratohial posterior; IH: Interhial; RB: Raios branquiostégios; HB: Hipobranquial; CB: Ceratobranquial; EB: Epibranquial; FB: Faringobranquiais; P: Pinças.

As espécies de Synodus possuem apenas raios moles nas nadadeiras. As nadadeiras dorsal e anal possuem os dois primeiros raios sempre simples, os seguintes ramificados, e o último ramificado desde sua base. A origem da nadadeira dorsal é posterior a origem das nadadeiras pélvicas. Em relação à cintura peitoral, Keivainy (2014c) destaca um extraescapular grande e supracleitrum também grande que se sobrepõe ao cleitrum e o pós-cleitrum. A escápula possui um forâmen completo e o coracóide é bastante largo (Figura 32). 


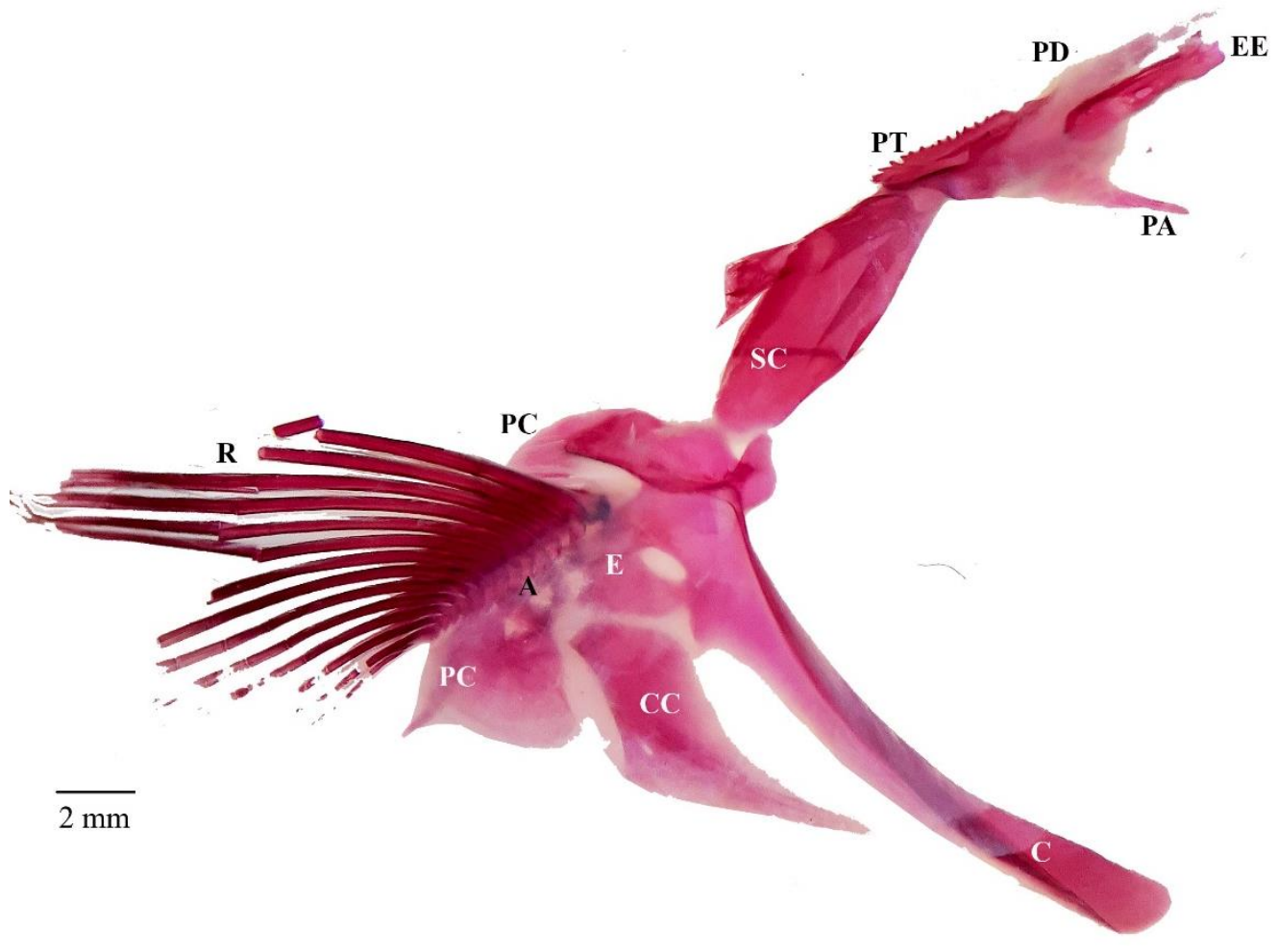

Figura 32. Cintura peitoral de Synodus foetens (MZUSP 16472, $106.2 \mathrm{~mm} \mathrm{CP}$ ). Legenda: R: Raios da nadadeira peitoral; C: Cleitrum; SC: Supracleitrum; PC: Pós-cleitrum; CC: Coracóide; A: Actinos; E: Escápula com foramên; PT: Pós temporal; PD: Processo dorsal; PA: Processo anteromedial; EE: Extraescapular.

O osso suspensório e ossos maxilares de S. synodus e $S$. intermedius tem estruturas com formatos distintos quando jovens, já que enquanto S. synodus possui pré-maxilar, dentário e anguloarticular mais robustos e dentes grandes, $S$. intermedius ainda apresenta pré-maxilar e dentário mais finos e dentes bem menores. Essa característica é curiosa, já que quando adultos, ambos possuem pré-maxilar e dentário robustos e dentes grandes. O exemplar de Synodus synodus diafanizado, apesar de ser bem menor que os exemplares de $S$. bondi e $S$. foetens, já apresenta formatos de ossos bem parecidos a ambos adultos. Synodus bondi e S. foetens também aparentam bastante entre si, mesmo com a diferença de tamanho dos exemplares (Figura 33). Em relação à cintura peitoral, todas as espécies de Synodus diafanizadas apresentaram formas de estruturas muito semelhantes entre si (Figura 34). 
A

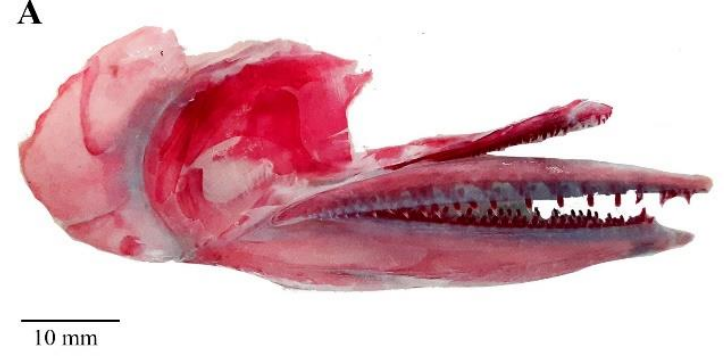

B

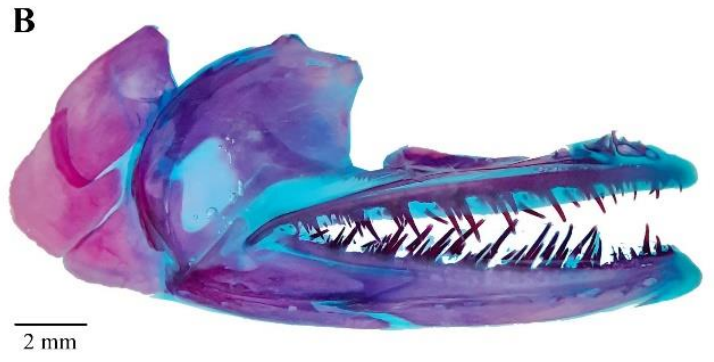

C

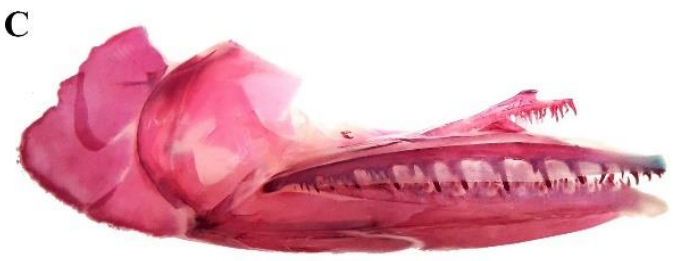

$\overline{2 \mathrm{~mm}}$

D

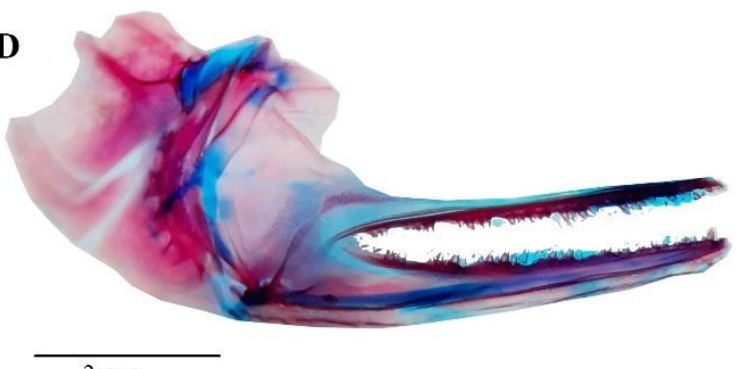

$2 \mathrm{~mm}$

Figura 33. Comparação entre o suspensório das espécies de Synodus. A. MPEG 35586, S. bondi, $252.5 \mathrm{~mm}$ CP; B. MZUSP 110433, S. synodus, $69.2 \mathrm{~mm}$ CP; C. MZUSP 16472, S. foetens, $106.2 \mathrm{~mm}$ CP; D. MZUSP 46254, S. intermedius, $33.8 \mathrm{~mm} \mathrm{CP}$ (palatino não visível).
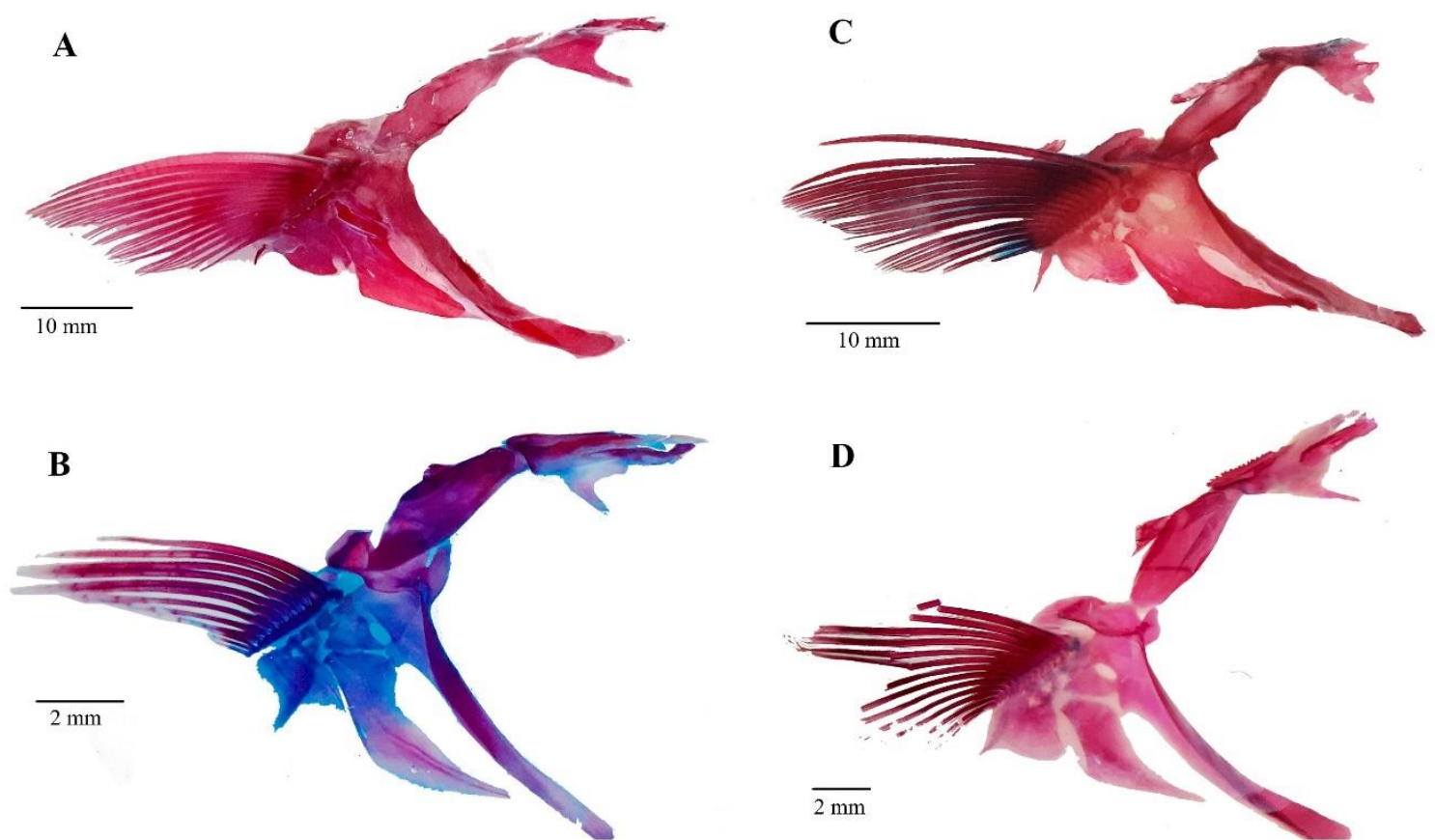

Figura 34. Cintura peitoral direita das espécies de Synodus em vista lateral. A. MPEG 35586, S. bondi, $252.5 \mathrm{~mm}$ CP; B. MZUSP 110433, S. synodus, $69.2 \mathrm{~mm}$ CP; C. MZUSP uncat., S. foetens, $222.0 \mathrm{~mm}$ CP; D. MZUSP 16472, S. foetens, $106.2 \mathrm{~mm} \mathrm{CP.}$ 


\section{Discussão}

Os peixes-lagartos são geralmente coletados em áreas costeiras ou mar aberto, como captura acessória de pesca de arrasto e armadilhas (RUSSELL, 2016). No Brasil, as espécies de Synodus não possuem grande interesse comercial pois sua carne não é muito apreciada. São peixes de hábitos demersais, podendo ser encontrados em fundos de recife, areia, lama e até mesmo dentro de estuários. São predadores vorazes, alimentando-se principalmente de pequenos peixes, crustáceos e lulas (RUSSELL, 2002).

As chaves taxonômicas atuais das espécies de Synodus do Atlântico (ANDERSON et al., 1966; RUSSELL, 2002; POLANCO, 2006; FRABLE et al., 2013), possuem diversos problemas, não sendo possível diferenciar vários espécimes depositados em coleções científicas brasileiras. A chave taxonômica mais recente foi realizada por Frable et al. (2013), que examinou uma quantidade considerável de exemplares de Synodus provenientes do Atlântico Norte ocidental e América Central, para diferenciar geneticamente e morfologicamente as espécies: 27 lotes de $S$. macrostigmus (65 exemplares), 45 de $S$. intermedius (73 exemplares), 44 de $S$. foetens (105 exemplares) e 24 de $S$. bondi (47 exemplares), além de 26 lotes de $S$. synodus e 5 de $S$. poeyi como material comparativo.

Porém, a chave taxonômica de Frable et al. (2013) não é aplicável às espécies do Atlântico Sul ocidental. Um dos pontos mais problemáticos é a não diferenciação concreta entre $S$. bondi e $S$. foetens, já que a grande maioria dos exemplares examinados não coincidia completamente em nenhuma das duas espécies, principalmente quando eram analisadas características como comprimento da membrana da narina anterior, largura da tampa adiposa da órbita e base da nadadeira anal em relação à base da nadadeira dorsal.

As chaves taxonômicas existentes também não são aplicáveis a S. synodus, já que uma das características aponta o diâmetro do olho sendo maior que o comprimento do focinho, caráter não observado nos espécimes brasileiros. Além disso, nenhuma chave taxonômica apontava o formato da membrana da narina anterior em formato de colher, característica observada em todos os exemplares de $S$. synodus brasileiros. A ausência dessas características nas chaves taxonômicas podem ser justificáveis considerando que as chaves atuais contendo $S$. synodus foram elaboradas com base em espécimes do Atlântico Oriental e Mar Mediterrâneo. Estudos recentes mostraram que as populações de S. synodus do Atlântico Oriental são geneticamente diferentes das que ocorrem no Atlântico Ocidental, o que pode alterar algumas características morfológicas (RUSSELL, 2016). Synodus synodus também parece ter ocorrência 
mais insular, sendo mais facilmente encontrado em ilhas oceânicas do que qualquer outra espécie de Synodus do Atlântico, já que dos 24 lotes analisados, oito eram provenientes de ilhas oceânicas e oito de ilhas continentais. Com exceção dessa espécie, nenhuma outra proveniente de coleções brasileiras foi coletada em ilhas oceânicas, apesar de Pinheiro et al. (2015) ter documentado a ocorrência de S. foetens, S. intermedius e S. synodus na cadeia de VitóriaTrindade.

Em relação a Synodus saurus, a presença da espécie em águas brasileiras foi documentada por Roux (1973), Carvalho-Filho (1999) e Moura (2003). Porém, não foram encontrados lotes da espécie em nenhuma coleção brasileira. De acordo com Carvalho-Filho et al. (2010), Roux (1973) identificou erroneamente um espécime de Synodus foetens como sendo S. saurus; Carvalho-Filho (1999) apenas reportou a presença da espécie baseado em Roux (1973); e Moura (2003) realizou a identificação de um espécime baseado em uma fotografia de um espécime coletado no Maranhão. Carvalho-Filho et al. (2010), a partir de imagens de $S$. saurus concluiu que não havia evidência suficiente para afirmar a ocorrência da espécie em águas brasileiras, além do fato de não haver exemplares da espécie coletados em águas brasileiras nos museus do mundo.

Os resultados incluem também o primeiro registro de Synodus macrostigmus em águas brasileiras baseado em exemplares coletados na foz do Rio Amazonas e ao largo de Atafona, no Rio de Janeiro (MNRJ 18209 e MNRJ 49610). A espécie foi descrita em 2013 e era conhecida apenas na América do Norte e América Central (Frable et al., 2013).

\subsection{Comparação entre Synodus foetens e Synodus bondi}

Synodus foetens e $S$. bondi são muito parecidos morfologicamente, sendo difícil diferenciá-las à primeira vista. Ambas as espécies possuem 54-65 escamas na linha lateral, nadadeiras peitorais que não ultrapassam a base das nadadeiras pélvicas e 20-30 escamas prédorsais. As duas espécies foram sinonimizadas no passado, mas separadas recentemente por Frable et al. (2013) principalmente por análise molecular e as seguintes características morfológicas: comprimento da base da nadadeira anal em relação à base da nadadeira dorsal, sendo menor ou igual em $S$. bondi e maior em S. foetens; número de raios na nadadeira anal, sendo 11-12 em S. bondi e 12-13 em S. foetens; largura da tampa adiposa da órbita, mais larga em $S$. bondi e mais estreita em S. foetens; e comprimento e formato da membrana da narina anterior longa e como filamento em $S$. bondi e curta e triangular em S. foetens. Porém, utilizando a chave taxonômica de Frable et al. (2013), muitos exemplares não puderam ser identificados 
principalmente em relação à base da nadadeira anal e o tamanho da membrana da narina anterior, características que se sobrepunham em muitos espécimes. Também não houve diferença na largura da tampa adiposa da órbita. A maior dificuldade foi chegar a nível de espécie em indivíduos que possuíam membrana triangular, mas longa, ultrapassando a extremidade posterior da narina posterior; e indivíduos com a base da nadadeira anal de mesmo tamanho que a base da dorsal, mas com mais de 12 raios na nadadeira anal. A Tabela 12 mostra as principais características apontadas por Frable et al. (2013) na diferenciação entre as espécies, e as variações encontradas nos exemplares brasileiros.

Tabela 12. Características normalmente utilizadas para diferenciar Synodus bondi e S. foetens.

\begin{tabular}{ccccc}
\hline \hline Variedade & Base da anal & $\mathbf{N}^{\mathbf{0}}$ de raios anal & $\begin{array}{c}\text { Formato } \\
\text { membrana }\end{array}$ & $\begin{array}{c}\text { Tamanho } \\
\text { membrana }\end{array}$ \\
1 & Igual ou menor & 13 ou mais & Triangular & Longa \\
2 & Igual ou menor & 11 ou 12 & Afunilada & Longa \\
3 & Maior & 12 ou mais & Triangular & Longa \\
4 & Maior & 12 ou mais & Triangular & Curta \\
5 & Igual ou menor & 11 & Afunilada & Curta \\
\hline \hline
\end{tabular}

A partir da Tabela 12, é possível observar que apenas as variedades 2 e 4 condizem com a chave taxonômica de Frable et al. (2013). Todas as variedades restantes não são possíveis de chegar à nível de espécie pela sobreposição de características (e.g. variedade 1, com tamanho da nadadeira anal e membrana da narina anterior triangular e longa - características mais parecidas a $S$. bondi - mas com 13 ou mais raios na nadadeira anal, característica de S. foetens). Para diferenciar consistentemente $S$. bondi de $S$. foetens, portanto, foram usadas características como o número de raios na nadadeira anal, porém desconsiderando o tamanho da base da nadadeira; formato e espessura da membrana da narina anterior, também desconsiderando o comprimento; e formato do focinho quando visto de cima; características já observadas em Frable et al (2013), mas de forma inconsistente devido a sobreposição de caracteres em exemplares do Atlântico Sul. Portanto, enquanto S. bondi possui 11 raios na nadadeira anal (muito raramente 12), membrana da narina anterior de espessura fina - como se fosse uma pele transparente - e afunilada (Figura 35 A-D), e focinho pontudo com "sulcos" nas laterais em vista dorsal, que na verdade são os lábios - Lábio supramaxilar (Figura 36 A e B); S. foetens possui 12 ou mais raios na nadadeira anal, membrana da narina anterior triangular com ponta 
arredondada (Figura $35 \mathrm{E}-\mathrm{H}$ ) e focinho mais arredondado que $S$. bondi (Figura $36 \mathrm{C}$ e D). Portanto, as variedades 2 e 5 da tabela 12 seriam referentes a $S$. bondi, e 1,3 e 4, de S. foetens. Synodus bondi também parece ter os ossos do crânio mais evidentes que S. foetens.

Ainda de acordo com Frable et al. (2013), ambas as espécies coexistem na América Central, mas enquanto $S$. bondi possui ocorrência até mesmo na costa brasileira, S. foetens fica restrito a América do Norte e Central. Outros trabalhos apontam a distribuição de S. foetens por toda a costa leste da América (ANDERSON et al., 1966; POLANCO, 2006). Frable et al. (2013) sugere que apenas $S$. bondi esteja presente no Atlântico Sul, mas não examinou material brasileiro suficiente. As análises de lotes provenientes de coleções brasileiras mostraram que, na verdade, ambas as espécies possuem distribuição por toda a costa do Brasil, não havendo separação entre as áreas de ocorrência. 



Figura 35. Comparação entre a membrana da narina anterior de $S$. bondi (A-D) e $S$. foetens $(\mathrm{E}-\mathrm{H})$, vista lateral. A. MPEG 35202; B. MPEG 35586; C. MPEG 35608; D. MPEG 35672; E. MNRJ 37114(1); F. MNRJ 37114(2); G. MNRJ 3486(2); H. MCP 16248. 


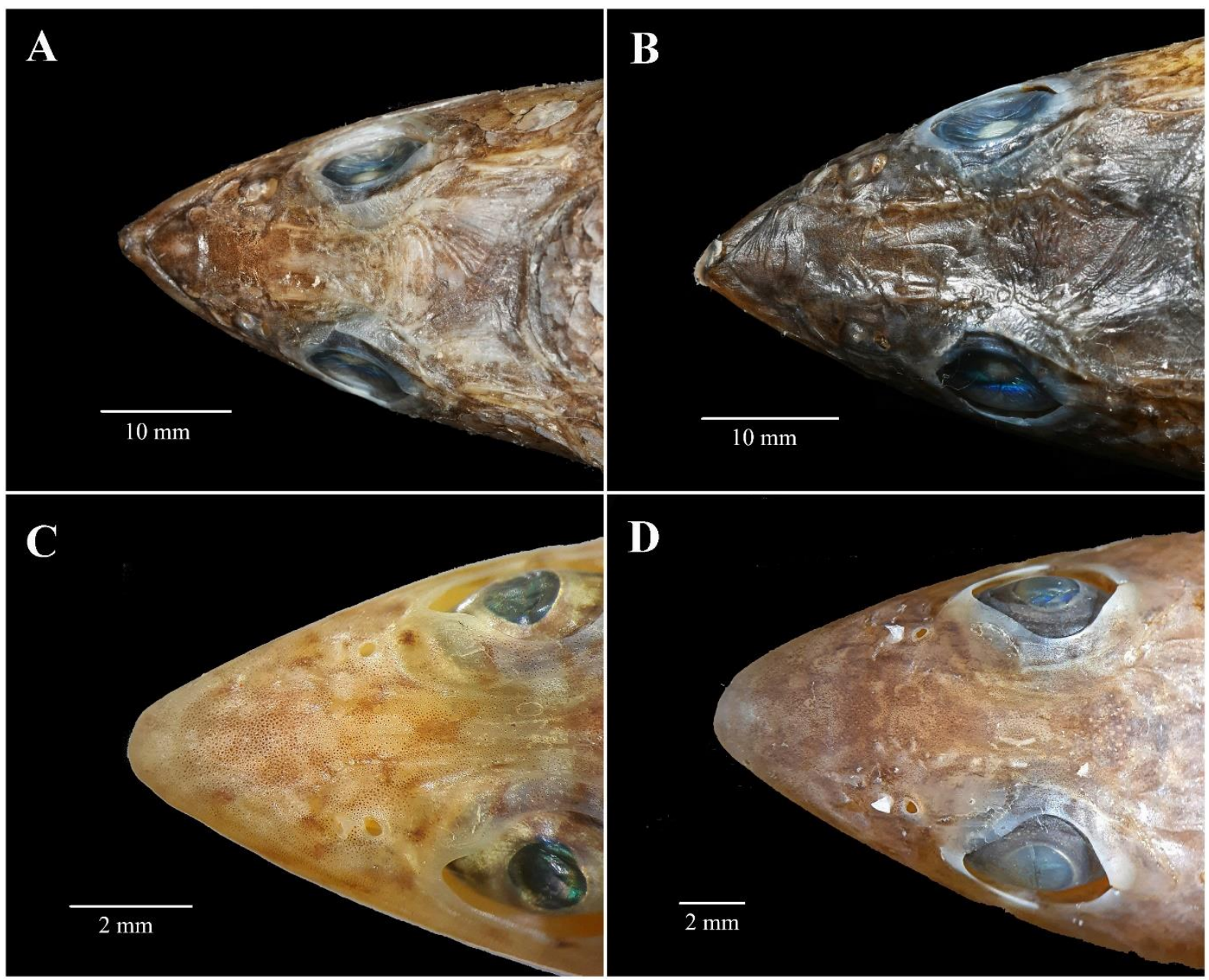

Figura 36. Comparação entre o focinho de $S$. bondi (A e B) e S. foetens (C e D) em vista dorsal. A. MPEG 35134; B. MPEG 35202(1); C. MZUSP 18405(1); D. MZUSP 90800(1).

\subsection{Comparação entre Synodus sp. N, Synodus intermedius e Synodus macrostigmus}

Synodus sp. N, S. intermedius e S. macrostigmus apresentam 15-18 escamas pré-dorsais (assim como S. synodus), porém, menor número de escamas na linha lateral. As três espécies são frequentemente confundidas entre si, mas Synodus sp. N pode ser distinguido por possuir raios anteriores da nadadeira dorsal longos, ponta da maxila inferior apresentando consistência carnosa e é o único das espécies do gênero do Atlântico Sul ocidental que possui o diâmetro do olho maior que o comprimento do focinho. Synodus intermedius e Synodus macrostigmus são ainda mais semelhantes entre si pela presença de uma mancha escapular preta, raios da nadadeira dorsal curtos e 3,5 escamas da linha lateral à base da nadadeira dorsal. Porém, enquanto $S$. intermedius possui 49-52 escamas na linha lateral, S. macrostigmus possui 45-48. De acordo com Frable et al. (2013), a mancha escapular de Synodus intermedius é arredondada e pequena (Figura 37 A e B), enquanto a de S. macrostigmus é grande e oval (Figura 37 C e D). 
As análises confirmaram essa característica, já que os exemplares de $S$. intermedius apresentaram mancha escapular 5.1-11.6\% do comprimento da cabeça (média 7.6\%), e $S$. macrostigmus possui mancha escapular 12.0-17.2\% do comprimento da cabeça (média 14.6\%).

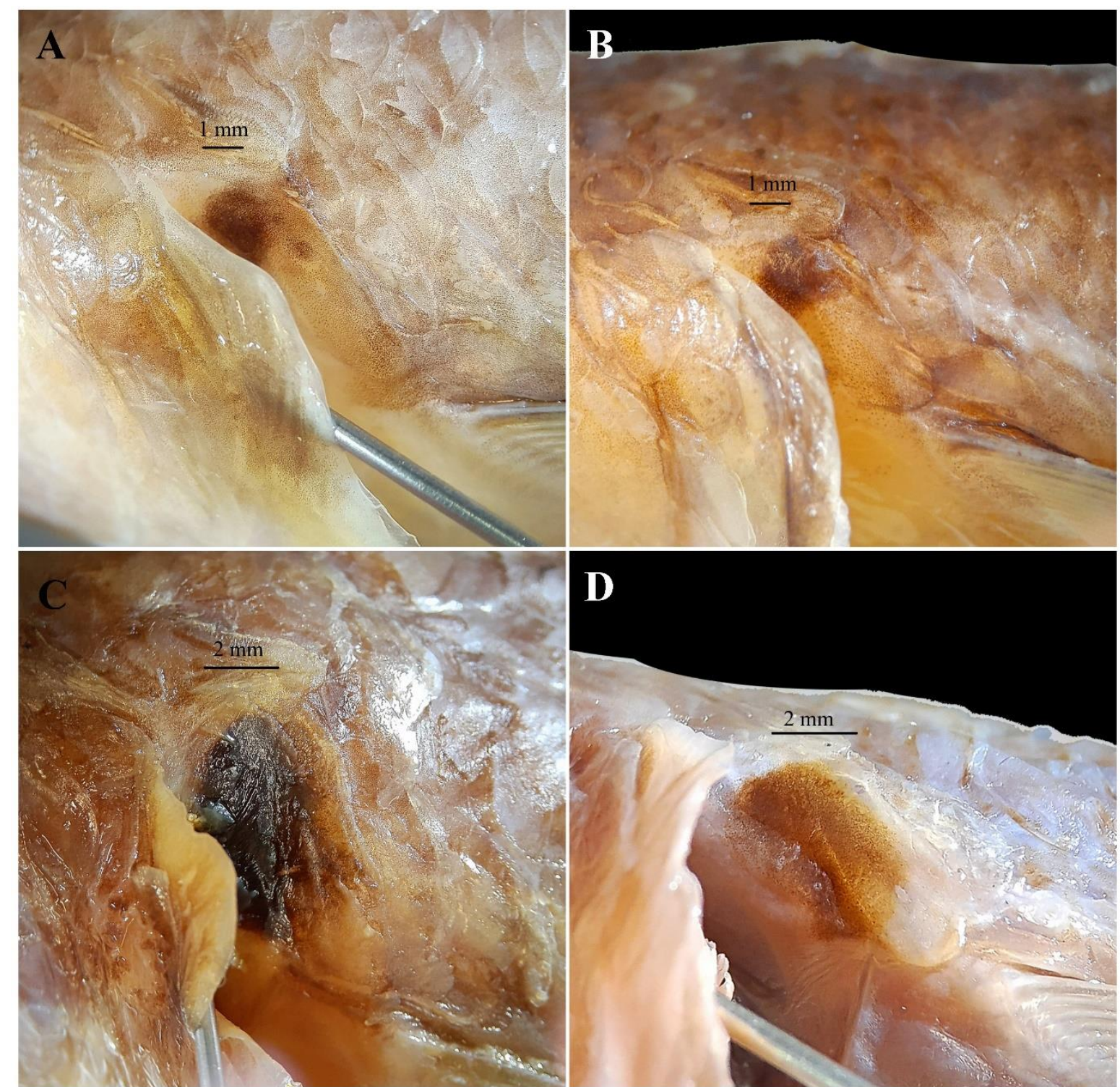

Figura 37. Comparação entre a mancha escapular de Synodus intermedius (A e B) e Synodus macrostigmus (C e D) em vista lateral. A. MZUSP 60547(1); B. MZUSP 65663; C. MNRJ 49610; D. MNRJ 18209(2).

Frable et al. (2013) também apontam que $S$. intermedius possui membrana da narina anterior curta e triangular (Figura $38 \mathrm{~A} \mathrm{e} \mathrm{B}$ ), enquanto $S$. macrostigmus possui membrana longa e mais afunilada (Figura $38 \mathrm{C}$ e D). Também destaca a presença de 3 a 6 barras verticais na nadadeira caudal de $S$. intermedius, enquanto $S$. macrostigmus possui apenas uma mancha escura no lobo inferior da nadadeira caudal. 

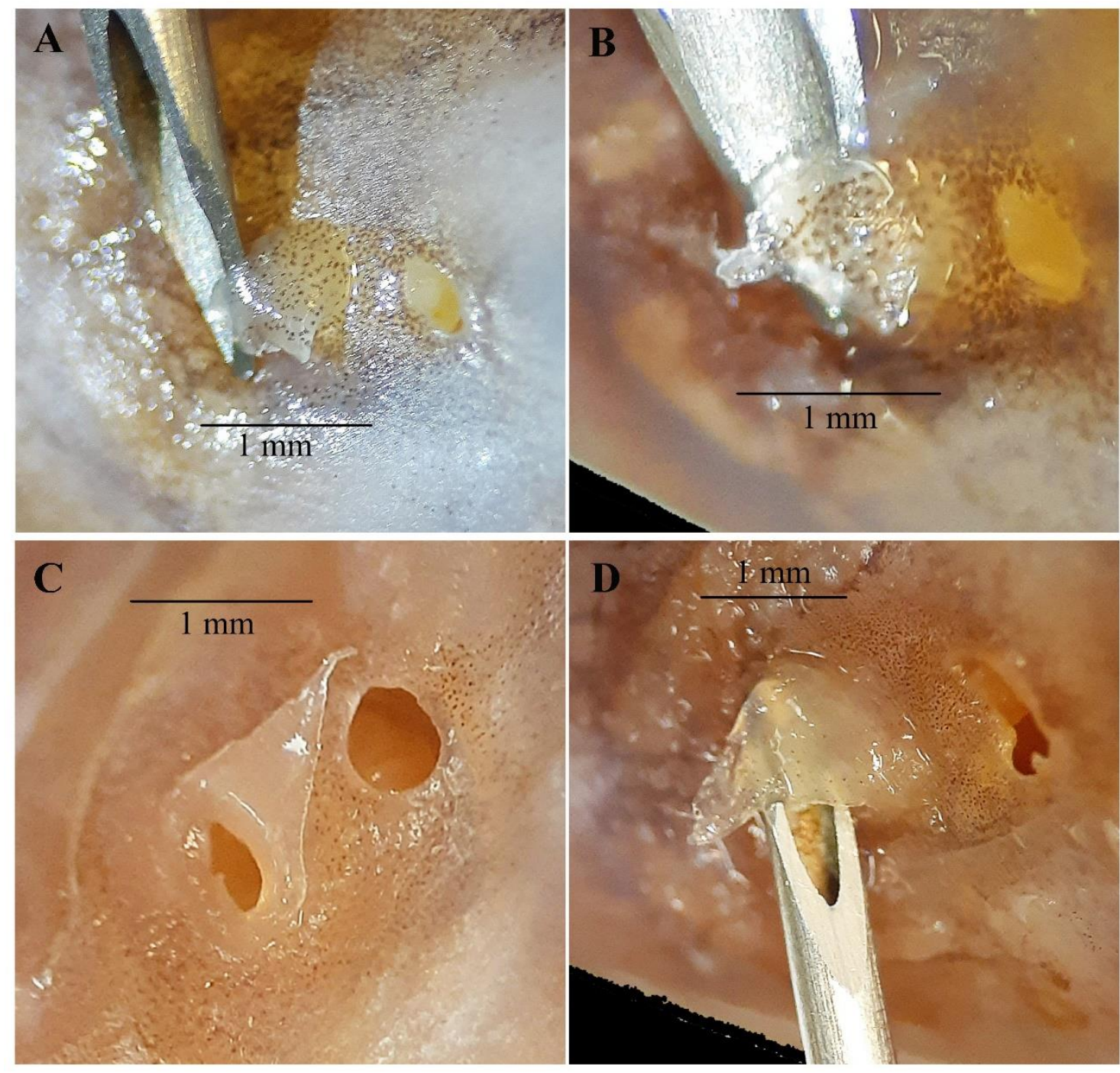

Figura 38. Comparação entre a membrana da narina anterior de Synodus intermedius (A e B) e Synodus macrostigmus (C e D) em vista lateral. A. MZUSP 60547; B. MZUSP 65663; C. MNRJ 18209; D. MNRJ 49610.

Ainda de acordo com Frable et al. (2013), S. macrostigmus possui distribuição restrita desde à Carolina do Sul, nos Estados Unidos, até o Golfo do México, sem ocorrência conhecida no Atlântico Sul ocidental. A análise taxonômica de exemplares depositados em museus brasileiros revelou a existência de dois lotes de S. macrostigmus provenientes do Museu Nacional do Rio de Janeiro, identificados previamente como $S$. intermedius, aumentando a área de ocorrência de $S$. macrostigmus. 


\subsection{Comparação entre Synodus foetens e Synodus synodus}

Cerca de 15 lotes de Synodus synodus estavam identificados erroneamente como Synodus foetens. A confusão de identificação entre as duas espécies provavelmente ocorre pelo número de escamas na linha lateral, já que ambas possuem de 54 a 65 escamas. Porém, existem diversas diferenças entre as duas espécies. Synodus foetens possui 20-30 escamas pré-dorsais, enquanto Synodus synodus apresenta 15-18; S. foetens também possui raios anteriores da nadadeira dorsal longos, base da nadadeira anal de comprimento semelhante ao da base da nadadeira dorsal e nadadeiras peitorais curtas ou apenas alcançando a base da nadadeira pélvica; S. synodus possui raios anteriores da nadadeira dorsal curtos não ultrapassando os posteriores quando deprimida, base da nadadeira anal quase metade do tamanho da base da nadadeira dorsal e extremidade distal da nadadeira peitoral ultrapassando a base da nadadeira pélvica (ANDERSON et al., 1966; FRABLE et al., 2013). Além disso, S. foetens possui membrana da narina triangular, enquanto $S$. synodus possui membrana da narina anterior longa e em formato de colher (Figura 39), além de apresentar uma mancha escura na ponta superior do maxilar superior (Figura 40), característica ausente em S. foetens.
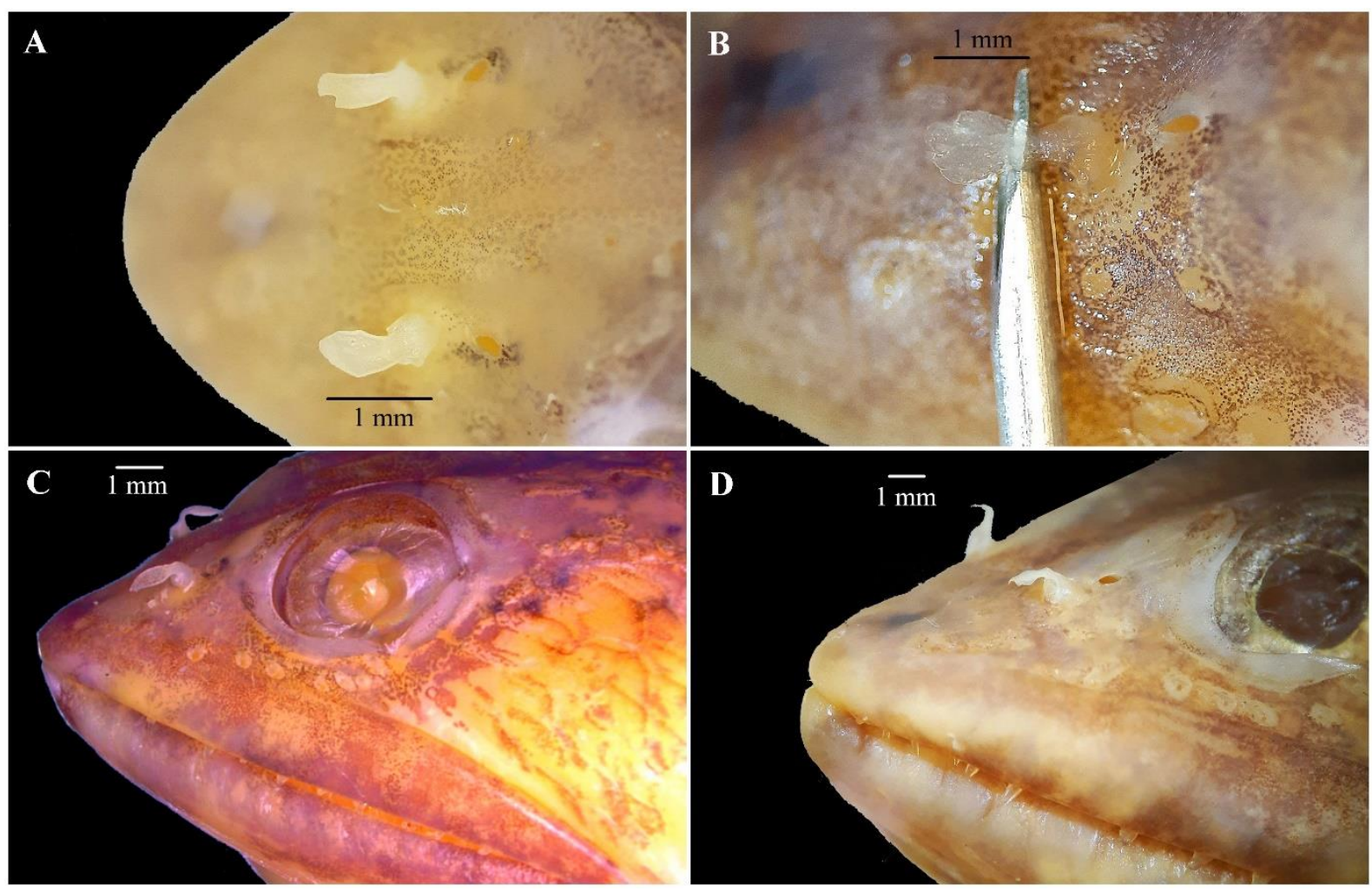

Figura 39. Fotografias evidenciando a membrana da narina anterior de Synodus synodus. A. MZUSP 66784; B. MZUSP 43483; C. CIUFES 1558(1); D. UFPB 3886. 


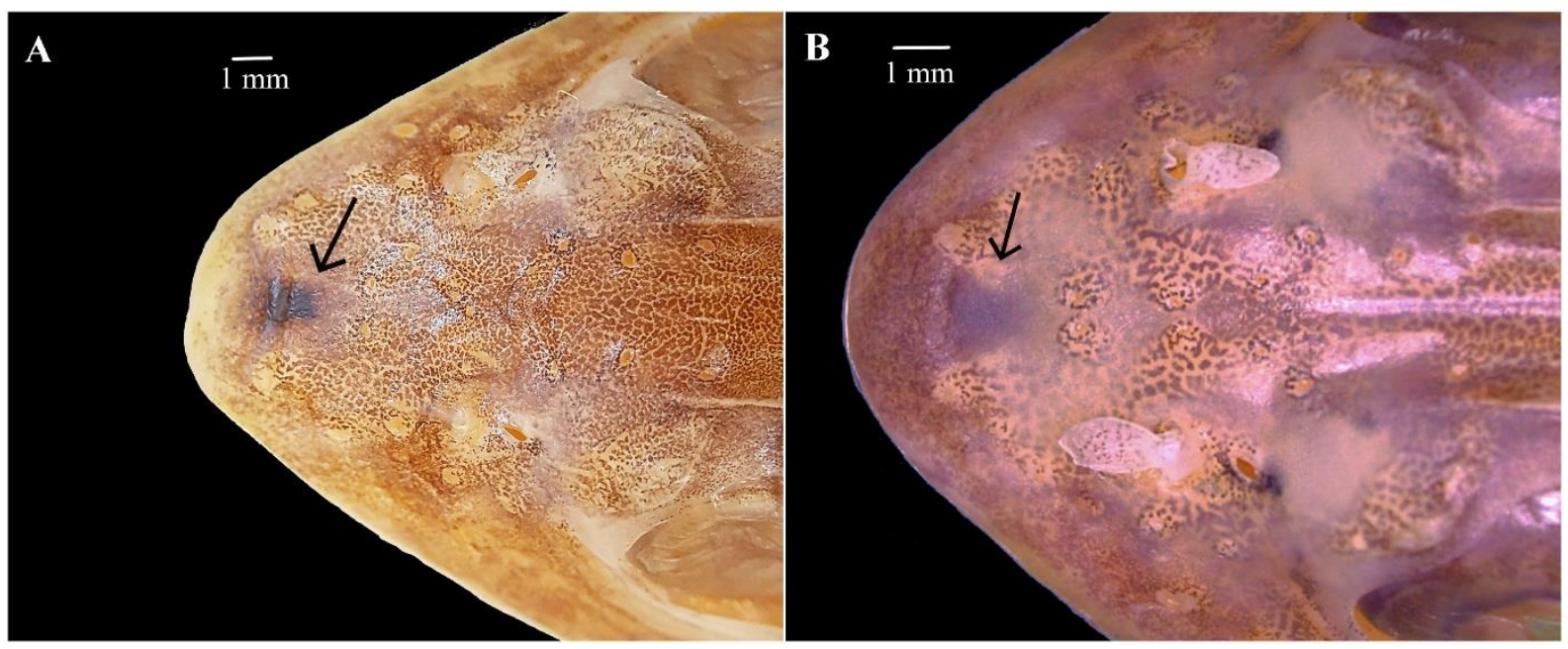

Figura 40. Fotografias evidenciando a mancha escura na parte superior da maxila superior de Synodus synodus. A. MZUSP 43483; B. CIUFES 1558(1).

Synodus synodus também possui lábios mais largos e espessos juntamente com um focinho mais curto, enquanto S. foetens possui lábios mais finos e focinho longo (Figura 41).

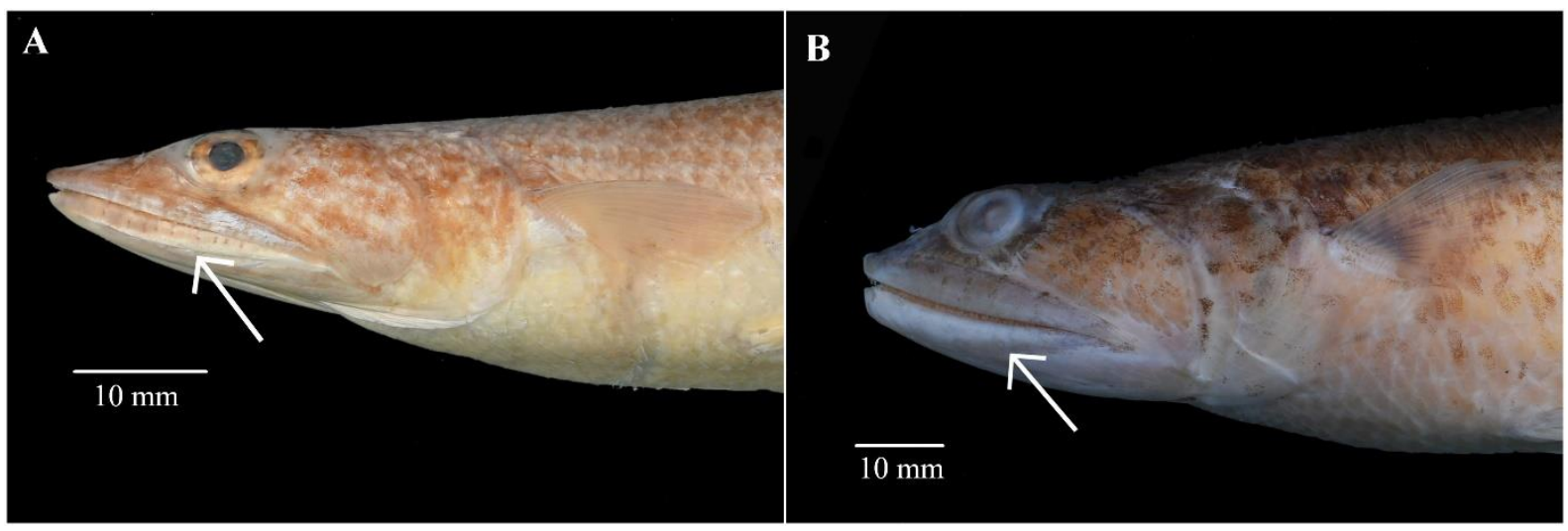

Figura 41. Fotografias evidenciando os lábios de A. S. foetens (MZUSP 18299) e B. S. synodus (MZUSP 45590).

\subsection{Comparação entre Synodus intermedius e Synodus synodus}

Cinco lotes de S. synodus estavam identificados erroneamente como S. intermedius. As duas espécies podem ser confundidas principalmente por possuírem 15-18 escamas pré-dorsais, raios anteriores da nadadeira dorsal curtos quando deprimida, ponta da nadadeira peitoral ultrapassando a origem da nadadeira pélvica e talvez pelo formato parecido dos lábios, mais grossos quando comparado a $S$. foetens e $S$. bondi. Porém, enquanto $S$. intermedius possui 4952 escamas na linha lateral, 3,5 escamas da linha lateral à base da nadadeira dorsal, 12-13 raios na nadadeira anal e membrana da narina anterior triangular e curta; S. synodus possui 55-60 
escamas na linha lateral, 4,5-5,5 escamas da linha lateral à base da nadadeira dorsal, 8-10 raios na nadadeira anal e membrana da narina anterior longa e em formato de colher. Além disso, $S$. intermedius possui 3-6 barras verticais na nadadeira caudal e a presença de uma mancha escapular atrás do opérculo, características ausentes em S. synodus. Da mesma forma, $S$. synodus, possui uma mancha preta no dorso do focinho, o que não ocorre em $S$. intermedius.

\subsection{Comparação entre Synodus sp. N. e Synodus poeyi e a presença da espécie em águas brasileiras}

A princípio Synodus sp. N pode ser confundida com $S$. poeyi, porém Synodus sp. N é a única espécie do Atlântico Sul ocidental que possui diâmetro da órbita maior ou igual ao comprimento do focinho (ver Tabela 10) ( $v s$. menor em S. poeyi, tanto no síntipo designado por Bertin \& Estève (1950) MNHN 1887-0383 (1), 85.0 mm CT; quanto na descrição original da espécie em Jordan (1887)) (Figura 42). Polanco (2006) encontrou diferenças entre populações de $S$. poeyi do Caribe e Estados Unidos na contagem do número de raios da nadadeira peitoral e anal, além do diâmetro da órbita em relação ao comprimento do focinho, onde apenas exemplares do Caribe maiores que $11 \mathrm{~cm} \mathrm{CP}$ apresentaram focinho ligeiramente maior que o diâmetro da órbita. Polanco (2006) argumenta que apesar das diferenças encontradas, não aconselha a separação taxonômica dos morfotipos pois os padrões merísticos e morfométricos parecem ser limitados. Frable et al. (2013), apesar de não ter realizado análises morfológicas em S. poeyi, aponta a existência de duas linhagens da espécie geneticamente diferentes entre si, sendo a primeira proveniente do Golfo do México, e a segunda de águas profundas da América Central. Em relação ao grande diâmetro da órbita, os exemplares provenientes de coleções brasileiras mostram diferenças morfológicas consistentes que justificam a possível separação em uma nova espécie, já que foram analisados exemplares de diversos estágios de crescimento (25.2-129.4 mm CP) e todos apresentavam diâmetro da órbita maior que o comprimento do focinho. Estudos futuros envolvendo coleta de exemplares e análises genéticas talvez auxiliem a elucidar essa questão, apesar da grande dificuldade em encontrar ambas as espécies em museus e até mesmo em coletas científicas. 


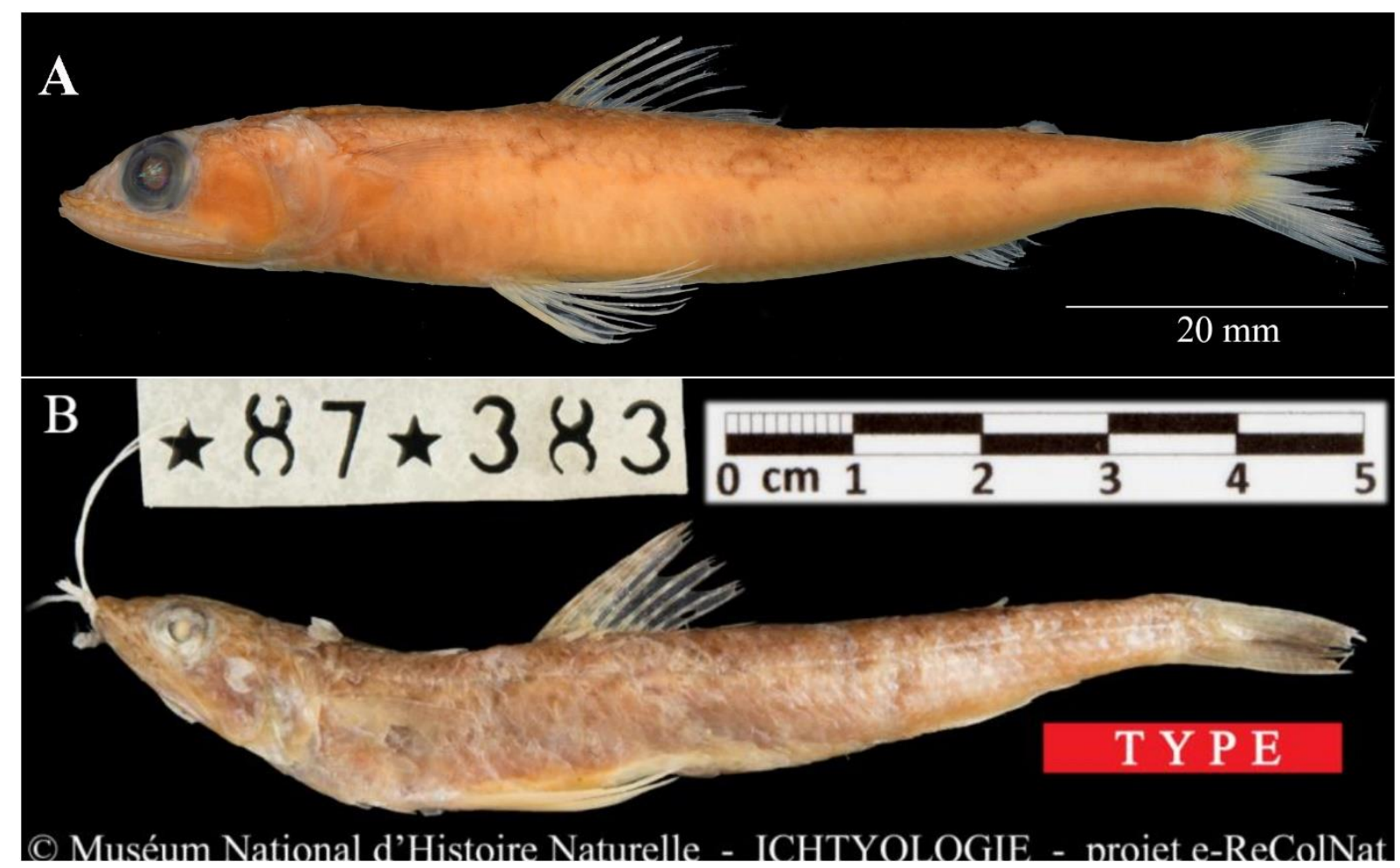

Figura 42. Comparação entre Synodus sp. n e Synodus poeyi. A. Synodus sp. n, MS holótipo, MNRJ 44976 (2), 81.8 mm CP. B. Síntipo de Synodus poeyi, MNHN 1887-0383 (1), 85.0 mm CT, Havana, Cuba.

Synodus poeyi estava listado em Camargo \& Isaac (2001) com ocorrência na região norte do Brasil. Porém, a presença da espécie em águas brasileiras foi baseada apenas em revisão bibliográfica. A espécie não estava listada em Menezes (2003). Moraes et al. (2009) fizeram o primeiro registro de ocorrência de $S$. poeyi no Brasil, em Ilhéus, Bahia. Os espécimes foram depositados no Museu de Zoologia da Universidade de São Paulo, sob o número de catálogo MZUSP 95441 e 95442 . Ambos os exemplares possuem diâmetro da órbita maior que comprimento do focinho, atualmente sendo identificados, portanto, como Synodus sp. N. Carvalho-Filho et al. (2010) analisou os mesmos exemplares de Moraes et al. (2009). Anderson et al., (1966) e Robins et al. (1986) mencionam que a espécie possui ocorrência da Carolina do Norte ao Suriname e Guianas. Carpenter (2002), porém, aponta que a espécie é restrita ao Caribe. A ausência da espécie em coleções brasileiras sugere que $S$. poeyi pode não ter ocorrência na costa brasileira - sendo restrita a América do Norte e Central, enquanto Synodus sp N. possui distribuição ao longo da costa brasileira. 


\section{Conclusões}

A revisão taxonômica possibilitou a melhor diferenciação entre as espécies, permitindo a criação de uma nova chave de identificação com ajustes e adição de características não documentadas (e.g. formato da membrana da narina anterior de S. synodus), e novos registros de ocorrência no litoral brasileiro com atualização das áreas de distribuição e descoberta de uma nova espécie (Synodus sp. N). Estudos envolvendo diversas áreas da biologia e taxonomia podem ser realizados futuramente, assim como análises moleculares que ajudem a elucidar questões ainda não resolvidas.

\section{Referências}

ALLEN, G.R.; ERDMANN, M.V.; PERISTIWADY, T. 2017. Synodus nigrotaeniatus, a new species of lizardfish (Aulopiformes: Synodontidae) from Indonesia. Journal of the Ocean Science Foundation, 26, 59-67.

ANDERSON, W.W., GEHRINGER, J.W.; BERRY, F.H. 1966. Family Synodontidae. In: ANDERSON, W.W. et al. Fishes of the Western North Atlantic. Part Five. Memoirs Sears Foundations Marine Research, 1(5):30-102.

BALDWIN, C.C. \& JOHNSON, G.D. 1996. Interrelationships of Aulopiformes. In: STIASSNY, M.L.J.; PARENTI, L.R.; JOHNSON, G.D. Interrelationships of Fishes. Academic Press, San Diego, California, EUA. p. 355-404.

BERTIN, L. \& ESTÈVE, R. 1950. Catalogue des types de poissons du Muséum National d'Histoire Naturelle. 6e partie. Haplomes, Hétéromes, Catostéomes. Imp. Nationale. 6e partie: $1-60$.

BETANCUR-R et al., 2013. The tree of life and a new classification of bony fishes. PLoS Currents Tree of Life, 5, ecurrents.tol.53ba26640df0ccaee75bb165c8c26288. http://doi.org/10.1371/currents.tol.53ba 26640df0ccaee75bb165c8c26288.

BETANCUR-R et al., 2017. Phylogenetic classification of bony fishes. BMC Evolutionary Biology (2017) 17:162. 40 pgs.

BLOCH, M. E \& SCHNEIDER, J.G. 1801. Blochii, Systema Ichthyologiae Iconibus cx Ilustratum. Post obitum auctoris opus inchoatum absolvit, correxit, interpolavit Jo. Gottlob Schneider, Saxo. Berolini. Sumtibus Auctoris Impressum et Bibliopolio Sanderiano Commissum. i-lx + 1-584, Pls. 1-110.

BROWN, J. et al. 2019. The fishes of St Helena Island, central Atlantic Ocean-new records and an annotated check-list. Zootaxa, 4543(2), 151. 
CAMARGO, M.; ISAAC, V. 2001. Os peixes estuarinos da região norte do Brasil: lista de espécies e considerações sobre sua distribuição geográfica. Boletim Museu Paraense Emílio Goeldi, série Zoologia,. v. 17, n. 2, p. 133-157.

CARPENTER, K.E. 2002. The living marine resources of the Western Central Atlantic. In FAO Species Identification Guide for Fishery Purposes and American Society of Ichthyologists and Herpetologists. FAO, Rome, p. 601-1374. (v. 2, part 1, special publication n. 5).

CARVALHO-FILHO, A. 1999. Peixes: Costa Brasileira. Editora Melro, São Paulo. 283p.

CARVALHO-FILHO et al. 2010. First report of Aulopus (Teleostei: Aulopidae) from Southwestern Atlantic, with a review of records and a key to Western Atlantic Aulopoidei species. Zootaxa 2628: 27-42.

DAVIS, M.P. 2010. Evolutionary relationships of the Aulopiformes (Euteleostei: Cyclosquamata): a molecular and total evidence approach. In: NELSON, J.S.; SCHULTZE, H.P.; WILSON, M.V.H. Origin and Phylogenetic Interrelationships of Teleosts. Verlag Dr. Friedrich Pfeil, München, Germany. p. 431-470.

DAVIS, M.P. \& FIELITZ, C. 2010. Estimating divergence times of lizardfishes and their allies (Euteleostei: Aulopiformes) and the timing of deep-sea adaptations. Molec. Phylogenet. Evol.57:1194-1208.

ELBARAASI, H. et al. 2019. Updated checklist of bony fishes along the Libyan coast (southern Mediterranean Sea). Mediterranean Marine Science v. 20 (no. 1): 90-105.

FIGUEIREDO, J.L. \& MENEZES, N.A. 1978. Manual de Peixes Marinhos do Sudeste do Brasil. II. Teleostei (1). Museu de Zoologia da Universidade de São Paulo, São Paulo, Brasil, $110 \mathrm{p}$.

FOWLER, H.W. 1939. Notes on fishes from Jamaica with descriptions of three new species. Notulae Naturae 35, 16 p. Acad. Sci., Philadelphia, PA.

FRABLE, B.W. et al. 2013. A new species of western Atlantic lizardfi sh (Teleostei: Synodontidae: Synodus) and resurrection of Synodus bondi Fowler, 1939, as a valid species from the Caribbean with redescriptions of $S$. bondi, S. foetens (Linnaeus, 1766), and S. intermedius (Agassiz, 1829). Fishery Bulletin 111(2). 25p.

FRABLE, B.W. 2015. Família Synodontidae. In: MELO, M.R.S.; MENEZES, N.A.; WOSIACKI, W.B. (Eds.) Catálogo Taxonômico da Fauna do Brasil: Actinopterii Cope, 1871. Disponível em: (http://fauna.jbrj.gov.br/fauna/listaBrasil/ConsultaPublicaUC/ ConsultaPublicaUC.do). Acesso em out. 2019.

FRICKE, R.; ESCHMEYER, W. N.; VAN DER LAAN, R. (eds) 2020. Eschmeyer's Catalog of Fishes: Genera, Species, References. Disponível em : <http://researcharchive.calacademy.org/research/ichthyology/catalog/fishcatmain.asp >. A cesso em: 28 jan. 2020. 
GREENWOOD, P.H. et al. 1966. Phyletic studies of teleostean fishes, with a provisional classification of living forms. Bulletin of the American Museum of Natural History. Volume 131: article 4, New York.

GRONOW, L.T. 1754. Museum Ichthyologicum, sistens piscium indigenorum et quorundam exoticorum, qui in Museo Laur. Theod. Gronovii adservantur, descriptiones, ordine systematico; accedunt nonullorum exoticorum piscium icones, aeri incisae. 2 vols. [v. 1 (1754): i-viii + 1-70, pls. 1-4; v. 2 (1756): i-vi + 1-88, pls. 5-7.

GRONOW, L. T. 1763. Zoophylacii Gronoviani fasciculus primus exhibens animalia quadrupeda, amphibia atque pisces, quae in museo suo adservat, rite examinavit, systematice disposuit, descripsit atque iconibus illustravit Laur. Theod. Gronovius, J.U.D.... Lugduni Batavorum. 1-136, Pls. 1-13, $8^{\text {a }}$.

HO, H.; CHEN, J.; SHAO, K. 2016. A new species of the lizardfish genus Synodus (Aulopiformes: Synodontidae) from the western Pacific Ocean. Zootaxa 4162 (1): 134142.

HORTON, T. et al. 2020. World Register of Marine Species. Disponível em: http://www.marinespecies.org. VLIZ. Acesso em: 28 jan. 2020. doi:10.14284/170

JOHNSON, G.D. 1992. Monophyly of the euteleostean clades Neoteleostei, Eurypterygii and Ctenosquamata. Copeia: $8-25$.

JOHNSON, R.K. 1982. Fishes of the families Evermannellidae and Scopelarchidae: Systematics, morphology, interrelationships, and zoogeography. Fieldiana, Zool. [N.S.] $12,1-252$.

JONES, P.W.; MARTIN, F.D.; HARDY JR., J.D. 1978. Development of fishes of the MidAtlantic Bight. An atlas of eggs, larval and juvenile stages. Vol. 1. Acipenseridae through Ictaluridae. U.S. Fish Wildl. Ser. Biol. Serv. Program FWS/OBS-78/12. 336 p.

JORDAN, D. S. 1887. Notes on typical specimens of fishes described by Cuvier and Valenciennes and preserved in the Musée d'Histoire Naturelle in Paris. Proceedings of the United States National Museum v. 9 (no. 593): 525-546.

KEIVANY, Y. 2014a. Osteology of hyobranchial arches in eurypterygian fishes. Iran. J. Ichthyol. 1(3): 129-151.

KEIVANY, Y. 2014b. Comparative Osteology of the Jaws in Representatives of the Eurypterygian Fishes. Zoology 2014, 4(2): 29-42.

KEIVANY, Y. 2014c. Pectoral girdle bones in eurypterygian fishes. International Journal of Aquatic Biology (2014) 2(5): 253-274.

KEIVANY, Y. 2014d. Comparative osteology of the suspensorial and opercular series in representatives of the eurypterygian fishes. Iran. J. Ichthyol. 1(2): 73-90. 
LINNAEUS, C. 1758. Systema Naturae per regna tria naturae, secundum classes, ordines, genera, species, cum characteribus, differentiis, synonymis, locis. Editio decima, reformata [10th revised edition], vol. 1: 824 pp. Laurentius Salvius: Holmiae. Disponível em <https://biodiversitylibrary.org/page/726886>

LINNAEUS, C. 1766. Systema Naturae per Regna Tria Naturae, Secundum Classes, Ordines, Genera, Species, cum Characteribus, Differentiis, Synonymis, Locis. 12th Edition. Volume 1, Part 1. Stockholm.

MEEK, S.E. 1884. A Review of the American Species of the Genus Synodus. Proceedings of the Academy of Natural Sciences of Philadelphia. Vol. 36. P. 130-136.

MENEZES, N.A. et al. 2003. Catálogo das Espécies de Peixes Marinhos do Brasil. Museu de Zoologia USP, São Paulo. 160p.

MORAES, L. E. et al. 2009. Ictiofauna da plataforma continental interna de Ilhéus, Bahia, Brasil. Biota Neotrop; vol. 9; no. 4.

MOURA, R.L. 2003. Riqueza de espécies, diversidade e organização de assembléias de peixes em ambientes recifais: um estudo ao longo do gradiente latitudinal da costa brasileira. Tese de Doutorado, Universidade de São Paulo.

NELSON, J.S.; GRANDE, T.C.; WILSON, M.V.H. 2016. Order Aulopiformes. In:

Fishes of the World. Fifth edition. | Hoboken, New Jersey : John Wiley \& Sons. p. 266-276.

NIELSEN, J.G. 1973. [Many individual family accounts.]. In: HUREAU, J.C. \& MONOD, T. Check-list of the Fishes of the North-eastern Atlantic and of the Mediterranean. CLOFNAM. Unesco, Paris. v. 1: i-xxii + 1-683.

NIÓN, H.; RIOS, C.; MENESES, P. 2016. Peces del Uruguay: Lista sistemática y nombres comunes. Segunda edición corregida y ampliada. DINARA, Montevideo: i-xi + 19-172.

NORMAN, J.R. 1935. 4. A Revision of the Lizard-fishes of the Genera Synodus, Trachinocephalus, and Saurida. Proceedings of the Zoological Society of London, 105(1), 99-136.

PATTERSON, C. \& JOHNSON, G.D. 1995. The intermuscular bones and ligaments of teleostean fishes. Smithson. Contrib. Zool 559: 1-83.

PINHEIRO, H.T. et al. 2015. Fish biodiversity of the Vitória-Trindade Seamount Chain, southwestern Atlantic: an updated database. PLoS One, 10(3): e0118180.

POLANCO, F.A. 2006. Taxonomía y Biogeografía de los peces Synodóntidos (Aulopiformes: Synodontidae) del Nuevo Mundo. Tese (Doutorado em Biología Marina) - Instituto de Investigaciones Marinas y Costeras "José Benito Vives de Andreis" INVEMAR, Universidad Nacional de Colombia, Santa Marta.

POLANCO, F.A.; ACERO, P.A.; BETANCUR-R, R. 2016. No longer a circumtropical species: revision of the lizardfishes in the Trachinocephalus myops species complex, 
with description of a new species from the Marquesas Islands. The Fisheries Society of the British Isles, Journal of Fish Biology. P. 1-22.

RIBEIRO et al. 2019. Marine ichthyofauna of Santa Catarina Island, Southern Brazil: checklist with comments on the species. Biota Neotrop. vol.19 no.3.

ROBINS, C.H et al. 1986. Bony Fishes. In:___. A Field guide to Atlantic Coast fishes of North America. The Petterson Field Guide Series. Boston, Houghton Mifflin Company. Pg 46-314.354p.+64pl.

ROUX, C. 1973. Poissons Téléostéens du Plateau Continental Brésilien, In: Campagne de la Calypso au large des cotes atlantiques de Lámerique du Sud (1961-1962), Prémiere Parte (suite). Resultats Scientifiques des Campagnes de la Calypso, X. Annales de L'Institut Océanographique, Nouvelle Série, 49, Fascicule Supplémentaire. Maison et Cie., Editeurs, Paris. 2. P. 55-58

ROSEN, D.E. 1973. Interrelationships of higher euteleostean fishes. In: GREENWOOD, P.H.; MILES, R.S.; PATTERSON, C. Interrelationships of Fishes. Zool. J. Linn. Soc. 53, Suppl. no. 1: 297-513; London (Academic Press).

RUSSELL, B.C. 2002. Synodontidae. In: CARPENTER, K.E. (Ed) The living Marine Resources of the Western Central Atlantic. Volume 2: Bony Fishes part 1 (Acipenseridae to Grammatidae). FAO Species Identification Guide for Fishery Purposes and American Society of Ichthyologists and Herpetologists Special Publication No. 5. Rome, FAO. p. $923-$ 929.

RUSSELL, B.C.; GOLANI, D.; TIKOCHINSKI, Y. 2015. Saurida lessepsianus a new species of lizardfish (Pisces: Synodontidae) from the Red Sea and Mediterranean Sea, with a key to Saurida species in the Red Sea. Zootaxa 3956 (4): 559-568.

RUSSELL, B.C. 2016. Miscellaneous families. In: CARPENTER \& DE ANGELIS (eds.). 2016. The living marine resources of the Eastern Central Atlantic. Volume 3: Bony fishes part 1 (Elopiformes to Scorpaeniformes). FAO Species Identification Guide for Fishery Purposes, Rome, FAO. P. 1824-1854.

SAMPAIO, C.L.S. \& NOTTINGHAM, M.C. 2008. Guia para Identificação de Peixes Ornamentais Brasileiros - volume I: Espécies Marinhas. Brasília: Ibama. 205 p.

SATO, T. \& NAKABO, T. 2002a. Paraulopidae and Paraulopus, a new family and genus of aulopiform fishes with revised relationships within the order. Ichthyol. Res. 49(1):2546.

SATO, T.\& NAKABO, T. 2002b. Two new species of Paraulopus (Osteichthyes: Aulopiformes) from New Zealand and eastern Australia, and comparisons with $P$. nigripinnis. Species Diversity 7:393-404.

SCOPOLI, J.A. 1777. Introductio ad historiam naturalem, sistens genera lapidum, plantarum et animalium hactenus detecta, caracteribus essentialibus donata, in tribus divisa, subinde ad leges naturae. Prague, Czechoslovakia. 
SPIX, J. B. \& L. AGASSIZ. L. 1829. Selecta genera et species piscium quos in itinere per Brasiliam annis MDCCCXVII-MDCCCXX jussu et auspiciis Maximiliani Josephi I.... collegit et pingendos curavit Dr J. B. de Spix.... Monachii. Part 1: i-xvi + i-ii + 1-6 + 182, Pls. 1-48, Part 2: 83-138, Pls. 49-101. [Part 1 published June 1829, part 2 Jan. 1831].

SULAK, K.J. 1977. The systematics and biology of Bathypterois (Pisces: Chlorophthalmidae) with a revised classification of benthic myctophiform fishes. Galathea Rep. 14, 49-108.

TAYLOR, W.R. \& VAN DYKE. G.C. 1985. Revised procedures for staining and clearing small fishes and other vertebrates for bone and cartilage study. Cybium, 9 (2): 107-119.

TRAHERNE, T. 1908. Centuries of Meditations. Dobell, ed. Charing Cross Road, W.C., London.

WANG, S. et al. 2018. First record of Gauguin's blunt-nose lizardfish, Trachinocephalus gauguini Polanco, Acero \& Betancur 2016 (Teleostei: Synodontidae) outside the Marquesas Archipelago. Zootaxa 4476 (1): 151-156. 
Apêndice A. Material examinado do gênero Synodus.

Synodus bondi Fowler, 1939. 39 lotes. 57 exemplares.

Brasil: AZUSC 58 (1, 70.0 mm CP), Baía de Santos, Santos, São Paulo, 2359'12" S, 46²0'18" O; AZUSC 92 (2, 103.0-171.5 mm CP), Forte dos Andradas, Guarujá, São Paulo, 2401'13" S, 46¹6’40" O; AZUSC 1130 (1, 121.5 mm CP), Ponte Edgard Perdigão, Santos, São Paulo, 2359’30" S, 46¹8’10" O; AZUSC 1164 (1, 122.5 mm CP), Ilha do Arvoredo, Guarujá, São Paulo, 2359'50" S, 4608'15" O; AZUSC 1274 (1, 146.5 mm CP), Ponte Edgard Perdigão, Santos, São Paulo, 2359’30" S, 46¹8’10" O; AZUSC 1835 (1, 143.0 mm CP), Ponte Edgard Perdigão, Santos, São Paulo, 2359’30" S, 46¹8’10" O; AZUSC 2070 (4, 137.0-330.0 mm CP), Farol do Boi, São Sebastião, São Paulo, 2446’15" S, 45¹5’30" O; AZUSC 2090 (1, 261.0 mm CP), Ilha de Queimada Grande, Itanhaém, São Paulo, 2440’20" S, 4640’10" O; AZUSC 2127 (1, 304.0 mm CP), Ilha de Queimada Grande, Itanhaém, São Paulo, 24¹5’04" S, 46³1'25" O; AZUSC 2212 (1, 197.0 mm CP), Praia de Baraqueçaba, São Sebastião, São Paulo, 2349'42" S, 45²6’15" O; AZUSC 2294 (4, 286.5-337.0 mm CP), Arraial do Cabo, Rio de Janeiro, Rio de Janeiro, 2306’50" S, 4156’50" O; AZUSC 2324 (2, 254-263.5 mm CP), Ilha Anchieta, Ubatuba, São Paulo, 2440’17" S, 4405’14" O; AZUSC 2351 (1, 313.0 mm CP), Ilha de Búzios, Ilhabela, São Paulo, 2347’00" S, 4507’30" O; AZUSC 2453 (1, 257.0 mm CP), Ilha da Moela, Guarujá, São Paulo, 24²4’40" S, 46¹0’39" O; AZUSC 2526 (1, 154.0 mm CP), Juréia, Peruíbe, São Paulo, 2445’00" S, 4708’30" O; AZUSC 2601 (2, 203.0-292.0 mm CP), Barra de Santos, Praia Grande, São Paulo, 2407’37" S, 46³1'56" O; AZUSC 2760 (1, 220.0 mm CP), Praia do Toque Pequeno, São Sebastião, São Paulo, 2349’33" S, 45³2’15" O; AZUSC 2790 (1, 181.0 mm CP), Ilha dos Currais, Matinhos, Paraná, 2549’54" S, 48¹7’18" O; AZUSC 2834 (1, 207.0 mm CP), Canal dos Barreiros, São Vicente, São Paulo, 2358'59" S, 46²4’01" O; AZUSC 2901 (1, 160.0 mm CP), Praia do Toque Pequeno, São Sebastião, São Paulo, 2449’15" S, 46²1’28" O; AZUSC 2915 (1, 166.0 mm CP), Ilha Comprida, Cananéia, São Paulo, 2458’48" S, 4741’35" O; AZUSC 3818 (1, 402.0 mm CP), Ilha de Queimada Grande, Itanhaém, São Paulo, 2440’35" S, 4653’20" O; AZUSC 3963 (1, 141.5 mm CP), Rio Icanhema, Guarujá, São Paulo, 2359’41" S, 46¹8’00" O; AZUSC 4330 (1, 178.0 mm CP), São Sebastião, São Paulo, 2349’25" S, 45³2’11" O; AZUSC 4425 (2, 95.0-133.5 mm CP), Ilha Diana, Santos, São Paulo, 235'54" S, 46¹8’33" O; AZUSC 5500 (1, 241.0 mm CP), Ao largo dos recifes amazônicos, Pará, 1²0’25" N, 4802’21" O;

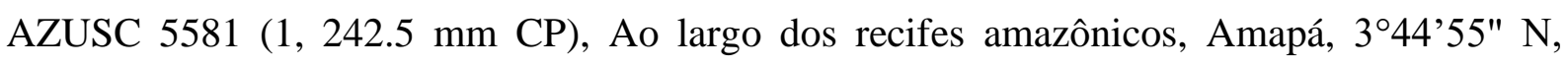
5009’50" O; AZUSC 5412 (4, 246.0-294.0 mm CP), Ao largo dos recifes amazônicos, Pará, 
2¹9’45" N, 48²7’26" O; AZUSC 5594 (1, 271.0 mm CP), Ao largo dos recifes amazônicos, Pará, 2¹5’55" N, 48³4'14" O; AZUSC 5581 (1, $242.5 \mathrm{~mm} \mathrm{CP),} \mathrm{Ao} \mathrm{largo} \mathrm{dos} \mathrm{recifes}$ amazônicos, Amapá, 344'55" N, 5009'50" O; AZUSC 5800 (1, 253.5 mm CP), Ao largo dos recifes amazônicos, Pará, 3³5’27" N, 5003’30" O; MPEG 35134 (1, 234.0 mm CP), Amapá, 1²5’00" N, 4808'00" O; MPEG 35202 (2, 241.5-255 mm CP), Amapá, 1³7’00" N, 48¹6’00" O; MPEG 35586 (2, 252.5-261.0 mm CP), Amapá, 2¹9’59" N, 48³6’48" O; MPEG 35608 (1, 239.5 mm CP), Amapá, 2¹7’28" N, 48³3’46" O; MPEG 35672 (2, 247.0247.5 mm CP), Amapá, 2¹7’28" N, 48³3’46" O; MPEG 35747 (1, 249.5 mm CP), Amapá, 341’24" N, 50¹0’07" O; MZUSP 16575 (1, 198.7 mm CP), Ilha do Arvoredo, Guarujá, São Paulo, 2358'03" S, 46¹0' 30" O [coordenadas inferidas]; MZUSP 118968 (4, 48.6-123.7 mm CP), Poça de maré na Baía do Araçá, São Sebastião, São Paulo, 234ํ'55" S, 45²4’15" O.

Synodus foetens (Linnaeus, 1766). 83 lotes. 117 exemplares.

Brasil: AZUSC 431 (1, 344.0 mm CP), Praia dos Pescadores, Itanhaém, São Paulo, 24¹7'15" S, 46²3’30" O; AZUSC 3254 (1, 155.5 mm CP), Largo do Canéu, Santos, São Paulo, 235’35" S, 46²2’03" O; CIUFES 825 (1, 192.5 mm CP), Baía de Vitória, Espírito Santo, 20¹9’08" S, 40¹6’52" O [coordenadas inferidas]; CIUFES 826 (2, 90.9-95.1 mm CP), Baía de Vitória, Espírito Santo, 20¹9’08" S, 40¹6’52" O [coordenadas inferidas]; CIUFES 878 (1, $8.3 \mathrm{~mm} \mathrm{CP}$ ), Praia de Itaparica, Vila Velha, Espírito Santo, 20²2’10" S, 40¹7'59" O [coordenadas inferidas]; CIUFES 935 (1, 307.0 mm CP), Guarapari, Espírito Santo, 2040’40" S, 40²9’54" O; CIUFES 971 (1, 196.5 mm CP), Litoral de Guarapari, Espírito Santo, 2040’40" S, 40²9’54" O; CIUFES 2102 (1, 42.0 mm CP), Barra do Riacho, Aracruz, Espírito Santo, 1949’45" S, 4003’28" O [coordenadas inferidas]; CIUFES 3192 (1, 96.3 mm CP), Barra Nova, São Mateus, Espírito Santo, 1856’44" S, 3943’56" O [coordenadas inferidas]; CIUFES 3710 (1, 40.8 mm CP), Piraquê-Açu, Espírito Santo, 1951'55" S, 4002’26" O [coordenadas inferidas]; CIUFES 3735 (1, $165.1 \mathrm{~mm} \mathrm{CP),} \mathrm{Piraquê-Açu,} \mathrm{Espírito} \mathrm{Santo,}$ 1951'55" S, 4002’26" O [coordenadas inferidas]; CIUFES 131664 (1, 147.7 mm CP), Baía de Camburi, Vitória, Espírito Santo, 20¹6’55" S, 40¹7’14" O [coordenadas inferidas]; CIUFES 131686 (1, 83.7 mm CP), Ilha do Frade, Vitória, Espírito Santo, 20¹8’09" S, 40²'48.0" O [coordenadas inferidas]; MCP 1465 (1, $193.5 \mathrm{~mm} \mathrm{CP})$, Canal da Barra de Tramandaí, Rio Grande do Sul, 2958'54" S, 5007’52" O [coordenadas inferidas]; MCP 5025 (1, 204.0 mm CP), Praia do Araçá, Porto Belo, Santa Catarina, 2708’00" S, 48³2’00" O; MCP 16248 (1, 203.5 mm CP), Praia de Ponta das Canas, Florianópolis, Santa Catarina, 27²3’00" S, 48²6’00" O; MCP 51732 (1, 168.1 mm CP), Baía de Aratu, Candeias, Bahia, 1247’17" S, 
38 28'07" O. MNRJ 3486 (5, 135.6-185.1 mm CP), Praia da Saudade, Rio de Janeiro, 22 56'57” S, 4310’32” O; MNRJ 20622 (2, 265.0-325.5 mm CP), estado do Paraná, 2502'00” S, 47¹7'00" O [coordenadas inferidas]; MNRJ 20806 (10, 34.7-83.8 mm CP), Saco da Ferradura, Armação dos Búzios, Cabo Frio, Rio de Janeiro, 2246’12” S, 41 53’12" O; MNRJ 32322 (1, $195.0 \mathrm{~mm} \mathrm{CP),} \mathrm{costa} \mathrm{do} \mathrm{estado} \mathrm{do} \mathrm{Rio} \mathrm{de} \mathrm{Janeiro} \mathrm{sobre} \mathrm{a} \mathrm{plataforma}$ continental, 2259’37” S, 43¹0’21” O; MNRJ 32657 (1, 272.0 mm CP), costa do estado do Rio de Janeiro sobre a plataforma continental, 2259’37” S, 43¹0’21” O; MNRJ 37010 (1, 172.2 mm CP), Praia da Ribeira, Baía de Guanabara, Rio de Janeiro, 2249’30” S, 43¹0’04” O; MNRJ 37114 (1, 196.0 mm CP), Prainha, Arraial do Cabo, Rio de Janeiro, 2257’29” S, 4201'27” O; MNRJ 37326 (1, 197.8 mm CP), Prainha, Arraial do Cabo, Rio de Janeiro, 22 57’29” S, 4201'27’ O; MNRJ 45356 (1, 209.0 mm CP), Canal do Itajuru, Cabo Frio, Rio de Janeiro, 22 53'00” S, 42 00’04” O; MNRJ 46453 (1, 131.7 mm CP), Prainha, Arraial do Cabo, Rio de Janeiro, 22 57'36” S, 42 ${ }^{\circ} 01^{\prime} 24$ " O [coordenadas inferidas]; MNRJ 48827 (2, 80.7-100.1 mm CP), (sem localização); MNRJ 49001 (1, $251.0 \mathrm{~mm} \mathrm{CP),} \mathrm{costa} \mathrm{do} \mathrm{estado} \mathrm{do}$ Rio de Janeiro, entre Joatinga e São Conrado, 2300'35” S, 4316'56” O; MNRJ 49002 (2, 120.2-138.6 mm CP), Baía de Guanabara, Rio de Janeiro, 2248'46” S, 4309’07” O; MNRJ 49037 (1, 254.5 mm CP), Prainha, Arraial do Cabo, Rio de Janeiro, 2257’28” S, 4201'28” O; MNRJ 49549 (1, 119.6 mm CP), Baía de Guanabara, Rio de Janeiro, 2248’46” S, 4309’07” O; MNRJ 50231 (1, 316.0 mm CP), Prainha, Arraial do Cabo, Rio de Janeiro, 2257’33” S, $42^{\circ} 01^{\prime 2} 25^{\prime \prime} \mathrm{O}$ [coordenadas inferidas]; MNRJ 50278 (6, 120.4-182.6 mm CP), Prainha, Arraial do Cabo, Rio de Janeiro, 22 ${ }^{\circ} 57^{\prime} 33^{\prime \prime}$ S, 42 01 '25” O [coordenadas inferidas]; MZUSP 896 (1, 165.0 mm CP), Largo do Caneu, Santos, São Paulo, 2355’32" S, 46²0’ $11^{\circ}$ O [coordenadas inferidas]; MZUSP 7899 (1, 111.5 mm CP), Ubatuba, São Paulo, 23²5’40" S, 45³’27" O [coordenadas inferidas]; MZUSP 16383 (1, $62.2 \mathrm{~mm} \mathrm{CP),} \mathrm{Praia} \mathrm{da} \mathrm{Siriúba,} \mathrm{Illhabela,} \mathrm{São}$ Paulo, 234'22" S, 45²1'02" O [coordenadas inferidas]; MZUSP 16384 (1, 72.4 mm CP),

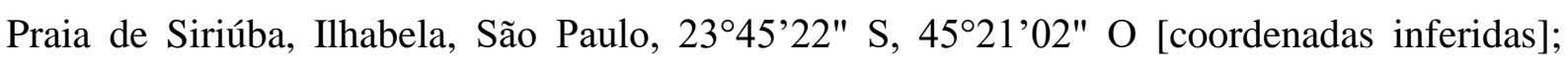
MZUSP 16394 (1, 133.6 mm CP), São Sebastião, São Paulo, 2348'22" S, 45²4’05" O [coordenadas inferidas]; MZUSP 16408 (2, 136.6-140.8 mm CP), Vila Bela, São Sebastião, São Paulo, 2349’41" S, 45²6’07" O [coordenadas inferidas]; MZUSP 16472 (1, 106.2 mm CP), Baixio Grande, Cananéia, São Paulo, 2504" S, 4755'16" O [coordenadas inferidas]; MZUSP 16575 (1, 198.7 mm CP), Ilha do Arvoredo, Guarujá, São Paulo, 2358'03" S, 46¹0’03" O [coordenadas inferidas]; MZUSP 16604 (3, 160.5-180.3 mm CP), Aracaju, Sergipe, 1057’35" S, 3659’46" O [coordenadas inferidas]; MZUSP 16953 (2, 159.5-166.9 mm CP), Praia da base do Instituto Oceanográfico, norte de Ubatuba, São Paulo, 23³0’10" S, 
45'’22" O [coordenadas inferidas]; MZUSP 17151 (1, 287.0 mm CP), Baía de Santos, São Paulo, 2358'32" S, 46¹9’39" O [coordenadas inferidas]; MZUSP 17794 (1, 83.9 mm CP), N. Oc. Prof. W. Besnard, Espírito Santo, 1905’00" S, 39³4’59" O; MZUSP 17795 (1, 101.5 mm CP), N. Oc. Prof. W. Besnard, Espírito Santo, 1905'00" S, 39³4’59" O; MZUSP 17798 (1, 157.37 mm CP), N. Oc. Prof. W. Besnard, Itabapoana, Rio de Janeiro, 21¹9’26" S, 4057’21" O; MZUSP 17850 (2, 268.0-279.9 mm CP), N. Oc. Prof. W. Besnard, São Paulo, 2452’00" S, 4700’00" O; MZUSP 17910 (1, 279.9 mm CP), N. Oc. Prof. W. Besnard, São Paulo, 25¹7’59" S, 47²2’59" O; MZUSP 17920 (2, 252.7-311.3 mm CP), N. Oc. Prof. W. Besnard, Santa Catarina, 2601'59" S, 4802’01" O; MZUSP 18299 (1, 177.8 mm CP), Mar de Dentro, Itamaracã, Pernambuco, $07^{\circ} 45^{\prime} 02^{\prime \prime}$ S, 34²9'11" O [coordenadas inferidas]; MZUSP 18384 (1, 292.5 mm CP), Morro Branco, próximo a Beberibe, Ceará, 0407’21" S, 3807’24" O; MZUSP 18405 (3, 50.0-77.9 mm CP), Barra do Gil, Ilha de Itaparica, Bahia, 1300’56" S, 38³8’37" O [coordenadas inferidas]; MZUSP 18407 (1, $60.7 \mathrm{~mm} \mathrm{CP}$ ), Praia de Cacha Pregos, Ilha de Itaparica, Bahia, 1306’00" S, 3848’00" O; MZUSP 18444 (2, 88.0-93.0 mm CP), Ponta Verde, Maceió, Alagoas, 09³9’28" S, 35²41’51" O [coordenadas inferidas]; MZUSP 18460 $(1,131.8 \mathrm{~mm} \mathrm{CP})$, em frente ao Instituto de Biologia Marinha da USP, São Sebastião, São Paulo, 2349'40" S, 45²5'22" O [coordenadas inferidas]; MZUSP 18466 (2, 158.5-204.0 mm CP), Cananéia, São Paulo, $25^{\circ} 02^{\prime} 00^{\prime \prime}$ S, 4755’00" O [coordenadas inferidas]; MZUSP 18500 (4, 213.5-277.0 mm CP), N. Oc. Prof. W. Besnard, Santos, São Paulo, 24¹0’00" S, 4555’00" O [coordenadas aproximadas]; MZUSP 19134 (1, 204.0 mm CP), Arquipélago dos Alcatrazes, São Paulo, 2407’01" S, 4541’59" O [coordenadas inferidas]; MZUSP 19148 (1, 255.0 mm CP), N. Oc. Prof. W. Besnard, Paraná, 25³0’00" S, 4755’00" O [coordenadas inferidas]; MZUSP 27291 (1, 222.2 mm CP), Rio Curuçá, São Luís, Maranhão, 0³3’41" S, 4750’32" O [coordenadas inferidas]; MZUSP 46672 (1, $70.5 \mathrm{~mm} \mathrm{CP}$ ), Porto Belo, Santa Catarina, 2709’02" S, 48³4'15" O [coordenadas inferidas]; MZUSP 55465 (1, 160.8 mm CP), Porto Belo, Santa Catarina, 2709’02" S, 48³4’15" O [coordenadas inferidas]; MZUSP 75283 (1, $45.1 \mathrm{~mm} \mathrm{CP}$ ), Praia da Pajuçara, Maceió, Alagoas, 940’19" S, 3542’52" O [coordenadas inferidas]; MZUSP 82163 (1, 246.5 mm CP), entre Valença e Itacaré, Bahia, 13²3'13" S, 3858'25" O [coordenadas inferidas]; MZUSP 90800 (2, 120.3-137.3 mm CP), Praia do Além, Anchieta, Espírito Santo, 2047’59" S, 40³5’00" O; MZUSP 116208 (1, 40.1 mm CP),

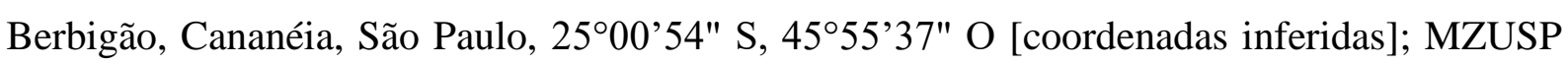
118968 (8, 38.6-196.5 mm CP), Poça de maré na Baía do Araçá, São Sebastião, São Paulo, 2348'55" S, 45²4'15" O; MZUSP 121479 (1, 194.4 mm CP), Santos, São Paulo, 24¹6’19" S, 46³1'33" O [coordenadas inferidas]; UFPB 2498 (1, $48.1 \mathrm{~mm} \mathrm{CP})$, Ponta do Seixas, João 
Pessoa, Paraíba, 709'10.0" S, 34²4'36.8" O [coordenadas inferidas]; UFPB 2826 (1, 156.5 mm CP), Barra de Mamanguape, Rio Tinto, Paraíba, 646'37.5" S, 3454'52.8" O [coordenadas inferidas].

Estados Unidos da América: MZUSP 17105 (2, 220.5-278.8 mm CP), Estação 1271, 2807’00" $\mathrm{N}, 80^{\circ} 04^{\prime} 00^{\prime \prime} \mathrm{O}$.

Synodus intermedius (Agassiz, 1829). 24 lotes. 33 exemplares.

Brasil: CIUFES 1971 (1, $111.1 \mathrm{~mm} \mathrm{CP),} \mathrm{Ilha} \mathrm{dos} \mathrm{Franceses,} \mathrm{Itapemirim,} \mathrm{Espírito} \mathrm{Santo,}$ 2055’31" S, 4045’25" O [coordenadas inferidas]; CIUFES 131038 (4, 218.0-228.0 mm CP), Foz do Rio Doce, Praia de Regência, Linhares, Espírito Santo, 19³9’23" S, 3949’03" O [coordenadas inferidas]; MNRJ 10656 (1, 82.9 mm CP), Ilha Siriba, Arquipélago de Abrolhos, Bahia, 1758'10” S, 3842’35” O; MNRJ 44976 (4, 87.8-121.1 mm CP), Talude continental do estado da Bahia, 16²4’00” S, 38²4'53” O; MNRJ 49293 (1, 120.0 mm CP), Recife de Viçosa, Nova Viçosa, Bahia, 1758'26”' S, 39¹5’37” O [coordenadas inferidas]; MZUSP 5200 (1, 298.0 mm CP), Ilha dos Búzios, São Paulo, 2348’55" S, 4508’23" O [coordenadas inferidas]; MZUSP 10646 (1, 211.1 mm CP), Mar de Dentro, Itamaracá, Pernambuco, 741'19" S, 3450'53" O [coordenadas inferidas]; MZUSP 18445 (1, 75.3 mm CP), Ponta Verde, Maceió, Alagoas, 9³9’28" S, 3541’51" O [coordenadas inferidas]; MZUSP 19133 (1, 436.0 mm CP), Laje de Santos, Santos, São Paulo, 24¹9’09" S, 46²10'59" O [coordenadas inferidas]; MZUSP 43484 (1, 164.8 mm CP), Laje de Santos, Santos, São Paulo, 24¹9’09" S, 46¹0’59" O [coordenadas inferidas]; MZUSP 46254 (2, 32.5-33.8 mm CP), Praias de Baraqueçaba e Guaecá, São Sebastião, São Paulo, 2349’59" S, 45²6’47" O [coordenadas inferidas]; MZUSP 47090 (1, 386.5 mm CP), Arquipélago dos Alcatrazes, São Sebastião, São Paulo, 2407’00" S, 4541'59" O [coordenadas inferidas]; MZUSP 47091 (1, $436.5 \mathrm{~mm} \mathrm{CP),} \mathrm{Arquipélago} \mathrm{dos}$ Alcatrazes, São Sebastião, São Paulo, 2407’00" S, 4541'59" O [coordenadas inferidas]; MZUSP 52828 (1, 127.6 mm CP), Parcel dos Abrolhos, Arquipélago de Abrolhos, Bahia, 1757’08" S, 3841'06" O; MZUSP 52829 (1, 238.5 mm CP), Arquipélago das Três Ilhas, Guarapari, Espírito Santo, 20³7’00" S, 40²2’00" O; MZUSP 52870 (1, 68.5 mm CP), Ilha Sueste, Arquipélago de Abrolhos, Bahia, 1758'00" S, 3842’00" O; MZUSP 60502 (1, 94.3 mm CP), Ilha Siriba, Arquipélago de Abrolhos, Bahia, 1758’10" S, 3842’30" O; MZUSP 60547 (2, 60.1-153.3 mm CP), Ilha de Santa Bárbara, Arquipélago de Abrolhos, Bahia, 1757’50" S, 3842’00" O; MZUSP 60793 (1, 52.8 mm CP), Recife Popa Verde, Arquipélago de Abrolhos, Bahia, 1759’12" S, 3858'02" O; MZUSP 65105 (1, 159.0 mm CP), Recifes João 
da Cunha, Cabeços de W, Rio Grande do Norte, 444’50" S, 3657’53" O; MZUSP 65663 (1, 92.5 mm CP), Tamandaré, Camurupim, Pernambuco, 849’00" S, 3505’00" O; MZUSP 66785

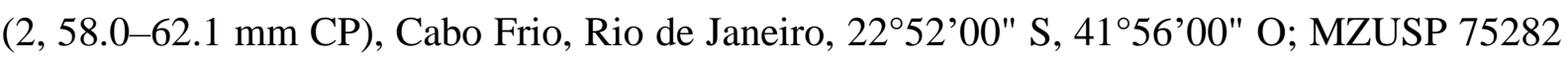
(1, 307.3 mm CP), Ilha dos Búzios, Ilhabela, São Paulo, 2348’00" S, 4508’00" O; UFPB 4269 (1, $94.2 \mathrm{~mm} \mathrm{CP}$ ), Recifes do Poço, Areia Vermelha, Cabedelo, Paraíba, 701'07.7" S, 3449'17.5" O.

Synodus macrostigmus Frable, Luther \& Baldwin, 2013. 2 lotes. 3 exemplares.

Brasil: MNRJ 18209 (2, 130.3-131.4 mm CP), foz do Amazonas (entre Salinópolis e Cabo Orange), Amapá, 2¹0’00” N, 4807’00” O; MNRJ 49610 (1, $197.1 \mathrm{~mm} \mathrm{CP})$, ao largo de Atafona, Rio de Janeiro $21^{\circ} 45^{\prime} 00^{\prime}$ S, $40^{\circ} 12^{\prime} 00^{\prime}$ ' O.

Synodus synodus (Linnaeus, 1758). 29 lotes. 44 exemplares.

Brasil: AZUSC 4522 (2, 174.5-209.5 mm CP), Praia do Toque Pequeno, São Sebastião, São Paulo, 2349’44" S, 45³2’34" O; CIUFES 972 (2, 170.6-179.9 mm CP), Guarapari, Espírito Santo, 2040’40" S, 40²9’54" O [coordenadas inferidas]; CIUFES 1558 (4, 67.7-113.4 mm CP), Ilha da Trindade, Vitória, Espírito Santo, 20³0`45" S, 29²0’49" O [coordenadas inferidas]; CIUFES 1748 (1, 154.9 mm CP), Ilhas Rasas, Guarapari, Espírito Santo, 20³9’28" S, 40³0’39" O; CIUFES 1873 (1, 160.8 mm CP), Ilhas Rasas, Guarapari, Espírito Santo, 20³9’28" S, 40³0’39" O; CIUFES 3121 (4, 36.6-70.9 mm CP), Ponta da Calheta, Ilha da Trindade, Vitória, Espírito Santo, 20³1'15" S, 29¹8’45" O [coordenadas inferidas]; CIUFES 3124 (2, 37.9-39.6 mm CP), Ponta da Calheta, Ilha da Trindade, Vitória, Espírito Santo, 20³1'15" S, 29¹8’45" O [coordenadas inferidas]; CIUFES 3138 (2, 141.4-159.2 mm CP), Ponta da Calheta, Ilha da Trindade, Vitória, Espírito Santo, 20³1’15" S, 29¹8’45" O [coordenadas inferidas]; CIUFES 131353 (1, $160.2 \mathrm{~mm} \mathrm{CP),} \mathrm{Ilhas} \mathrm{Rasas,} \mathrm{Guarapari,} \mathrm{Espírito}$ Santo, 2040’38" S, 40²1'56" O [coordenadas inferidas]; MNRJ 15345 (2, 193.9-251.0 mm CP), Praia do Forno, Arraial do Cabo, Rio de Janeiro, 2257’57” S, 4200’53” O; MNRJ 48998 (1, 246.5 mm CP), Prainha, Arraial do Cabo, Rio de Janeiro, 22 $57^{\prime} 00^{\prime}$ S, 42¹0’00” O; MNRJ 51526 (1, 89.9 mm CP), foz do Amazonas, entre Salinópolis e Cabo Orange, Amapá, 2¹0’00” N, 4807’00” O; MZUSP 43483 (1, 168.7 mm CP), Laje de Santos, São Paulo, 24¹9’09” S, 46¹0'59” O [coordenadas inferidas]; MZUSP 43485 (1, $102.7 \mathrm{~mm} \mathrm{CP),} \mathrm{Ilha} \mathrm{da} \mathrm{Queimada}$ Grande, Peruíbe, São Paulo, 24²9’17” S, 4640’36” O [coordenadas inferidas]; MZUSP 45590 (1, $206 \mathrm{~mm} \mathrm{CP}$ ), Arquipélago dos Alcatrazes, São Paulo, 2407’01” S, 4541’59” O 
[coordenadas inferidas]; MZUSP 45747 (1, $152.0 \mathrm{~mm} \mathrm{CP),} \mathrm{Ilha} \mathrm{da} \mathrm{Queimada} \mathrm{Grande,} \mathrm{Peruíbe,}$ São Paulo, 24²9’17” S, 4640’36” O [coordenadas inferidas]; MZUSP 46221 (1, 60.6 mm CP), Praia de Baraquecaba, São Sebastião, São Paulo, 2349’39” S, 45²6’17” O [coordenadas inferidas]; MZUSP 47107 (1, 192.5 mm CP), Arquipélago dos Alcatrazes, São Sebastião, São Paulo, 2407’01” S, 4541'59” O [coordenadas inferidas]; MZUSP 66784 (1, 87.4 mm CP), Cabo Frio, Rio de Janeiro, 2252’00" S, 4156’00" O; MZUSP 69282 (1, 190.4 mm CP), Ilha

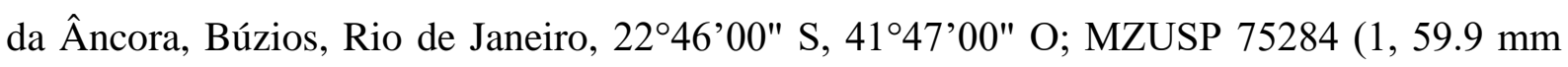
CP), Itaparica, Bahia, 1253’18" S, 3841’20" O [coordenadas inferidas]; MZUSP 108068 (1, $48.1 \mathrm{~mm}$ CP), Arquipélago de Fernando de Noronha, Pernambuco, 350’00" S, 32²5’00" O; MZUSP 110433 (2, 69.2-84.2 mm CP), Arquipélago da Vitória, Ubatuba, São Paulo,

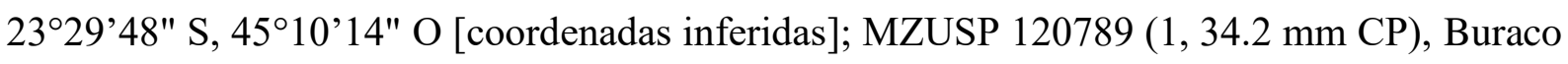
do Inferno, Ilha Rata, Fernando de Noronha, Pernambuco, 348’31" S, 32²2’51" O [coordenadas inferidas]; MZUSP 121495 (1, $182.6 \mathrm{~mm} \mathrm{CP})$, Ilha Escalvada, Guarapari, Espírito Santo, 2042’05" S, 40²5’02" O; UFPB 3886 (1, 157.0 mm CP), Arquipélago dos Alcatrazes, São Sebastião, São Paulo, 700'04.3" S, 3450'32.4" O [coordenadas inferidas]; UFPB 4330 (2, 48.2-61.3 mm CP), Talude continental da costa da Paraíba, 702'36.7" S, 3449'53.4" O [coordenadas inferidas]; UFPB 5961 (1, 75.9 mm CP), Piscina do Salão, Atol das Rocas, Rio Grande do Norte, $3^{\circ} 51^{\prime} 39.4^{\prime \prime}$ S, 3347'59.5" O [coordenadas inferidas].

São Tomé e Príncipe: CIUFES 161 (3, 79.0-119.1mm CP), Lagoa Azul, São Tomé e Príncipe, $0^{\circ} 24^{\prime} 23^{\prime \prime} \mathrm{N}, 6^{\circ} 36^{\prime} 30^{\prime \prime} \mathrm{E}$ [coordenadas inferidas].

Synodus sp. N. 6 lotes. 9 exemplares.

Brasil: AZUSC 5814 (1, 129.4 mm CP), Ao largo dos recifes amazônicos, Pará, 3³5’27" N, 5003’30" O; CIUFES 1266 (1, 25.2 mm CP), Ilhas Rasas, Guarapari, Espírito Santo, 2040’38.5" S, 40²1'56" O [coordenadas inferidas]; CIUFES 3720 (1, 49.8 mm CP), PiraquêAçu, Espírito Santo, 1951’55" S, 4002’26" O [coordenadas inferidas]; MNRJ 44976 (4, 74.0104.4 mm CP), talude continental do estado da Bahia, 16²4'00” S, 38²4’53” O; MZUSP 95441 (1, 71.8 mm CP), Ilhéus, Bahia, 1449’12." S, 390’14." O; MZUSP 95442 (1, 58.8 mm CP), Ilhéus, Bahia, 1449’12." S, 390’14." O. 